\title{
ESTUDO DOS CASOS DE INTOXICAÇÃO OCASIONADAS PELO USO DE AGROTÓXICOS NO ESTADO DO PARANÁ, DURANTE O PERÍODO DE 1993 A 2000
}

\author{
DALMO POLASTRO
}

Dissertação apresentada à Escola Superior de

Agricultura "Luiz de Queiroz", Universidade de São Paulo, para obtenção do título de Mestre em Ecologia de Agroecossistemas.

PIR A CICAB A

Estado de São Paulo - Brasil

Maio - 2005 


\title{
ESTUDO DOS CASOS DE INTOXICAÇÃO OCASIONADAS PELO USO DE AGROTÓXICOS NO ESTADO DO PARANÁ, DURANTE O PERÍODO DE 1993 A 2000
}

\author{
DALMO POLASTRO \\ Engenheiro Agrônomo
}

Orientador: Prof. Dr. VALDEMAR LUIZ TORNISIELO

\footnotetext{
Dissertação apresentada à Escola Superior de Agricultura "Luiz de Queiroz", Universidade de São Paulo, para obtenção do título de Mestre em Ecologia de Agroecossistemas.
}

\author{
$P \mid R A C I C A B A$ \\ Estado de São Paulo - Brasil \\ Maio - 2005
}


Dados Internacionais de Catalogação na Publicação (CIP) DIVISÃO DE BIBLIOTECA E DOCUMENTAÇÃO - ESALQ/USP

Polastro, Dalmo

Estudo dos casos de intoxicação ocasionadas pelo uso de agrotóxicos no Estado do Paraná, durante o período de 1993 a 2000 / Dalmo Polastro. - - Piracicaba, 2005. $116 \mathrm{p}$.

Dissertação (mestrado) - - Escola Superior de Agricultura Luiz de Queiroz, 2005. Bibliografia.

1. Consumidor - Característica 2. Intoxicação 3. Pesticida 4. Saúde ocupacional 5. Toxicologia - Classificação 6. Toxicologia ocupacional 7. Trabalhador rural I. Título

CDD 615.902

"Permitida a cópia total ou parcial deste documento, desde que citada a fonte - 0 autor" 


\section{OFEREÇO}

A Deus, pela oportunidade diária.

A Cesarinho Ricomini "in memorian", pela amizade, bondade e exemplo de ser humano. A minha avó Genoveva (Efa) "in memorian", quem primeiro me ensinou a ter amor pelas plantas .

Aos meus queridos pais, Luiz e Thereza, pelo amor, educação e apoio, incondicionais A minha filha Heloísa, minha jóia preciosa, companheira de todos os momentos. 


\section{AGRADECIMENTOS}

Ao Prof. Dr. Valdemar Luiz Tornisielo, pela orientação e amizade.

Ao amigo Ralph Rabelo Andrade, pelo incentivo e colaboração incondicional em todas as etapas desta jornada.

A Prof. Dr. Ângelo Zanaga Trapé, pelo desprendimento e pela opinião decisiva e segura.

A Regina Telles de Freitas, pela amizade, antes de tudo, e pela paciência e colaboração plena durante todo o mestrado.

Aos amigos Kurt W. Reinchenbach e Edson Koike, pela amizade sempre, e pelo apoio logístico na gramática e informática, respectivamente.

A Secretaria de Estado da Agricultura e do Abastecimento do Paraná, pela oportunidade desta especialização.

Aos amigos da SEAB, Nilson, Marcos, Keller, Jânio, Hatschbach, Norberto, Célia Nascimento e Salvador, que de um modo ou de outro, colaboraram para que este trabalho se concretizasse.

A Bibliotecária Eliana M. Garcia, pela presteza, bom humor e auxílio providencial.

A Gilka Cardoso Andretta e Baltazar H. dos Santos, do DERAL, que com colaboraram prontamente.

A Gisélia B. G. Rúbio, da SESA, que forneceu o Banco de Dados sobre as intoxicações, e ajudou a esclarecer inúmeras dúvidas.

Aos Professores Arquimedes Lavorenti, Regina Monteiro e Marcos Sorrentino, pelo exemplo grave como mestres e pela influência científica positiva. 


\section{SUMÁRIO}

Página

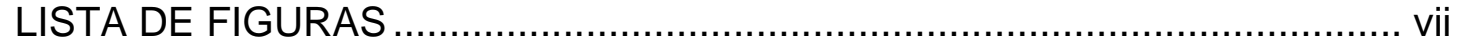

LISTA DE TABELAS ................................................................................

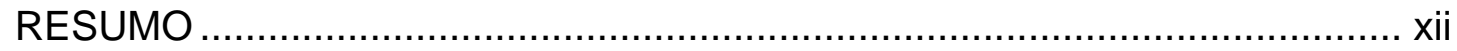

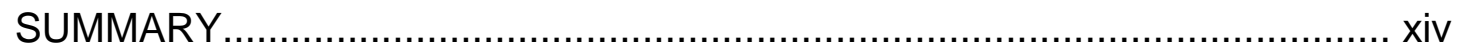

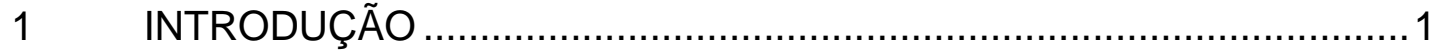

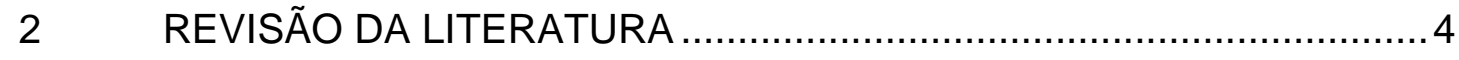

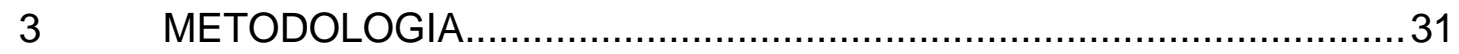

3.1 Fonte, filtragem e tratamento dos dados ...................................... 31

3.2 Relacionamento entre intoxicações e perfis agrícolas regionais ............35

4 RESULTADOS E DISCUSSÃO ….............................................. 38

4.1 Intoxicações segundo as Causas................................................. 38

4.2 Distribuição das intoxicações nos núcleos regionais .........................4 41

4.3 Intoxicações segundo as vias de contaminação ..............................43

4.4 Intoxicações segundo a classe dos agrotóxicos, grupos químicos e causas de intoxicação ......................................................... 45

4.5 Intoxicações segundo a classe, grupo químico e vias de

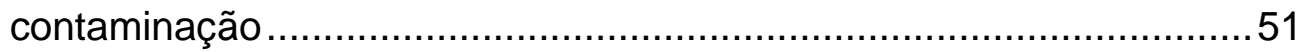

4.6 Intoxicações através das diferentes faixas de idade .........................52

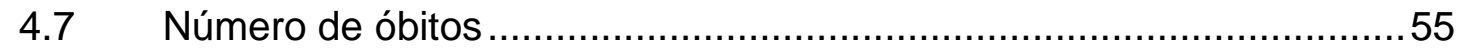

4.8 Relação entre Intoxicações, regiões e respectivas áreas de cultivo ....59

4.9 Intoxicações segundo o local da ocorrência.....................................67

4.10 Intoxicações segundo a ocupação ............................................ 71 
4.11 Intoxicações nas regiões e núcleos regionais, segundo a classe e respectivos grupos químicos dos agrotóxicos ................................72

4.11 .1 Região norte................................................................... 76

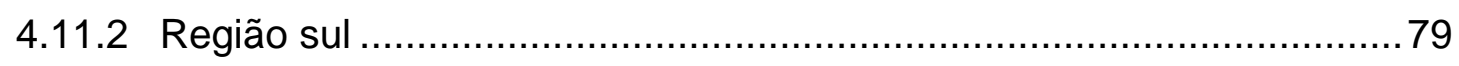

4.11 .3 Região centro-oeste ......................................................... 81

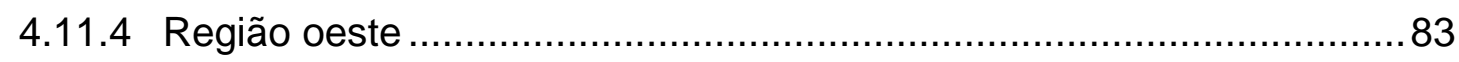

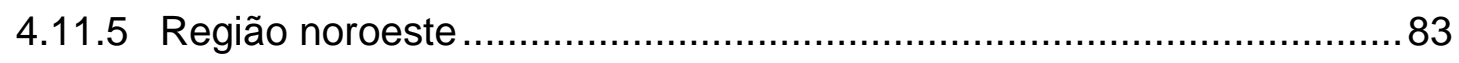

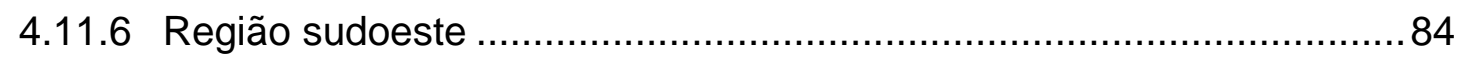

4.12 Óbitos segundo as classes e principais grupos químicos dos agrotóxicos, dentro das regiões e núcleos regionais........................ 86

4.13 Óbitos segundo as classes e principais grupos químicos dos agrotóxicos, entre as classes de idade e sexo ................................ 88

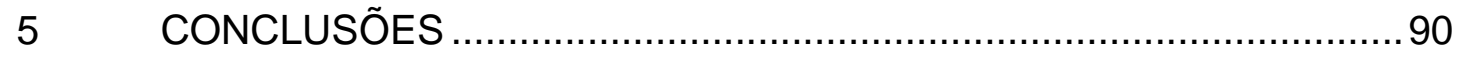

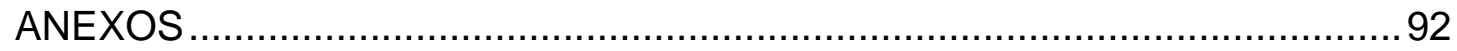

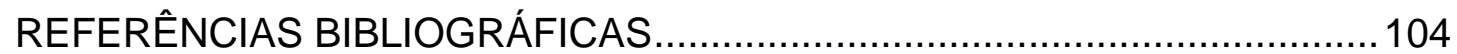

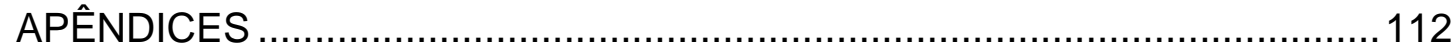




\section{LISTA DE FIGURAS}

Página

1 Proporção do número e da área dos estabelecimentos, por grupos de área total e proporção do número e da área dos estabelecimentos, explorados pelo proprietário, arrendatário, ocupante e administrador Paraná - 1970/1995.

2 Histórico,síntese e utilização dos principais inseticidas organoclorados 16

3 Óbitos registrados segundo agente tóxico. Brasil, 1997.

4 Parâmetros da $\mathrm{DL}_{50}$ utilizados na classificação dos agrotóxicos segundo a classe toxicológica e tipo de formulação; dados estabelecidos através da Portaria nº3/1992 da Secretaria Nacional de Vigilância Sanitária.

5 Evolução dos casos de intoxicação por agrotóxicos, para as causas profissional, suicídio e acidental, ocorridos no Estado do Paraná, nos anos de 1993 a 2000

6 Evolução dos casos de intoxicação por agrotóxicos, para as regiões norte, sul, centro-oeste, oeste, noroeste e sudoeste, ocorridos no Estado do Paraná, nos anos de 1993 a 2000

7 Intoxicações por classes de produto, ocorridas no Estado do Paraná, durante o período de 1993 a 2000

8 Evolução do número de intoxicações causadas pelos quatro principais grupos químicos, responsáveis pelas intoxicações ocorridas no Estado do Paraná, durante o período de 1993 a 2000

9 Principais causas e grupos químicos, responsáveis pelas intoxicações ocorridas no Estado do Paraná, durante o período de 1993 a 2000 
10 Principais vias de intoxicação e grupos químicos, responsáveis pelas intoxicações ocorridas no Estado do Paraná, no período de 1993 a 2000.

11 Distribuição das intoxicações para as causas profissional, suicídio, acidental, ignorada e alimentos contaminados, dentro das faixas de idade, ocorridas no Estado do Paraná, durante o período de 1993 a 2000.

12 Distribuição do número de óbitos entre homens e mulheres, nas diversas faixas de idade estudadas, segundo a causa suicídio, no Estado do Paraná, durante o período de 1993 a 2000.

13 Distribuição do número de óbitos, por causa de intoxicação para homens e mulheres, no Estado do Paraná, durante o período de 1993 a 2000

14 Distribuição do número de óbitos entre homens e mulheres, dentro das diversas faixas de idade, ocorridas no Estado do Paraná, durante o período de 1993 a 2000.

15 Evolução do número de casos de intoxicação e áreas de cultivo do grupo de cultivos de frutas, no Estado do Paraná, durante o período de 1993 a 2000.

16 Evolução do número de casos de intoxicação e das áreas de cultivo do grupo de cultivos de olerícolas grandes, no Estado do Paraná, durante o período de 1993 a 2000.

17 Evolução do número de casos de intoxicação e das áreas de cultivo do grupo de cultivos de olerícolas, no Estado do Paraná, durante o período de 1993 a 2000.

18 Evolução do número de casos de intoxicação e das áreas de cultivo do grupo de cultivos de verão, no Estado do Paraná, durante o período de 1993 a 2000 . 
19 Evolução do número de casos de intoxicação e das áreas de cultivo do grupo de cultivos de inverno, no Estado do Paraná, durante o período de 1993 a 2000.

20 Evolução do número de casos de intoxicação e das áreas de cultivo do grupo de outros cultivos, no Estado do Paraná, durante o período de 1993 a 2000.

21 Evolução do número de casos de intoxicação e das áreas totais de grupos de cultivos, no Estado do Paraná, durante o período de 1993 a 2000.

22 Evolução dos percentuais de intoxicação, segundo o local de ocorrência, durante o período de 1993 a 2000

23 Número de intoxicações nos núcleos regionais da região norte, segundo a classe dos agrotóxicos, durante o período de 1993 a 2000. .

24 Percentual das intoxicações segundo a classe dos agrotóxicos, na região sudoeste, durante o período de 1993 a 2000.

25 Evolução dos casos de intoxicação e óbito, durante os anos de 1993 a 2000 . 


\section{LISTA DE TABELAS}

Página

1 Casos registrados de intoxicações humanas por causa, sexo e óbitos. Brasil, 1997

2 Regiões administrativas e respectivos núcleos regionais da SEAB .... 36

3 Grupos de culturas e respectivos cultivos.................................... 37

4 Casos de intoxicação por agrotóxicos no Estado do Paraná, por causa de intoxicação, nos anos de 1993 a 2000

5 Casos de intoxicação por agrotóxicos no Estado do Paraná, por via de contaminação, durante o período de 1993 a 2000

6 Casos de intoxicação por agrotóxicos no Estado do Paraná, por via de contaminação, para a causa PROFISSIONAL, durante o período de 1993 a 2000

7 Casos de intoxicação por agrotóxicos no Estado do Paraná, por via de contaminação, para a causa SUICÍDIO, durante o período de 1993 a 2000

8 Casos de intoxicação por agrotóxicos no Estado do Paraná, por via de contaminação, para a causa ACIDENTAL durante o período de 1993 a 2000

9 Casos de intoxicação por agrotóxicos no Estado do Paraná, por causa e faixas etárias, durante o período de 1993 a 2000

10 Óbitos causados pela intoxicação por agrotóxicos no Estado do Paraná, por sexo, faixa de idade e causa, durante o período de 1993 de 1993 a 2000 
11 Ánalise de correlação entre as variáveis, grupos de cultura e intoxicações

12 Número de intoxicações segundo o local de ocorrência, durante o período de 1993 a 2000

13 Número total de intoxicações segundo as causas de contaminação e locais de ocorrência, para o período de 1993 a 2000

14 Número de intoxicações segundo o local de ocorrência e via de contaminação, durante o período de 1993 a 2000

15 Número de intoxicações segundo o local de ocorrência e a ocupação dos intoxicados

16 Número de intoxicações por regiões, segundo a classe e principais grupos químicos de agrotóxicos, ocorridas durante o período de 1993 a 2000

17 Número de intoxicações entre os núcleos regionais da região norte, por classe e principais grupos químicos ocorridas durante o período de 1993 a 2000

18 Número de intoxicações entre os núcleos regionais da região sul, por classe e principais grupos químicos, ocorridas durante o período de 1993 a 2000

19 Número de intoxicações entre os núcleos regionais das regiões centro-oeste e oeste, por classe e principais grupos químicos, ocorridas durante o período de 1993 a 2000.

20 Número de intoxicações entre os núcleos regionais das regiões noroeste e sudoeste, por classe e principais grupos químicos, ocorridas durante o período de 1993 a 2000.

21 Número de óbitos, segundo as classes e principais grupos químicos dos agrotóxicos, ocorridos durante o período de 1993 a 2000. 


\section{ESTUDO DOS CASOS DE INTOXICAÇÃO OCASIONADAS PELO USO DE AGROTÓXICOS NO ESTADO DO PARANÁ, DURANTE O PERÍODO DE 1993 A 2000}

Autor: DALMO POLASTRO

Orientador: Prof. Dr. VALDEMAR LUIZ TORNISIELO

\section{RESUMO}

O Estado do Paraná destaca-se por ser responsável por mais de $20 \%$ da produção nacional de grãos. Prevalecem em sua estrutura agrária, pequenas e médias propriedades onde predomina a mão-de-obra familiar. Buscando manter e aumentar as produtividades atuais, a agricultura paranaense utiliza intensivamente os insumos disponíveis no comércio, como é o caso nos agrotóxicos, onde o Paraná é tido como segundo maior consumidor nacional. A venda maciça deste insumo, o baixo grau de escolaridade dos usuários, aliado a falta de cuidados quando da sua utilização resultam no surgimento de intoxicações. Baseado nesta realidade, o presente estudo objetivou identificar e caracterizar o perfil das populações intoxicadas por agrotóxicos no Estado do Paraná, durante o período de 1993 a 2000 e propor medidas que visem diminuir os prejuízos às populações expostas. Para tanto, foram analisadas as intoxicações agudas notificadas durante o período de 1993 a 2000, referentes ao banco de dados fornecido pela Secretaria Estadual da Saúde. As intoxicações foram analisadas segundo as seguintes variáveis: sexo, 
idade, local de ocorrência, via de contaminação, ocupação, evolução final (cura ou óbito), classe e grupo químico dos agrotóxicos. Após a tabulação dos dados, as variáveis foram relacionadas aos Núcleos Regionais que compõe a Secretaria de Estado da Agricultura do Paraná e as intoxicações foram correlacionadas às áreas de seis grupos de cultivos (frutas, culturas de inverno e verão, olerícolas, olerícolas grandes e outros cultivos). Os resultados do estudo apontaram que a maior parte das intoxicações ocorreu em atividades relacionadas à causa profissional $(53,1 \%)$, tendo sido os inseticidas os agentes causadores da maioria das intoxicações (37,9\%) e óbitos (42\%). A maioria dos intoxicados foram indivíduos do sexo masculino (79,8\%), sendo a faixa de idade compreendida entre os 18 e 23 anos, onde ocorreram o maior número de intoxicações $(21,2 \%)$ e óbitos $(15,8 \%)$. O maior percentual de óbitos ocorreu mediante a tentativa de suicídio (86\%), principalmente na faixa de idade entre 18 e 23 anos (16,1\%). Foi na zona rural onde se deu o maior número de ocorrências (65\%), em indivíduos ligados a ocupação agrícola (63\%). As principais vias de contaminação, para a causa profissional foram a via respiratória com 58,3\% dos casos e suas combinações com as demais vias $(82,2 \%)$. Para a causa suicídio a via prioritária foi a digestiva, tendo atingido $95,7 \%$ dos casos notificados. A região norte (composta pelos núcleos regionais de Apucarana, Cornélio Procópio, Ivaiporã, Jacarezinho, Londrina e Maringá) deteve o maior número de ocorrências de intoxicações $(43,1 \%)$ e óbitos $(37 \%)$, sendo os organofosforados os maiores responsáveis por ambas. A análise de Correlação concluiu ser positiva a relação existente entre as intoxicações notificadas e as áreas de cultivos de culturas de inverno e verão, frutíferas e olerícolas. O acesso fácil, associado ao armazenamento inadequado dos agrotóxicos, assim como a participação prematura em atividades agrícolas resultou na ocorrência de intoxicações e óbitos em indivíduos menores de idade. O uso do Receituário agronômico e Guia de aplicação para agrotóxicos de venda aplicada não impediram a ocorrência de intoxicações e óbitos causados por herbicidas bipiridílios. 


\section{CASES OF INTOXICATION CAUSED BY THE USE OF PESTICIDES IN THE STATE OF PARANÁ DURING THE PERIOD OF 1993 TO 2000: A STUDY}

Author: DALMO POLASTRO

Adviser: Prof. Dr. VALDEMAR LUIZ TORNISIELO

\section{SUMMARY}

The state of Paraná is responsible for more than $20 \%$ of the national grain production. Its agricultural structure is organized in small and mediumsized properties where the labor force comes mainly from families. In order to mantain and also increase productivity, the agriculture system in Paraná makes intensive use of the available products in the market, such as pesticides, where Paraná is considered to be the second largest consumer in Brazil. The massive sale of these products, the user's low schooling level and the careless use of the products result in intoxications. Based on all that, the present study aimed at identifying and characterizing the profile of populations informedly intoxicated by pesticides in the state of Paraná during the period from 1993 to 2000, as well as proposing preventive measures in order to help such exposed populations. Therefore, the acute intoxications informed during the period from 1993 a 2000 refering to the State of Paraná Health Department databank were analyzed. The intoxications were analyzed according to the following variables: sex, age, location of occurrence, contamination method, occupation, final evolution (cure 
or death), and pesticides class and chemical group. After the data tabulation, the variables were related to the Regional Centers which compose the State of Paraná Agriculture Department and the intoxications were correlated to the áreas of six different crops (fruits, winter and summer crops, vegetable crops, large vegetable crops and other crops). The results show that most of the intoxications took place during professional activities (53.1\%), and insecticides were the agents causing most of the intoxications (37.9\%) and deaths (42\%). Most of the intoxicated people were males (79.8\%) between 18 and 23 years old, with the largest number of intoxications (21.2\%) and deaths (15.8\%). The largest death rate occurred due to suicide attempts (86\%), mainly between the ages of 18 and 23 (16.1\%). The rural area accounted for most of the occurrences (65\%), in individuals somehow connected to agricultural jobs (63\%). The main contamination methods for a professional reason were the respiratory tract with $58.3 \%$ of the cases and its combinations with the other tracts (82.2\%). For the cause of suicide the digestive tract was the most relevant, with $95.7 \%$ of the informed cases. The north region (composed by the regional centers of Apucarana, Cornélio Procópio, Ivaiporã, Jacarezinho, Londrina and Maringá) had the highest number of intoxications (43.1\%) and deaths (37\%), mainly caused by organophosphates. The Correlation analysis showed the relationship between informed notifications and the winter and summer crop areas, as well as fruit and vegetable crops, was positive. Easy access, together with inadequate storage of pesticides and premature participation in agricultural activities resulted in the occurrence of intoxications and deaths in underaged individuals. The dipyridylium herbicides, even being sold strictly under agronomic prescription associated to the aplication guide, did not imped the occurrence of intoxications and deaths of pesticides's users. 


\section{INTRODUÇÃO}

O Estado do Paraná atualmente ocupa uma posição de destaque no cenário agrícola nacional. Apesar de possuir 2,3\% da área do país, o Paraná é responsável por $23,4 \%$ da produção nacional de grãos, sendo $01^{\circ}$ produtor nacional de milho, feijão, trigo, mandioca, aveia e o $2^{\circ}$ produtor de soja, centeio e cevada. O Paraná também é um grande consumidor de agrotóxicos, situandose como o segundo maior consumidor de Produtos Agrotóxicos Comerciais (Paraná, 2001).

O Estado do Paraná, com uma área de $199.324 \mathrm{~km}^{2}$, possuía em 1996, ano do último censo agropecuário realizado pelo Instituto Brasileiro de Geografia e Estatística (IBGE), uma população de 9.003.804 habitantes, sendo $77,9 \%$ residentes em áreas urbanas e 22,1\% em áreas rurais. Em sua estrutura agrária, predominam pequenas e médias propriedades, exploradas, principalmente, pela mão-de-obra familiar, onde, $87 \%$ delas possuem menos de 50 ha (IBGE, 1997).

Nas pequenas propriedades, as culturas que prevalecem são culturas de subsistência, como milho e feijão, e perenes como o café, culturas estas onde ocorreram, conforme levantamento da Secretaria de Estado da Saúde do Paraná (SESA), os maiores números de casos de intoxicação entre 1997 a 1999 (Paraná, 2002a). 
No atual estágio da agricultura paranaense, o uso de agrotóxicos consiste em fator essencial para o alcance dos níveis de produtividade preconizados pelos órgãos de tecnologia e pesquisa. Entretanto, este uso deve ser efetuado de forma parcimoniosa e de modo seguro, permitindo assim, a produção de alimentos em quantidade e qualidade aceitáveis, sem comprometer a saúde dos trabalhadores rurais e dos consumidores.

Quando abordamos questões afetas aos agrotóxicos, inevitavelmente somos levados aos perigos toxicológicos inerentes ao uso destes insumos, sobremaneira no Brasil, país continental com acentuadas diferenças regionais.

A Organização Mundial da Saúde (OMS), citada por Organização Pan-Americana da Saúde (OPAS) (1996) estima que nos países em desenvolvimento ocorrem aproximadamente três milhões de intoxicações agudas causadas por agrotóxicos, resultando em 220 mil mortes por ano.

No Estado do Paraná, os dados referentes ao uso de agrotóxicos igualmente apontam uma desanimadora realidade. A Secretaria de Estado da Saúde informou que no período de 1990 a 1999 ocorreram 8.768 casos de intoxicação aguda por agrotóxicos, destes, 913 vieram a óbito. Em outro levantamento, aquele órgão público apurou as causas das intoxicações, especificando que $50 \%$ delas decorreram do uso profissional desses produtos, $29 \%$ derivaram de suicídio e $17 \%$ foram acidentais. E ainda, que desse total, $78 \%$ atingiram pessoas do sexo masculino e $22 \%$ do sexo feminino. A faixa etária na qual predominou o maior número de casos de óbito foi acima de 40 anos. Em outro levantamento, abrangendo o período de 1997 a 1999 a SESA apurou que $90 \%$ dos óbitos foram provocados por suicídio, 5\% pelo uso profissional e 5\% por outras causas (Paraná, 2002a). 
O nível de instrução dos trabalhadores rurais, bem aquém do desejável, e o descaso com que muitos tratam as questões de segurança inerentes ao uso de agrotóxicos e afins, seu armazenamento, destinação das embalagens e resíduos desses produtos, comprometem a eficácia da aplicação e elevam os riscos de acidentes. Tais fatos em grande parte justificam os casos de intoxicação aguda e de óbitos, consideradas as bem sucedidas tentativas de suicídio pela ingestão desses produtos.

O objetivo geral deste estudo foi o de identificar e caracterizar o perfil das populações notificadamente intoxicadas por agrotóxicos, de uso agrícola, no Estado do Paraná no período de 1993 a 2000. Para tanto, buscou-se conhecer os seguintes aspectos relacionados às intoxicações: quais as principais causas e vias de intoxicação; quais as classes e grupos químicos dos agrotóxicos causadores das intoxicações; qual o perfil do intoxicado, segundo a faixa de idade, sexo, ocupação e local de ocorrência da intoxicação; e à luz dos casos de intoxicação notificados, quais são as regiões e respectivos núcleos regionais da Secretaria de Estado da Agricultura e Abastecimento do Paraná (SEAB) consideradas mais problemáticas, e quais as possíveis justificativas, relacionando seus respectivos índices de intoxicação às suas características agrícolas, como os tipos de atividade agrícola (culturas) e intensidade de exploração (áreas de cultivo). 


\section{REVISÃO DE LITERATURA}

A questão dos agrotóxicos, seu uso e seus benefícios, tem sido larga e exaustivamente discutida nos últimos anos. Nesta discussão surgem as mais relevantes polêmicas acerca do tema, principiando pela denominação deste insumo. De um lado, os fabricantes, na sua maioria, grandes conglomerados multinacionais e suas fusões a cada dia mais freqüentes, e no outro extremo, todos os seres vivos, onde se incluí a sociedade humana nas suas mais variadas formas de organização social e intelectual.

De modo geral, os agrotóxicos no Brasil são utilizados por agricultores de pouca instrução, que ignoram os perigos da exposição a este insumo, haja vista que nem sempre recebem as informações necessárias ou, então, quando as recebem, desconsideram, julgando possuírem capacidade e experiência suficientes para bem utilizá-los (Nieweglowski et al., 1992; Albuquerque et al., 2004).

No que diz respeito ao conhecimento sobre os riscos oferecidos pelo manuseio de produtos agrotóxicos e a evidente desatenção por parte dos indivíduos manipuladores, comportamento análogo também pode ser encontrado em países desenvolvidos, onde o nível cultural das populações expostas é superior aos do Brasil. Realidade semelhante a nossa, foi constatada em estudo sobre intoxicações agudas por pesticidas, realizado na 
Holanda, pelo National Poisons Control Centre. Foram selecionados 54 casos de possível intoxicação aguda por pesticidas, destes, apenas 37 apresentaram relação direta entre exposição a agrotóxicos e problemas agudos de saúde. Dos 54 casos analisados, em 67\% a exposição não ocorreu devido à aplicação de pesticidas, mas sim, durante o seu preparo (35\%); 14\% durante o reparo do equipamento de aplicação e 14\% durante a inadvertida reentrada no local de aplicação. O autor conclui afirmando que embora a maioria dos trabalhadores seja consciente do risco em se usar pesticidas, estes ainda são negligentes nos cuidados com medidas de proteção (Meulenbelt \& De Vries, 1997).

Além da questão referente à consciência sobre os perigos oferecidos pelos agrotóxicos quando da sua utilização, outro aspecto que determina terminantemente a efetividade ou não da intoxicação pelos agricultores, é o aspecto da proteção, representada pelos Equipamentos de Proteção Individual - EPI's. Agostinetto (1988), estudando os procedimentos de segurança de trabalho adotados por fumicultores do município de Pelotas-RS, concluiu que apenas 12,8\% usam equipamento básico de proteção, sendo que 26,6\% não utilizam nenhum tipo de equipamento de proteção, que $27,7 \%$ destes já passaram mal após as aplicações e 6,4\% já se intoxicaram com agrotóxicos. Os percentuais de uso de alguns dos equipamentos de proteção variam sobremaneira, como se pode observar em levantamento feito com produtores de olerícolas de um município do Estado de Minas Gerais, onde se apurou que a maioria dos entrevistados (59\%) não utilizava EPI's, dos restantes, alguns (29\%) utilizavam apenas luvas e botas, e os demais (12\%), apenas máscara (Albuquerque et al., 2004).

A grande maioria dos estudos realizados atesta que os agricultores usuários de produtos agrotóxicos tem ciência da necessidade do uso de EPI"s, entretanto, boa parte deles não os utiliza e, quando o fazem, tendem a utilizálos parcialmente, como botas, luvas e máscara, alegando, inclusive, que apesar 
da utilização dos equipamentos não estariam totalmente livres dos riscos de contaminação (Albuquerque et al., 2004).

Em estudo realizado por Oliveira-Silva et al. (2001) no Estado do Rio de Janeiro visando avaliar a exposição de trabalhadores rurais e a influência dos fatores socioeconômicos na contaminação por agrotóxicos, concluiu-se que, apesar de 90\% dos entrevistados considerarem de grande importância a utilização de EPI's, apenas 70\% destes os utilizavam.

A utilização parcial dos EPI's, sua não utilização ou o uso de equipamentos inadequados, seja no preparo das caldas ou na aplicação dos agrotóxicos, é um ato generalizado no ambiente das populações expostas (Agostinetto et al., 1988; Albuquerque et al., 2004; Bueno, 2004; Delgado \& Paumgartten, 2004 e Faria et al., 2004).

Muitas são as justificativas pelas quais os aplicadores de agrotóxicos não utilizam os EPI's. Albuquerque et al. (2004, p.4), apurou junto a aplicadores entrevistados no município de Caratinga - MG, que:

\footnotetext{
"as luvas são grossas e dificultam o manuseio ou são finas e rasgam com facilidade. As botas são quentes e dificultam a locomoção em ambientes molhados, como é o caso das hortas. As máscaras são desconfortáveis e dificultam a respiração ou por acharem que elas não são necessárias ou simplesmente por não se interessarem em usá-las".
}

A falta de costume; serem desconfortáveis; quentes; dificultar o trabalho; custarem caro; foram outros motivos encontrados por Delgado \& Paumgartten (2004), para que os aplicadores não utilizassem os EPI's. Faria et al. (2004) cita em estudo feito no Sri Lanka que, apesar da consciência dos aplicadores pela existência da maioria dos itens que compõe o conjunto de 
equipamentos de proteção, a grande maioria não os utilizava em razão do desconforto e dos custos. Mesmo que alguns agricultores tenham a consciência da importância do uso de EPI's, ainda sim, não o utilizam, pelo fato deles provocarem calor e limitarem a mobilidade, conforme conclusão que se chegou num trabalho realizado em Alberta, EUA. (Garcia, 2001b).

Outro tipo de conduta, porém mais rara, e que justifica o não uso de EPI's está ligado ao aspecto cultural, mais precisamente ao comportamento "machista" que prevalece em certas comunidades. Guivant (1994) em trabalho realizado junto a olerícultores do Estado de Santa Catarina, argumenta que os agricultores tendem a impingir às intoxicações não ao manuseio incorreto dos agrotóxicos, mas sim, à fragilidade dos aplicadores. Segundo a autora, a utilização de equipamentos de proteção é tida pela comunidade estudada, como coisa de indivíduos "afeminados ou medrosos".

Quando se aborda o aspecto de segurança na utilização dos agrotóxicos não se deve esquecer que parte daqueles que manuseiam estes produtos nem sempre se constituem em proprietários das áreas onde tal insumo é aplicado. Muitos são empregados, porcenteiros, arrendatários, além de outras categorias de funcionalidade e servidão. A estes, são oferecidas péssimas condições de trabalho, baixa remuneração pelos seus serviços, restando desinformados dos custos, da utilidade e da necessidade do uso de EPI's. Também é notório o despreparo da classe patronal, insuficientemente preocupada com a saúde de seus empregados, aos quais poucas vezes disponibilizam, como é de seu dever, equipamentos, vestimentas ou maquinários adequados, capazes de diminuir sobremaneira a exposição dos aplicadores aos agrotóxicos.

Ao tratar dos itens pertinentes a proteção individual dos aplicadores de agrotóxicos, encontra-se esteio legal nas mais diversas instâncias 
jurisdicionais. No âmbito estadual, a Lei $n^{\circ} 7827 / 83$, que dispõe sobre a distribuição e comercialização de produtos agrotóxicos e outros biocidas no território Paranaense, estabelece em seu art. 20 que:

"todo proprietário agrícola que venha a aplicar, em sua propriedade, agrotóxicos ou biocidas deverá se utilizar ou fornecer, àqueles que para ele trabalharem, equipamentos de proteção para a aplicação, na lavoura, de agrotóxicos e/ou biocidas" (Paraná, 1997, p.5).

O Decreto Estadual $n^{\circ}$ 3876/84, que regulamenta a citada Lei, caracteriza adequadamente, em seu art. 23, os personagens relacionados à exploração agrícola, como donos, parceiros ou arrendatários e, no seu art. 24, especifica suas obrigações enquanto usuários de agrotóxicos e/ou biocidas: "1. fornecer, conforme normas técnicas de segurança recomendada para 0 produto, equipamento de proteção àqueles que sobre ordem, transportem, manuseiem ou apliquem agrotóxicos e/ou biocidas" (Paraná, 1997, p.20).

Já a Lei Federal $n^{0} 7.802 / 89$, art. 14, alínea f, dispõe que as responsabilidades administrativas, civil e penal, pelos danos causados à saúde das pessoas e ao meio ambiente, cabem:

“f) ao empregador, quando não fornecer e não fizer manutenção dos equipamentos adequados à proteção da saúde dos trabalhadores ou dos equipamentos na produção, distribuição e aplicação dos produtos" (Paraná, 1997, p.74).

Do mesmo modo, o Decreto Federal n 98.816/90 que regulamentava a citada Lei, em seu art. 73, tipificava como sendo infração o disposto nos seus incisos VIII e IX: 
"Inciso VIII - utilizar inadequadamente agrotóxicos, seus componentes e afins, bem como não utilizar equipamentos de proteção da saúde do trabalhador Inciso IX - utilizar agrotóxicos, seus componentes e afins sem os devidos cuidados com a proteção da saúde humana e do meio ambiente;" e inciso XV: "não fornecer ou não fazer a manutenção dos equipamentos de proteção do trabalhador" (Paraná, 1997, p.115).

Hoje, o Decreto Federal $n^{\circ} 4.074 / 02$ que revogou seu anterior, de $n^{\circ}$ 98.816/90, no caput do seu art. 84, inciso VI, imputa as responsabilidades, administrativa, civil e pena, pelos danos causados à saúde das pessoas e ao meio ambiente, ao que: "Inciso VI - o comerciante, o empregador, o profissional responsável ou prestador de serviços que deixar de promover as medidas necessárias de proteção à saúde ou ao meio ambiente" (Paraná, 2002b, p.22).

Como se pode notar, existe farta legislação que ampare àqueles que manuseiam, em qualquer que seja sua categoria funcional, os produtos agrotóxicos. Entretanto, na prática observa-se que o uso de Equipamentos de Proteção Individual só ocorre mediante o convencimento através de práticas educacionais, e na maioria das vezes, através da expressa imposição de sanções legais aos proprietários, empregadores e funcionários, por meio da ação de fiscais de defesa sanitária vegetal.

Ainda no quesito segurança, não se deve olvidar dos itens relativos aos equipamentos utilizados na aplicação dos agrotóxicos, como os pulverizadores, principais instrumentos do ato de se aplicar agrotóxicos, sejam eles de ação motorizada ou manual.

Tordoir \& Maroni (1994) propõem a seguinte ordem das medidas gerais envolvidas na prática agrícola: substituição de produtos em uso por produtos que ofereçam menor risco a saúde; melhoria das embalagens e equipamentos utilizados na prática agrícola; melhoria na execução das 
atividades, visando minimizar a exposição; uso de EPI's enquanto as exigências anteriormente citadas são executadas.

Garcia (2001a) em estudo que visava avaliar o impacto da Lei Federal $n^{\circ} 7.802 / 89$ sobre a questão das intoxicações e outros aspectos relacionados a toxicologia deste insumo, concluiu que a intensificação da fiscalização sobre o uso destes produtos, associada a medidas normativas que restrinjam o registro de produtos de alta periculosidade e priorizem o registro de produtos menos tóxicos, são providências que podem circunstancialmente minimizar o impacto destes sobre as populações expostas.

Em estudo recentemente realizado por Gandolfo \& Antuniassi (2004) durante um período de cinco anos, foram avaliados, em propriedades, cooperativas e fabricantes de máquinas, cerca de 200 equipamentos de pulverização, do tipo tratorizado, onde concluíram que $80 \%$ dos aparelhos com mais de dois anos de uso apresentaram bicos de pulverização desgastados; $70 \%$ operam com erros de dosagem e $100 \%$ deles apresentaram problemas nos medidores de pressão (manômetros), ou seja, a manutenção dos equipamentos utilizados na aplicação de agrotóxicos ainda não é tida como um procedimento rotineiro e obrigatório. Deste fato implica a aplicação incorreta de agrotóxicos, gerando sub ou superdosagens de ingredientes ativos no ambiente, potencializando a ocorrência indesejável da resistência dos alvos biológicos.

A utilização de equipamentos de aplicação, modernos ou em perfeito estado de funcionamento, não é condição assaz para a não ocorrência de acidentes de trabalho junto às populações expostas ao uso de agrotóxicos. $O$ uso adequado dos equipamentos de aplicação, apoiado pelo constante assessoramento por parte de técnicos experimentados, que levem até estas populações, de modo contínuo e continuado, as tecnologias mais adequadas a 
cada conjunto de circunstâncias, é fator preponderante à minimização dos riscos de exposição a estes produtos.

Ramos et al. (2002), em trabalho realizado na cultura da uva para avaliação da exposição dérmica de aplicadores de agrotóxicos, onde foram utilizados 4 tipos de equipamentos de pulverização: semi-estacionário típico, pulverizador de barras adaptado a cultura da uva (bicos voltados para cima), turbopulverizador marca Hatsuta (modelo café com turbina adaptada a cultura da uva) e turbopulverizador marca KO (modelo Jales), concluiu que a maior exposição, quantificada através da extração do elemento marcador (cátion $\mathrm{Cu}^{+2}$ ) presente nos coletores (absorvente higiênicos femininos) afixados em partes estratégicas do corpo dos aplicadores, aconteceu por ocasião do uso do pulverizador semi-estacionário típico, onde os bicos de pulverização são posicionados à frente dos aplicadores, obrigando-os a atravessarem a nuvem de pulverização (fog) enquanto aplicam o agrotóxico e a exposição foi elevada em praticamente todo o corpo. Os demais equipamentos utilizados no trabalho proporcionaram grande redução na exposição dérmica potencial, quando comparado ao sistema semi-estacionário, sendo as mãos, cabeça e dorso as regiões mais atingidas, o que implica em deduzir que estas são áreas que devem ser priorizadas quando da elaboração de vestuários destinados à proteção do trabalhador.

A mudança de condutas e procedimentos, consolidados de modo pétreo, geração a geração, é tarefa que deve ser implementada por elementos preferencialmente ligados a órgãos oficiais de pesquisa e assistência técnica governamental, para que os agricultores, de modo geral, não sejam logrados na sua boa fé por elementos, principalmente aqueles ligados a setores de venda de insumos, que não primam por promover a redução dos riscos à saúde dos trabalhadores rurais. 
O Paraná é atualmente o principal Estado agrícola do país. No último Censo Agropecuário realizado pelo IBGE (1997), este apurou que na estrutura agrária do Estado do Paraná (Figura 1) predominam pequenos e médios estabelecimentos com $87 \%$ possuindo menos de 50 ha, onde são cultivados anualmente 5,7 milhões de hectares com lavouras; 6,7 milhões com pastagens; e 2,8 milhões com matas e florestas. Neste mesmo Censo, na discussão dos padrões tecnológicos então vigentes, concluiu-se que mais de $86 \%$ dos estabelecimentos onde vigoram explorações agrícolas, realizam o controle de pragas e doenças, e que apenas $40 \%$ destes se servem da assistência técnica, sendo $27 \%$ desta, oriunda de técnicos de fontes governamentais. O mesmo Relatório chama atenção para o fato da alta incidência de estabelecimentos que utilizam agrotóxicos, sem a devida assistência técnica.

\begin{tabular}{|c|c|c|c|c|}
\hline & \multicolumn{2}{|c|}{ Proporçäo do número em 31/12 ("(h) } & \multicolumn{2}{|c|}{ Proporção da área em 31/12(徎) } \\
\hline & 1970 & 1995 & 1970 & 1995 \\
\hline $\begin{array}{l}\text { Grupos de área total (ha) } \\
\text { Menos de } 10 \\
10 \text { a menos de } 100 \\
100 \text { a menos de } 1.000 \\
1.000 \text { a menos de } 10.000 \\
10.000 \text { e mais }\end{array}$ & $\begin{array}{c}53,2 \\
43,5 \\
3,1 \\
0,2 \\
0 \\
\end{array}$ & $\begin{array}{c}41,8 \\
50,9 \\
6,9 \\
0,4 \\
0 \\
\end{array}$ & $\begin{array}{c}10,8 \\
41,7 \\
28,9 \\
15,6 \\
3 \\
\end{array}$ & $\begin{array}{c}5 \\
33,9 \\
41,1 \\
17,3 \\
2,7 \\
\end{array}$ \\
\hline Condição do responsáwel & 1970 & 1995 & 1970 & 1995 \\
\hline $\begin{array}{l}\text { Proprietarió } \\
\text { Arrendatário } \\
\text { Ocupante } \\
\text { A.dministrador }\end{array}$ & $\begin{array}{l}54,1 \\
33,8 \\
8,9 \\
3,2\end{array}$ & $\begin{array}{l}71,3 \\
14,4 \\
8,6 \\
5,7\end{array}$ & $\begin{array}{c}59 \\
11,2 \\
4,8 \\
25\end{array}$ & $\begin{array}{c}61,8 \\
5,8 \\
2,6 \\
29,8\end{array}$ \\
\hline
\end{tabular}

Fonte:Modificado de IBGE (1997).

Figura 1 - Proporção do número e da área dos estabelecimentos por grupos de área total e proporção do número e da área dos estabelecimentos, explorados pelo proprietário, arrendatário, ocupante e administrador - Paraná - 1970/1995 
É de conhecimento público, que no atual panorama econômico já não existe mais a "agricultura nacional", e sim uma "agricultura global", onde alguns produtos agrícolas são considerados commodities e seu valor é ditado pelos pregões de Bolsas de Valores internacionais, que sabidamente manipulam preços conforme interesses políticos tendenciosos e protecionistas.

Submissos e dependentes deste mercado, encontram-se os produtos agrícolas brasileiros. A quase inexistência, o desarranjo e a descontinuidade das políticas agrícolas governamentais, a ausência de subsídios que visem proteger e amparar, ao menos o pequeno agricultor, bem como taxas, impostos, elevadas cargas tributárias, e medidas de vigilância sanitária impingidas exclusivamente para proteger mercados, seguramente desfavorecem 0 agricultor brasileiro.

Em tempos de globalização, a aplicação de novas tecnologias associadas ao aporte de investimentos financeiros, são requisitos cada dia mais necessários à sobrevivência do produtor rural. Desta forma, não resta ao produtor outra opção se não a de lançar mão de todos os recursos e meios para se obter bons resultados de produtividade. Neste contexto, os agrotóxicos, como outros insumos, se constituem em componentes insubstituíveis dentro do processo de produção, para que as produtividades preconizadas como mínimas, possam ser alcançadas.

Para Newman (1978), os pesticidas são utilizados na agricultura por três motivos: aumentar a produção das safras; aumentar a qualidade da produção; reduzir os gastos com a de mão-de-obra e energia dentro da produção agrícola. Em 1850 um agricultor produzia o suficiente para 4 pessoas, em 1960 para 25 pessoas e em 1975 para 44 pessoas. Este incremento na eficiência não se deve apenas ao uso de pesticidas, mas também a evolução 
progressiva das atividades de mecanização e o desenvolvimento de cultivares mais produtivos.

As primeiras tentativas usadas no intuito de controlar pragas foram feitas através do uso de substâncias químicas tóxicas, como o mercúrio, enxofre, ou através do extrato de plantas como a nicotina, píretro etc. Já na era moderna, grande parte dos pesticidas sintéticos, data do ano de 1939 quando as propriedades inseticidas do DDT (Dicloro Difenil Tricloroetano) foram descobertas (Newman, 1978).

À semelhança do que afirmou Newman (1978), Bull \& Hathaway (1986) relatam que até a década de 1930, os pesticidas (como os agrotóxicos eram então conhecidos) utilizados se resumiam a produtos de origem botânica (píretros, nicotina, rotenona etc) ou inorgânicos artificiais (arseniacais, mercuriais, sulfurosos etc), qualquer que fosse a nação usuária, fosse ela pertencente aos países industrializados ou do $3^{\circ}$ mundo. Foi durante as duas Grandes Guerras Mundiais que foram desenvolvidos e produzidos em grande escala, na Europa e Estados Unidos, os pesticidas orgânicos, contendo cadeias e anéis, mais ou menos extensas de átomos de carbono, em combinação com outros elementos químicos, principalmente fósforo, enxofre e nitrogênio e, um pouco mais tarde, o cloro. A finalidade principal da criação destes produtos era bélica e não agrícola. Tão logo os pesquisadores descobriram o poder biocida, em especial o inseticida, é que as indústrias promoveram o desenvolvimento técnico e comercial destes produtos, agora chamados de pesticidas.

Fundamentado nos incontáveis trabalhos científicos realizados até os dias atuais, é indiscutível os danos causados pelos agrotóxicos ao meio ambiente, em especial aos seres humanos. O despertar desta consciência se deu após a publicação, em 1962, da obra "Silent Spring" da escritora Rachel Carson (1970). Rachel descobriu, após vários levantamentos, os prejuízos 
ambientais que os agrotóxicos agrícolas, especialmente o DDT, estavam causando a espécies animais, como a águia americana, por causas decorrentes da bioacumulação seguida da biomagnificação destes produtos.

Todavia, são inegáveis os benefícios trazidos ao mundo pelos pesticidas, quando ainda inexistiam outras alternativas eficientes, principalmente no uso em campanhas de saúde pública em países subdesenvolvidos com sérios problemas de epidemias causadas por doenças tropicais. A exemplo, a grande campanha empreendida após o ano de 1955 pela OMS, que intencionou erradicar globalmente a malária. Para se ter uma idéia, num balanço feito até 1970, estimou-se que a referida campanha tenha prevenido 2 bilhões de casos de malária e salvo 15 milhões de vidas (Bull \& Hathaway, 1986).

O primeiro inseticida organoclorado a ser sintetizado foi o $\mathrm{BHC}$, em 1825 por Faraday. Entretanto, sua aplicação prática como biocida ocorreu apenas em 1947 no Egito, quando foi utilizado no combate de caramujos do gênero Planorbis e Bulinus, hospedeiros intermediários do Schistosoma, agente etiológico da esquistossomose (Almeida et al., 1962). Já os organofosforados, segundo Newman (1978), são compostos perigosos, altamente tóxicos aos mamíferos, que devido a esta característica despertaram especial interesse à indústria química armamentista durante os períodos de guerra. Estes tiveram sua origem em pesquisas realizadas na Alemanha no final da década de 30.

Dos inseticidas organoclorados conhecidos, o DDT (dicloro difenil tricloroetano) foi o de uso mais intenso na agricultura. Sintetizado em 1874 na Alemanha, por Ziedler, só teve descoberta suas propriedades inseticidas em 1940 na Suíça, pelas mãos de Laüger, Martin e Muller, então pesquisadores da Cia. Geigy. A aplicação inicial descoberta por estes, consistia no uso do DDT na 
proteção de lã contra o ataque de traças e outros insetos. Tal aplicação conferiu a Paul Muller, o Prêmio Nobel de Medicina em 1948 (Almeida et al., 1962).

A maioria dos organoclorados teve sua síntese na década de 1940, porém, a aplicação como agentes, inseticidas, larvicidas e molusquicidas, se deu ao final da $2^{\mathrm{a}}$ Grande Guerra Mundial, tendo como grande descobridor o pesquisador Julius Hyman, nos Estados Unidos (Almeida et al., 1962), como pode se observar na Figura 2.

\begin{tabular}{|c|c|c|c|c|}
\hline $\begin{array}{c}\text { Nome } \\
\text { Comercial }\end{array}$ & $\begin{array}{c}\text { Nome } \\
\text { Químico }\end{array}$ & Sintetizado & Utilizado & Finalidade \\
\hline DDT & \begin{tabular}{|l} 
Dicloro Difenil \\
Tricloroetano
\end{tabular} & 1874/Zeidler & 1940/Ciba & $\begin{array}{c}\text { malária } \\
\text { febre amarela }\end{array}$ \\
\hline $\begin{array}{c}\text { BHC (lindane) } \\
\text { DDD }\end{array}$ & $\begin{array}{l}\text { Hexaclorociclohexano } \\
\text { Dicloro Difenil } \\
\text { Dicloroetano }\end{array}$ & 1825/Faraday & 1942/Dupine & $\begin{array}{l}\text { inset/molusqu. } \\
\text { inseticida } \\
\text { (pouco eficaz) }\end{array}$ \\
\hline TOXAFENO & Canfeno clorado & 1945/EUA & \begin{tabular}{|l|} 
1946/Jones \\
1950/Reimschneid
\end{tabular} & larvicida \\
\hline CLORDANE & & 1945/J.Hyman & er & inseticida/larvicida \\
\hline HEPTACLORO & & 1945/J.Hyman & March & inseticida \\
\hline ALDRIN & & 1948/J.Hyman & 1948/J.Hyman & inseticida \\
\hline DIELDRIN & & 1948/J.Hyman & 1950/J.Hyman & inseticida \\
\hline ISODRIN & & 1950/J.Hyman & 1950/J.Hyman & inseticida \\
\hline ENDRIN & & 1950/J.Hyman & 1950/J.Hyman & inseticida \\
\hline THIODAN & Endosulfan & & 1956/Hoechst & inseticida \\
\hline
\end{tabular}

Fonte: Almeida et al. (1962).

Figura 2 - Histórico, síntese e utilização dos principais inseticidas organoclorados

O término da $2^{\mathrm{a}}$ Grande Guerra, e suas conseqüências político econômicas foram determinantes no emprego inicial e maciço dos inseticidas organoclorados. Foi após a $2^{\mathrm{a}}$ Guerra que a agricultura passou a sofrer suas grandes mudanças. Equipamentos agrícolas mais sofisticados, abandono da diversificação de culturas em prol da monocultura praticada em áreas de grande porte etc (National Research Councill, 1989). Oportunamente ao início 
deste processo, surgem os inseticidas organoclorados e organofosforados, como a grande promessa tecnológica de fomento a esta nova agricultura.

A partir de 1945, pesticidas como o DDT, BHC (Hexaclorociclohexano), parathion e malathion, entre outros, passaram a dominar o mercado mundial por completo. E não diferente do ocorrido no restante do mundo, foi a partir da $2^{\mathrm{a}}$ Guerra Mundial que os pesticidas orgânicos adentraram no Brasil. Já em 1946, o BHC, conhecido na época como pó-debroca, já era fabricado no Rio de Janeiro pela Eletroquímica Fluminense (Bull \& Hathaway, 1986).

O primeiro uso de inseticidas no Brasil de que se tem notícia, ocorrido por meio do BHC, aconteceu em dezembro de 1946, na cidade de Caçador-SC, utilizado no combate de gafanhotos, tendo sido também largamente utilizado no combate de pragas do cafeeiro, como a broca do café e pragas do algodoeiro. Em seguida vieram outros pesticidas, como o DDT, o parathion e o toxafeno (Nieweglowski et al., 1992).

Em 1950, o DDT era fabricado na cidade do Rio de Janeiro pela Fábrica Bonsucesso da Diretoria de Fabricação do Exército, aproveitando as instalações já equipadas para a fabricação de gases de guerra. Com a chegada do regime militar em 1964, a indústria de agrotóxicos sofre um fomento substancial em seu desenvolvimento, alavancada pelos ideais militaristas da época, que tinha como ícone e arquiteto de todo o golpe, o Gal. Golbery do Couto e Silva, na época, um dos Diretores da Dow Química. No final da década de 1960, os agrotóxicos já eram isentos de impostos como ICM e IPI, além de outros benefícios, como a isenção de taxas de importação para agrotóxicos não produzidos no Brasil. Até mesmo, aviões, utilizados na aplicação de pesticidas, ficaram livres dos impostos de importação (Bull \& Hathaway, 1986). 
A aquisição dos agrotóxicos era condicionada aos recursos do crédito rural, com a inclusão de uma cota contingenciada ao montante do financiamento. Neste cenário, o Estado atuava como incentivador, através de um processo político orientado pelo princípio da modernização da economia nacional. Em razão da obrigatoriedade da aquisição instituída por ocasião da liberação dos recursos, a política de importação brasileira oportunizou a entrada dos produtos de grandes indústrias químicas multinacionais, inclusive com a implantação de algumas destas indústrias nos parques industriais do sul e do sudeste na década de 70 . Aliada ainda à maciça propaganda dos fabricantes, intensificou-se o uso dos agrotóxicos na época, com repercussão na atualidade, tornando o Brasil um dos maiores consumidores em termos mundiais, ressaltando-se que muitos destes, consumidos no país, até hoje enfrentam proibição de utilização nos países onde são fabricados.

Na década de 1970, o $1^{\circ}$ PND - Plano Nacional de Desenvolvimento, se caracterizava principalmente pela ambição do aumento de produtividade, e contemplaria um novo modelo de agricultura através da adoção de insumos modernos, como o dos pesticidas organoclorados e organofosforados, que tiveram seus usos potencializados. A utilização de insumos modernos, nos quais, obviamente se incluíam os pesticidas, teve em 1975, a coroação de seu sucesso através da instituição do $2^{\circ}$ PND e do PNDA (Plano Nacional de Desenvolvimento Agrícola) (Nieweglowski et al., 1992). À época, a imposição ao consumo de agrotóxicos era tão desavergonhada, que ao captar recursos financeiros junto ao sistema oficial de crédito rural, o contratante, no caso os agricultores, era compelido a adquirir de modo obrigatório o "pacote" de agroquímicos (OPAS, 1996; Lobato, 2004).

Quando se analisa o histórico de consumo de pesticidas no Brasil, fica notória a ligação existente entre membros do governo e a indústria de pesticidas, que pode ser exemplificada através de alguns dos casos mais 
famosos: Gen. Golbery do Couto e Silva (Conselho Administrativo da Dow Chemical); Ernesto Geisel (Conselho Administrativo da Norquisa, durante o governo Figueiredo); Íris Resende (Conselho Honorífico da Andef); Nestor Jost (Conselho Administrativo da Bayer Brasil); Lourenço José Tavares Vieira da Silva (Secretário do Ministério da Agricultura no governo Collor - Presidente da Andef) (Nieweglowski et al., 1992).

Segundo a Associação Nacional de Defesa Vegetal (ANDEF) (ANDEF, 2002), o Estado do Paraná ostentava no ano de 1999, o segundo maior consumo de agrotóxicos do país em Produtos Comerciais - 42.396 t, ou seja, $14,7 \%$ do total comercializado no Brasil.

Com o freqüente aparecimento de novos agrotóxicos, motivados quer pela descoberta de novas moléculas (princípios ativos), quer pela competitividade a cada dia mais acirrada entre as empresas produtoras ou pelo advento do surgimento quase freqüente de novas pragas, ou ainda, pela resistência adquirida pelo uso inadequado de agrotóxicos, obrigaram o agricultor a utilizar produtos sem registro para a respectiva cultura e praga, ou até mesmo utilizar dosagens não indicadas, muitas vezes superiores ao recomendado pelos próprios fabricantes.

O uso abusivo desses produtos incorre naturalmente no aumento do número de casos de intoxicações, tornando estas um dos principais problemas de saúde pública no meio rural, seja devido ao aumento respectivo da exposição, seja pela ingestão de alimentos e água contendo resíduos de agrotóxicos em níveis além dos tolerados (Oliveira-Silva et al., 2001; Araújo et al., 2000).

Para Almeida et al. (1980), são relativamente freqüentes os casos de envenenamentos agudos provocados por pesticidas, incluindo casos fatais. 
Estas intoxicações são consideradas endêmicas entre os trabalhadores que manuseiam e aplicam defensivos agrícolas em países em desenvolvimento.

De acordo com Garcia (1998), estudos realizados nas décadas de 80 e 90 dão conta que são notificados por ano, cerca de 500 mil a 1 milhão de casos de intoxicações agudas causadas por pesticidas, destes resultam a morte de 3000 a 28000 indivíduos. Garcia relata também, que apesar do consumo de pesticidas ser maior em países desenvolvidos, é nos países em desenvolvimento que ocorrem o maior número de intoxicações. De modo análogo, Delgado \& Paumgartten (2004) também afirmam que a ocorrência de intoxicações agudas em países em desenvolvimento é superior ao ocorrido em países industrializados, atingindo, segundo alguns autores, percentuais de intoxicações 13 vezes maior.

Dados publicados no anuário estatístico de intoxicação e envenenamento pela Fundação Instituto Oswaldo Cruz (FIOCRUZ) (1998), situam os pesticidas agropecuários como sendo o quinto agente de intoxicação no Brasil no ano de 1997 (Tabela 1). Entretanto, quando daqueles dados são excluídos os casos de intoxicação provocados por animais peçonhentos e não peçonhentos, os pesticidas agropecuários passam a compor o quarto agente responsável por intoxicações no país. Segundo estes mesmos dados, os pesticidas agropecuários são os responsáveis pelo maior número de óbitos (143) no mesmo período, inferindo a estes um percentual de $33,8 \%$, quando comparado aos demais agentes intoxicantes mencionados na referida pesquisa (FIOCRUZ, 1998). 
Tabela 1. Casos registrados de intoxicações humanas por causa, sexo e óbitos. Brasil, 1997

\begin{tabular}{|c|c|c|c|c|c|c|c|c|c|c|c|c|c|c|}
\hline \multirow{3}{*}{ Agente } & \multicolumn{8}{|c|}{ Calsa } & \multicolumn{5}{|c|}{ Sexo } & orado \\
\hline & \multicolumn{3}{|c|}{ Acidente Abuso Suicidio } & \multicolumn{3}{|c|}{ Protis. Outras lgnorada } & \multicolumn{2}{|c|}{ Total } & \multicolumn{6}{|c|}{ Casos Obitos Casos Obitos Casos obitos } \\
\hline & $\Pi^{\circ}$ & $\Pi^{\circ}$ & $\Pi^{\circ}$ & $\Pi^{\circ}$ & $\Pi^{\circ}$ & $\Pi^{\circ}$ & $n^{*}$ & 莏 & $\Pi^{\circ}$ & $\Pi^{\circ}$ & $\Pi^{\circ}$ & $\Pi^{\circ}$ & $\Pi^{\circ}$ & $\Pi^{\circ}$ \\
\hline Medicamentos & 9376 & 434 & 8568 & 62 & 2443 & 465 & 21348 & 29,76 & 7955 & 30 & 13158 & 52 & 235 & 1 \\
\hline Ап. Peçonhentos & 12463 & - & - & 2058 & 180 & 115 & 14816 & 20,65 & 8836 & 28 & 5952 & 13 & 28 & - \\
\hline Апirтais пӑо Pec. & 4537 & - & - & 286 & 82 & 39 & 4946 & 6,89 & 2686 & - & 2237 & - & 21 & - \\
\hline Prod. Guim. Ind. & 3334 & 277 & 450 & 1309 & 184 & 86 & 5640 & 7,86 & 3660 & 19 & 1930 & 4 & 50 & - \\
\hline Agrotóxicos & 1668 & 9 & 1858 & 1434 & 133 & 96 & 5198 & 7,25 & 3491 & 99 & 1671 & 43 & 36 & 1 \\
\hline Pes. Domésticos & 1256 & 18 & 797 & 99 & 91 & 47 & 2306 & 3,22 & 1135 & 16 & 1144 & 7 & 29 & - \\
\hline Raticidas & 1123 & 3 & 1212 & 16 & 76 & 57 & 2487 & 3,47 & 1154 & 17 & 1302 & 18 & 31 & - \\
\hline Dorrissanitários & 5252 & 18 & 714 & 316 & 139 & 59 & 6498 & 9,06 & 3292 & 7 & 3125 & 1 & 81 & - \\
\hline Prod de Toalete & 560 & - & 23 & 5 & 39 & 10 & 640 & 0,89 & 313 & - & 319 & - & 8 & - \\
\hline Flantas & 1234 & 71 & 51 & 22 & 112 & 24 & 1514 & 2,11 & 762 & 2 & 709 & 1 & 23 & - \\
\hline Intox. Alimientos & 447 & 29 & - & 19 & 86 & 9 & 592 & 0,83 & 256 & 1 & 294 & 3 & 42 & - \\
\hline Outros Produtos & 849 & 2311 & 182 & 341 & 214 & 116 & 4013 & 5,59 & 2965 & 20 & 1013 & 7 & 35 & - \\
\hline Näo DeterrTiп. & 531 & 42 & 140 & 66 & 690 & 265 & 1734 & 2,42 & 885 & 20 & 805 & 12 & 44 & 1 \\
\hline Total & 42633 & 3212 & 13995 & 6035 & 4471 & 1380 & 71734 & 100,00 & 37412 & 259 & 39659 & 161 & 663 & 3 \\
\hline 8 & 59,43 & 4,46 & 19,51 & 8,41 & 6,23 & 1,93 & 100,0 & & 52,15 & 0,36 & 46,92 & 0,22 & 0,92 & 0,00 \\
\hline
\end{tabular}

Fonte: Modificado de FIOCRUZ (1998).

No Paraná a realidade se apresenta um pouco diferente. Neste Estado os agrotóxicos são os agentes que determinam $21 \%$ dos casos de intoxicação, ficando atrás apenas dos medicamentos (36\%), segundo estudo realizado no período entre 1997 a 1999, pela SESA (Paraná, 2002a).

Outro dado alarmante apontado no anuário da FIOCRUZ (1998), que pode ser constatado na Figura 3, é o fato dos Pesticidas Agropecuários serem responsáveis, em primeiro lugar, como o agente responsável pelo maior número de óbitos, decorrentes da prática do suicídio, inferindo a este, o percentual de 27,9\%. Dos casos de suicídio apontados pelo citado anuário, pode-se inferir que os agrotóxicos utilizados em tal prática, no mínimo não são armazenados adequadamente, permanecendo muitas vezes em ambientes de fácil acesso, inclusive a menores, o que pode ser comprovado através do êxito nas tentativas de suicídio nesta faixa de idade. Outra possível justificativa aos 
elevados casos de suicídio, talvez resida no fato do comportamento suicida ser um sintoma aparente das alterações neuropsicológicas e/ou depressivas, em decorrência das intoxicações agudas graves, próprias da exposição a inseticidas organofosforados (Trapé, 2004).

\begin{tabular}{|c|c|c|c|c|c|c|c|c|}
\hline \multicolumn{9}{|c|}{ Causa } \\
\hline \multirow[t]{2}{*}{ Agente } & \multirow[t]{2}{*}{ Acidente } & \multirow[t]{2}{*}{ Abuso } & \multirow[t]{2}{*}{ Suicídio } & \multirow[t]{2}{*}{ Profissional } & \multirow[t]{2}{*}{ Outras } & \multirow[t]{2}{*}{ Ignorada } & \multicolumn{2}{|c|}{ TOTAL } \\
\hline & & & & & & & $\mathbf{n}^{\mathbf{0}}$ & 跔 \\
\hline Medicamentos & 15 & & 49 & - & 13 & 6 & 83 & 19,62 \\
\hline An. Peçonhentos & 35 & & & 6 & - & - & 41 & 9,69 \\
\hline Animais nằ Peç. & & & & - & - & - & 0 & 0,00 \\
\hline Frod. Quim. Ind. & 3 & 3 & 10 & 3 & 2 & 2 & 23 & 5,44 \\
\hline Agrotóxicos & 7 & - & 118 & 2 & 6 & 10 & 143 & 33,81 \\
\hline Pes. Domésticos & 3 & 1 & 16 & - & 1 & 2 & 23 & 5,44 \\
\hline Raticidas & 4 & & 25 & - & 3 & 3 & 35 & 8,27 \\
\hline Domissanitârios & 1 & & 5 & 2 & - & & 8 & 1,89 \\
\hline Prod. de Toalete & & & & - & - & & 0 & 0,00 \\
\hline Plantas & 3 & & & - & - & & 3 & 0,71 \\
\hline Intox. Alimentas & 4 & & & - & - & & 4 & 0,95 \\
\hline Outros Produtos & 2 & 11 & 7 & - & 3 & 4 & 27 & 6,38 \\
\hline Nẵo Determin. & 5 & & 1 & - & 2 & 25 & 33 & 7,80 \\
\hline Total & 82 & 15 & 231 & 13 & 30 & 52 & 423 & 100,00 \\
\hline 吅 & 19,39 & 3,55 & 54,61 & 3,07 & 7,09 & 12,29 & 100,0 & \\
\hline
\end{tabular}

Fonte: FIOCRUZ (1998).

Figura 3 - Óbitos registrados segundo agente tóxico. Brasil, 1997

Fato parecido ocorre em outras partes do mundo, como no Sri Lanka, onde em estudo realizado, Van der Hoek et al. (1998) concluiu que a intoxicação aguda por agrotóxicos é o maior problema de saúde pública, e que a maior partes dos casos é intencional (tentativa de suicídio), entre adultos, sobretudo mulheres; relata ainda que em uma área de irrigação os casos de suicídio atingiram 68\% dos intoxicados. Van der Hoek acredita que legislações mais rigorosas, que visem restringir a disponibilidade de pesticidas mais tóxicos, bem como a melhoria dos serviços de extensão, a longo prazo, de modo que promovessem métodos alternativos de controle de pragas, seria uma importante estratégia para se minimizar o problemas das intoxicações. 
Sheu et al. (1998) estudando casos de intoxicações agudas causadas por agrotóxicos na província de HsinChu, na Tailândia, concluiu que a incidência destas intoxicações é de 3,2 por 100000 habitantes onde, destes, 23\% morrem. Concluiu também, que o maior agente das intoxicações foram os organofosforados e a maior causa está ligada à tentativa de suicídio. Observese aqui que um levantamento realizado pela SESA entre os anos de 1993 e 2000, apurou que os organofosforados foram os maiores responsáveis por intoxicações agudas neste período, inferindo a este o índice de 32\% com relação aos demais agrotóxicos (Paraná, 2002a).

Entretanto, resta a dúvida se os aludidos casos de suicídio já não refletem os distúrbios neuropsicológicos causados pela exposição a agrotóxicos, quando em casos de intoxicações já consideradas crônicas (OPAS, 1996).

No Brasil, é vasto o mercado de agrotóxicos. Para se ter uma idéia, Alves Filho (2002) relata que até meados de 2000, o país contava com 444 princípios ativos registrados junto aos órgãos oficiais, estes por sua vez geravam uma combinação de mais de 850 produtos comerciais que, face a diversidade de tipos de volumes e embalagens, se desdobravam em 1.981 produtos. No estado do Paraná, devido a exigência de cadastro exclusivo para uso em território paranaense, estabelecida através da Lei Estadual no 7827/83:

\footnotetext{
"Art. $1^{\circ}$ - A distribuição e comercialização no terrritório do Estado do Paraná, de produtos agrotóxicos e outros biocidas, estão condicionados ao prévio cadastramento perante a Secretaria de Agricultura e Secretaria do Interior." (PARANÁ, 1997, p.1),
}

se tem um número mais reduzido de agrotóxicos legalmente permitidos para o comércio e uso. Atualmente, o número de princípios ativos cadastrados é de 360, e 720 produtos comerciais, destes, 321 deles apresentam alguma espécie 
de restrição de uso. Dos produtos comerciais atualmente cadastrados, liberados para uso, 268 são inseticidas/acaricidas (37,2\%); 241 herbicidas (33,5\%); 167 fungicidas $(23,2 \%) ; 29$ adjuvantes $(4,0 \%)$ e 15 reguladores de crescimento $(2,1 \%)$ (Nascimento, 2004).

A Lei Federal no 7.802/89, que dispõe sobre as várias ocupações e atividades relacionadas aos agrotóxicos, caracteriza este, no inciso I de seu Art. $2^{\circ}$, como sendo:

"I - agrotóxicos e afins:

a) os produtos e os agentes de processos físicos, químicos ou biológicos, destinados ao uso nos setores de produção, no armazenamento e beneficiamento de produtos agrícolas, nas pastagens, na proteção de florestas, nativas ou implantadas, e de outros ecossistemas e também de ambientes urbanos, hídricos e industriais, cuja finalidade seja alterar a composição da flora ou da fauna, a fim de preserva-las da ação danosa de seres vivos considerados nocivos;

b) substâncias e produtos empregados como desfolhantes, dessecantes, estimuladores e inibidores de crescimento" (Paraná, 1997, p.67).

Já os parâmetros de classificação relacionados a $D_{50}$ e que determinam a classe toxicológica, foram estabelecidos pela Secretaria Nacional de Vigilância Sanitária, por meio da Portaria nº 03, de 16 de janeiro de 1992 (Figura 4). Nestes, uma provável equalização à classificação utilizada pela OMS, os agrotóxicos são classificados em quatro diferentes categorias (classes), sendo identificadas na parte inferior dos rótulos através de cores distintas: classe I - extremamente tóxico (faixa vermelha); classe II - altamente tóxico (faixa amarela); classe III - medianamente tóxico (faixa azul); classe IV pouco tóxico (faixa verde). A diferenciação no colorido das faixas utilizado na rotulagem dos produtos auxilia sobremaneira a identificação do grau de periculosidade, principalmente para os indivíduos de baixa instrução. Este 
argumento é tão verdadeiro, que é comum em conversas junto aos agricultores, estes se referirem ou se referenciarem a determinados agrotóxicos por meio da cor da faixa, ou tarja, como eles geralmente a chamam.

\begin{tabular}{|c|c|c|c|c|}
\hline \multirow{3}{*}{ Classe } & \multicolumn{4}{|c|}{ DL50 para ratos ( $\mathrm{mg}^{+} / \mathrm{kg}$ de peso wiwo) } \\
\hline & \multicolumn{2}{|c|}{ Oral } & \multicolumn{2}{|c|}{ Dérmica } \\
\hline & sólidos & lículidos & sólidos & líquidos \\
\hline 1 & $\measuredangle=5$ & $<=20$ & $<=10$ & $<=40$ \\
\hline $\begin{array}{l}\text { Extremamente tóxico } \\
\text { II }\end{array}$ & 5 a 50 & 20 a 200 & 10 a 100 & 40 a 400 \\
\hline $\begin{array}{l}\text { Altamente tóxico } \\
\text { III }\end{array}$ & 50 a 500 & 200 a 2.000 & 100 a 1.000 & 400 a 4.000 \\
\hline $\begin{array}{l}\text { Medianamente tóxico } \\
\text { IV } \\
\text { Pouco tóxico }\end{array}$ & $>500$ & $>2.000$ & $>1.000$ & $>4.000$ \\
\hline
\end{tabular}

$\left(^{*}\right) \mathrm{mg}$ de produto formulado

Fonte: Paraná (1997).

Figura 4 - Parâmetros da DL5o utilizados na classificação dos agrotóxicos segundo a classe toxicológica e tipo de formulação; dados estabelecidos através da Portaria no 03/1992 da Secretaria Nacional de Vigilância Sanitária

Com relação aos tipos de intoxicações causadas por agrotóxicos, a OPAS (1996, p.23) as classificam em três tipos:

"Na intoxicação aguda os sintomas surgem rapidamente, algumas horas após a exposição excessiva, por curto período, a produtos extrema ou altamente tóxicos. Pode ocorrer de forma leve, moderada ou grave, a depender da quantidade de veneno absorvido. Os sinais e sintomas são nítidos e objetivos.

A intoxicação subaguda: ocorre por exposição moderada ou pequena a produtos altamente tóxicos ou medianamente tóxicos e tem aparecimento mais lento. Os sintomas são subjetivos e vagos, tais como dor de 
cabeça, fraqueza, mal-estar, dor de estômago e sonolência, entre outros.

A intoxicação crônica: caracteriza-se por surgimento tardio, após meses ou anos, por exposição pequena ou moderada a produtos tóxicos ou a múltiplos produtos, acarretando danos irreversíveis, do tipo paralisias e neoplasias.".

A relação existente entre a classe do agrotóxico utilizado, o grupo químico e as intoxicações sofridas pelos aplicadores em decorrência da prática agrícola, está diretamente relacionada ao tipo de lavoura (cultura) empreendida, e a conseqüente tecnificação demandada para sua exploração. Estudo realizado nos municípios de Antônio Prado e Ipê, ambos na serra Gaúcha, junto a plantadores de frutíferas, onde predominam pequenas e médias propriedades com exploração de natureza familiar, apontou as seguintes classes de agrotóxicos como causadores das intoxicações: fungicidas (28\%), herbicidas (16\%), inseticidas/formicidas (8\%), causas envolvendo 2 ou mais produtos (16\%) e $20 \%$ delas foram causadas por produtos não identificados. Entre os de ação fúngica, predominaram os pertencentes ao grupo dos ditiocarbamatos, já entre os herbicidas, o grupo predominante foram os derivados da glicina (glifosato) (Faria et al., 2004).

Trabalho realizado por Delgado \& Paumgartten (2004) em algumas localidades no município de Paty do Alferes-RJ, região em que predomina a exploração econômica de lavouras olerícolas, como o tomate, pimentão e repolho, foram entrevistados 55 agricultores, onde se buscou avaliar o impacto do uso de agrotóxicos sobre a saúde dos trabalhadores. Entre todos os entrevistados, 34 indivíduos relataram ter "passado mal" devido ao uso de agrotóxicos, destes, $57 \%$ declararam estar usando na ocasião organofosforados, sendo que, 51\% relataram que quando "passaram mal" usavam inseticidas organofosforados pertencentes à classe toxicológica I. Nas 55 propriedades visitadas foram encontrados inseticidas (19 marcas), fungicidas 
(15 marcas) e acaricidas (2 marcas), não foram encontrados nenhum produto herbicida. Dos produtos encontrados a maioria pertencia aos grupos organofosforados, piretróides e ditiocarbamatos.

Relatório da Organização Mundial da Saúde (OMS) publicado em 1990 estimou que ocorrem em torno de 3 milhões de intoxicações causadas por agrotóxicos, e que destas, 220 mil se convertem em óbitos, além de estimar também que $70 \%$ dos casos ocorrem em países pertencentes ao $3^{\circ}$ mundo (World Health Organization, 1990).

Não bastasse a crueldade dos números expostos pela OMS, resta ainda a tácita realidade dos casos de intoxicações não mensurados, decorrentes das subnotificações. Trapé (2004) relata que agências internacionais relacionadas a questões de saúde acreditam que, face ao frágil sistema de saúde pública existente em países em desenvolvimento, o número de subnotificações podem estar próximo a 98\% dos casos efetivamente ocorridos, ou seja, apenas 1 em cada 50 casos são efetivamente registrados.

Para Trapé (2004) vários são os motivos que justificam a não notificação de casos de intoxicações: dificuldade de diagnóstico por parte da comunidade médica, devido à insuficiência de conhecimento na área de toxicologia, por parte destes profissionais; os pacientes de intoxicações agudas leves e moderadas apresentam sintomas que podem ser confundidos com o de outras enfermidades; dificuldade de acesso dos intoxicados aos locais de diagnóstico e tratamento, na maioria públicos, o que resulta na auto-medicação; existência de casos onde, devido a exposição contínua a inseticidas, por exemplo, quando submetidos a análises laboratoriais, não são detectados nos intoxicados os respectivos indicadores enzimáticos da intoxicação. 
À semelhança do afirmado por Trapé (2004), Nunes (1995) atribui como causa das subnotificações os seguintes motivos: a dificuldade de acesso aos centros médicos hospitalares no caso de trabalhadores rurais; em alguns casos as intoxicações não são graves o suficiente para motivar a procura aos médicos, pois em alguns casos a sintomatologia é bastante vaga (diarréia, vômito, dor de cabeça, falta de ar, etc.); a falta de capacitação dos profissionais de saúde, quanto aos efeitos dos produtos químicos.

Forattini (1976) destaca como um dos aspectos importantes na análise epidemiológica de um quadro, a obtenção de dados que permitam a análise quantitativa.

É ponto pacífico que a principal ferramenta para se quantificar e qualificar os casos de intoxicações por agrotóxicos, que dão entradas nos hospitais e centros de controle de intoxicações, são as notificações de ocorrências toxicológicas apontadas através das Fichas de Ocorrência Toxicológica e Fichas Individual de Investigação de Intoxicação por Agrotóxico (OPAS, 1996). No entanto, percebe-se que além dos casos notificados, há um número ainda maior de subnotificações, que impedem que se dimensione de maneira real este problema, conforme concluiu Balderrama (2000), em estudo sobre as intoxicações profissionais rurais causadas por agrotóxicos no Estado do Paraná.

Ruegg et al. (1991) afirma que dados fidedignos sobre a mortalidade e morbidade de envenenamento por pesticidas em países em desenvolvimento são raros, uma vez que poucos casos são tratados por médicos e quase nunca são diagnosticados como envenenamento. Mesmo nos hospitais e centros de saúde, a falta de equipamentos adequados dificulta a confirmação do diagnóstico. 
Crítica semelhante também faz Assunção \& Ribeiro (2004), sobre o sistema de notificações e investigação dos casos de intoxicações causadas por agrotóxicos no Brasil. Segundo estes, as notificações não são investigadas pelos sistemas de vigilância epidemiológica e sanitária, além do fato do atendimento ambulatorial dado aos casos de intoxicação ser débil e deste modo contribuir para o subregistro destas.

Apesar das inúmeras censuras feitas pela comunidade científica com relação à qualidade e a quantidade (número de registros) dos dados de notificações ofertados por instrumentos de coleta de informações, como as Fichas Epidemiológica de Ocorrência Toxicológica, a análise destes, ainda se constitui como o melhor caminho para se aferir o real impacto do uso de agrotóxicos no contexto sócio-econômico de um país, bem como instrumentar os órgãos oficiais de vigilância, sejam das áreas de saúde, previdência ou defesa agropecuária, na proposição de políticas públicas que visem minimizar os impactos dos agrotóxicos junto a sociedade como um todo.

Implantados na década de 80, em muitos estados brasileiros, os Centros de Controle de Intoxicações são responsáveis pela recepção inicial dos dados, então apontados nas Fichas de Ocorrência Epidemiológicas, que em seguida, são sistematizados e encaminhados a Fundação Oswaldo Cruz, órgão do Ministério da Saúde, que por meio do Sistema Nacional de Informações Tóxico-Farmacológicas (SINITOX) coordena o tratamento destes dados, e após analisá-los, publica anualmente a compilação destes na forma de estatísticas.

Segundo o Manual de vigilância da saúde de populações expostas a agrotóxicos (OPAS, 1996) a existência de um sistema de vigilância epidemiológica, consiste em fator preponderante ao conhecimento do comportamento epidemiológico das doenças ou agravo escolhido como alvo 
das ações, a fim de que sejam providenciadas e desencadeadas ações com estimável sucesso.

O referido Manual, publicado pela Organização Pan-Americana da Saúde (OPAS, 1996, p.7), dita que: as ações de vigilância da saúde devem envolver todos os níveis do sistema e contemplar as seguintes funções:

"coleta de dados; processamento dos dados coletados; análise e interpretação das medidas de controle apropriadas; análise e interpretação dos dados processados; recomendação das medidas de controle indicadas; promoção das ações de controle indicadas; avaliação da eficácia e efetividade das medidas adotadas e divulgação de informações pertinentes.". 


\section{METODOLOGIA}

\subsection{Fonte, filtragem e tratamento dos dados}

Os dados utilizados no estudo foram obtidos a partir das Fichas Epidemiológica de Ocorrência Toxicológica (Apêndice 1) e Ficha Individual de Investigação-Intoxicação por Agrotóxico (Apêndice 2), que após terem sido devidamente digitadas e tabuladas, foram fornecidas pela Secretaria de Estado da Saúde do Paraná, na forma de planilhas do aplicativo Windows Excell. Os dados são referentes às notificações ocorridas no período de 1993 a 2000 e tratam dos casos de intoxicação ocorridos dentro do território paranaense, que tenham se submetido ao tratamento médico-hospitar, a ponto da ocorrência ter sido oficialmente registrada, e a notificação gerada.

Os quesitos que compõem o banco de dados, e que foram analisados, são os seguintes:

- Data do acidente - refere-se à ocasião em que o indivíduo intoxicado deu entrada no atendimento do Sistema de Saúde em questão e foi gerada a respectiva notificação. O estudo utilizou apenas o ano da ocorrência.

- Sexo - Classificados em masculino, feminino e ignorado. 
- Idade - Através deste dado, foram criadas onze faixas de idade para análise, sendo elas:

$$
\begin{aligned}
& 00 \text {-----| } 05 \text { anos } \\
& 05 \text {-----| } 11 \text { anos } \\
& 11 \text {-----| } 17 \text { anos } \\
& 17 \text {-----| } 23 \text { anos } \\
& 23 \text {-----| } 29 \text { anos } \\
& 29 \text {-----| } 35 \text { anos } \\
& 35 \text {-----| } 41 \text { anos } \\
& 41 \text {-----| } 47 \text { anos } \\
& 47 \text {----- } 53 \text { anos } \\
& 53 \text {-----| } 59 \text { anos } \\
& \geq 60 \text { anos }
\end{aligned}
$$

- Local de ocorrência da intoxicação - classificado em: rural, urbano, outro e ignorado. No local denominado como outro, foram agrupados aqueles casos onde não foi possível, através das informações contidas no banco de dados, serem enquadrados nas categorias rural e urbano, tais como: escola, lazer e residência.

- Tipo de intoxicação - classificado em aguda. Todas as ocorrências que compõe o banco de dados estudado pertencem a esta categoria de intoxicação.

- Tipo do agrotóxico - neste quesito, os casos foram classificados segundo a classe e grupo químico do agrotóxico responsável pela respectiva intoxicação. 
- Via de contaminação - refere-se ao meio pelo qual o agrotóxico entrou em contato com o intoxicado. Podendo ser respiratória, digestiva e cutânea, bem como suas combinações.

- Causa da contaminação - refere-se à atividade exercida pelo intoxicado na ocasião da contaminação. Podendo ser acidental, ambiental, profissional, suicídio, criminosa, alimento contaminado e ignorado.

- Ocupação - no presente estudo, as ocupações foram agrupadas segundo a natureza da atividade do intoxicado, de modo a minimizar o número de itens para análise. Em sendo assim, foram criadas quatro ocupações: agricultor (composto por indivíduos relacionados à atividade agrícola, tais como: agricultores, proprietários, arrendatários, meeiros e bóias-frias), estudante, doméstica e outra (composta por ocupações que não se enquadraram nas ocupações anteriores.

- Evolução final - refere-se ao estado final do intoxicado após a aplicação das medidas hospitalares convenientes. Pôde evoluir na forma de alta (cura) ou falecimento (óbito).

Durante a filtragem dos dados, operação esta essencial à boa análise das variáveis em estudo, foi constatada a presença do registro de muitas ocorrências contendo informações, em certas variáveis, inapropriadas. Muitas, aparentemente são oriundas do descaso no momento da coleta e preenchimento das Fichas de ocorrência. Outras tratam de ocorrências onde o agente causador da intoxicação não se caracteriza como sendo produto registrado junto ao Ministério da Agricultura e Abastecimento para o uso agrícola. E também foram encontradas muitas ocorrências com campos (variáveis) não preenchidos, e outras ainda que diziam respeito a intoxicações ocorridas em outros Estados da federação e até mesmo, em outros países. 
Todas estas ocorrências foram eliminadas a fim de dar maior confiabilidade aos resultados.

Para analisar a relação existente entre as intoxicações e os respectivos agrotóxicos responsáveis pelas mesmas, foram considerados dezessete grupos químicos (classe inseticida: organofosforados, carbamatos, piretróides, éster do ASDC e organoclorados; classe herbicida: derivados da glicina, bipiridílios, dinitroanilinas, fenoxiacéticos + derivados do ácido picolínico e fenoxiacéticos; classe fungicida: ditiocarbamatos, triazóis, benzimidazóis, cúpricos e triazóis + organofosforados; reguladores de crescimento: cianamidas e dinitroanilinas), visto que em tais grupos se concentraram 53,3\% das intoxicações contabilizadas no estudo, e que somado as categorias Outro e Misturas totalizou 94\%, do total de casos notificados, no período estudado.

Face à apresentação dos resultados, onde aparece a variável classe, que faz referência aos principais tipos de agrotóxicos conhecidos (inseticidas, herbicidas, fungicidas e reguladores de crescimento), faz-se necessário explicar o sentido da classe denominada por Misturas. Durante a tabulação e filtragem dos dados recebidos da SESA, foi constatada a presença de várias ocorrências onde, no campo da variável "nome comercial", referente ao agrotóxico responsável pela intoxicação, constavam a descrição de misturas de agrotóxicos pertencentes a grupos químicos diferentes, o que obviamente inviabilizou sua classificação dentro das quatro principais classes e posterior utilização na análise. Estas misturas, em alguns casos, chegavam a serem compostas por até cinco agrotóxicos diferentes. No campo "nome comercial" também foram verificadas misturas entre agrotóxicos conhecidos e outras substâncias, como, por exemplo: cola, pinga, álcool, entre outras.

A categoria Outro foi criada para abrigar produtos cuja informação contida no banco de dados não inspirou confiabilidade no que diz respeito ao 
seu uso nas análises. Foram constatadas as seguintes situações: produtos que não possuem nome comercial conhecido oficialmente, mas possuem o grupo químico (exemplo: mata mato, grupo químico: glifosato); o grupo químico não é condizente com aquele apontado no banco de dados (exemplo: nome comercial: Roundup, grupo químico: organofosforado); produtos relacionados com o nome comercial "ignorado"; além de outros como: semente preta, semente de milho, semente de algodão, mais, veneno para grama, negrinho, pó-de-bruxa, fersol, nortox, desfolin, kwell, piruleta, curisco, cupinicida, warfarin, bico fino, iskatoks, fu, mosquil, semente azul, ramiclops, entre outros. Estes registros são, muito provavelmente, resultantes da coleta deficiente por parte dos profissionais da área da saúde ou da informação prestada de modo incorreta pelos intoxicados ou seus responsáveis.

No intuito de se uniformizar as informações relativas às marcas comerciais apresentadas no banco de dados e respectivas classes e grupos químicos dos agrotóxicos envolvidos nas diversas ocorrências de intoxicação, foi utilizado o programa Agrofit 98: uso adequado de agrotóxicos, fornecido pelo Ministério da Agricultura e do Abastecimento (BRASIL, 1998).

\subsection{Relacionamento entre intoxicações e perfis agrícolas regionais}

Os dados referentes aos casos de intoxicação foram analisados e posteriormente cruzados, segundo as variáveis de maior interesse, com os respectivos municípios de ocorrência que compõe os 20 núcleos regionais, reunidos segundo a divisão política-administrativa da SEAB, e suas respectivas regiões (Tabela 2). Os núcleos regionais representam um total de 399 municípios (Anexo A). Complementarmente foi aplicada análise de Correlação (Crivisqui, 1999) entre as variáveis "número de intoxicações" e "área cultivada"

dos seis grupos de culturas (Tabela 3 ) referentes aos cultivos predominantes 
em cada região estudada, objetivando conhecer a relação entre estas duas variáveis. Os dados referentes aos grupos de culturas e suas respectivas áreas em cada região, foram obtidos a partir do banco de dados do Valor Bruto da Produção Paranaense (VBP) (Paraná, 2004), fornecido pelo Departamento de Economia Rural (DERAL), que serve como base de cálculo para 0 estabelecimento do índice do Fundo de Participação dos Municípios no ICMS arrecadado.

Tabela 2. Regiões administrativas e respectivos núcleos regionais da SEAB

\begin{tabular}{|c|c|}
\hline REGIÄO & NÚCLEOS REGIONAIS \\
\hline CENTRO-OESTE & Campo Mouräo \\
\hline NOROESTE & Umuarama e Paranawaí \\
\hline NORTE & Apucarana, Comélio Procópio, waiporä, Jacarezinho, Londrina e Maringá \\
\hline OESTE & Cascavel e Toledo \\
\hline SUDOESTE & Francisco Beltrầo e Pato Branco \\
\hline SUL & Curitiba, Guarapuava, Irati, Laranjeiras do Sul, Paranagua, Ponta Grossa e União da Vitória \\
\hline
\end{tabular}

As áreas de cultivo, com as quais foram cruzadas as informações referentes às intoxicações, são representadas aqui por agrupamentos de culturas, que também obedeceram à classificação utilizada pelo DERAL na confecção do Valor Bruto da Produção (Tabela 3). 
Tabela 3. Grupos de culturas e respectivos cultivos

\begin{tabular}{|c|c|}
\hline GRUPOS DE CLLTURAS & CULTIVOS \\
\hline FRUTAS & todas as frutas \\
\hline OLERICOLAS GRANDES & batata inglesa, tomate, cebola e alho \\
\hline OLERICOLAS & demais olericolas \\
\hline CULTURAS DE VERÄO & $\begin{array}{l}\text { soja, milho, feijäo, café, arroz, algodäo, sorgo, amendoim, girassol, milho de } \\
\text { pipoca e mamona }\end{array}$ \\
\hline CULTURAS DE INVERNO & trigo, aveias branca e preta, cevada, canola, centeio, trigo mourisco e triticale \\
\hline OUTROS & $\begin{array}{l}\text { cana-de-açucar, mandioca, fumo, vassoura, rami, bucha-vegetal, niger, sisal, } \\
\text { fibras, painço, porongo (cuia), pamarosa, milho (palha para cigarro) e babaçu }\end{array}$ \\
\hline
\end{tabular}




\section{RESULTADOS E DISCUSSÃO}

\subsection{Intoxicações segundo as causas}

No período estudado, constatou-se que a principal causa responsável pelas intoxicações foi a profissional $(53,1 \%)$, seguida pelo suicídio $(28,1 \%)$ e pela causa acidental $(15,2 \%)$ (Tabela 4). Está ordem foi válida para todos os anos e no decorrer de todo o período estudado. Interessante observar que a somatória de apenas estas três causas engloba 96,4\% dos casos notificados de intoxicação por agrotóxicos no Estado do Paraná. Percentuais diferentes foram encontrados, considerando o total de casos ocorridos no país, para as mesmas causas, no Anuário da SINITOX, onde a principal causa das intoxicações, no ano de 1997, foi o suicídio (35,7\%), seguido pela causa acidental (32\%) e causa profissional (27,5\%) (FIOCRUZ, 1998).

Tabela 4. Casos de intoxicação por agrotóxicos no Estado do Paraná, por causa de intoxicação, nos anos de 1993 a 2000

\begin{tabular}{|c|c|c|c|c|c|c|c|c|c|c|}
\hline \multirow[b]{2}{*}{ CAUSA DA INTOXICACAO } & \multicolumn{8}{|c|}{$\mathrm{ANO}$} & \multicolumn{2}{|c|}{ TOTAL } \\
\hline & 1993 & 1994 & 1995 & 1996 & 1997 & 1998 & 1999 & 2000 & $N 0^{\circ}$ & $\%$ \\
\hline PROFIS5IONAL & 554 & 596 & 418 & 281 & 330 & 280 & 207 & 272 & 2.946 & $53,1 \%$ \\
\hline SUlCílo & 274 & 203 & 194 & 173 & 174 & 175 & 194 & 170 & 1.557 & $28,1 \%$ \\
\hline ACIDENTAL & 193 & 104 & 106 & 106 & 102 & 81 & 93 & 58 & 843 & $15,2 \%$ \\
\hline IGNORADO & 13 & 9 & 14 & 24 & 15 & 7 & 12 & 29 & 123 & $2,2 \%$ \\
\hline ALIMENTO CONTAMINADO & - & - & 5 & 8 & 4 & 2 & 14 & 12 & 45 & $0,8 \%$ \\
\hline AMBIENTAL & 6 & 4 & 3 & 3 & 1 & 1 & - & 4 & 22 & $0,4 \%$ \\
\hline CR\|MOSA & - & 1 & - & - & 4 & 3 & 3 & 1 & 12 & $0,2 \%$ \\
\hline TOTAL & 1.040 & 917 & 740 & 595 & 638 & 549 & 523 & 546 & 5.548 & $100,0 \%$ \\
\hline
\end{tabular}


A relação percentual existente entre as diferentes causas de intoxicação, é alterada conforme a região geográfica em questão. Na América Central, por exemplo, no ano de 2000, 36\% das intoxicações estiveram relacionadas à causa ocupacional, seguido das causas suicídio e acidental (OPAS, 2002). Já no Sri Lanka, em determinada oportunidade chegou-se a constatar um percentual de 68\% para intoxicações motivadas pelo suicídio, numa população de usuários de agrotóxicos, que inclusive, possuía vasto conhecimento sobre os perigos inerentes a estes produtos (Van der Hoek et al., 1998).

Ao se analisar as intoxicações, para as causas profissional, suicídio e acidental, sob o ponto de vista das regiões que comportam os núcleos regionais, se observa que os percentuais de ocorrência obedecem semelhante distribuição aqueles apurados para o quadro geral do Estado (Tabela 4), à exceção das regiões centro-oeste e noroeste, que apresentaram percentuais divergentes das demais regiões (Anexo C). Entretanto, quando se analisam as causas de intoxicação, dentro dos núcleos regionais, nota-se que em alguns, a relação dos percentuais citados é desobedecida, como é o caso dos núcleos regionais de Apucarana, Guarapuava, Laranjeiras do Sul e Francisco Beltrão, onde o número de intoxicações decorrentes do suicídio superaram as decorrentes da causa profissional, tendo estes apresentado os seguintes percentuais: $39,2 \%$ e $30,4 \%$; $42 \%$ e $35,7 \% ; 43,8 \%$ e $35 \% ; 42 \%$ e $40,6 \%$, respectivamente para as causas suicídio e profissional. Outro ponto observado no Anexo C diz respeito ao NR. de União da Vitória, onde o percentual de casos de intoxicação para a causa profissional $(77,4 \%)$ se apresentou demasiadamente maior as demais causas estudadas, quando comparado a qualquer dos outros núcleos regionais. 
Isoladas as três principais causas de intoxicação por agrotóxicos, profissional, suicídio e acidental, e a respectiva evolução dos casos no decorrer do período estudado (Figura 5), nota-se que todas tiveram um declínio brusco nos números de casos, quando comparados aos números de ocorrências nos anos de 1993 e 2000. A causa profissional teve uma redução de 50,9\% no número de casos, enquanto o suicídio 38\% e a causa acidental $70 \%$. Entretanto, foi no ano de 1994 que as ocorrências tiveram, para as três causas, sua redução mais evidenciada, sendo que a causa profissional foi a que apresentou com maior clareza este comportamento. Parte da explicação para este evento talvez resida no fato de que a área plantada com a cultura do algodão, que era de 345.000 ha em 1993 , diminuiu para 171.039 ha no ano de 1995 (IBGE, 1997, p.35). O algodão, sabidamente uma cultura que demanda um uso elevado de agrotóxicos e na maioria das vezes, produtos pertencentes às classes toxicológicas I e II, a redução de sua área de plantio em 50,4\% provavelmente influenciou, proporcionalmente, na redução dos casos de intoxicações no período de 1994 a 1995 (52,8\%), considerando-se que o algodão plantado atravessa o ano civil, sendo colhido no ano seguinte, período em que ocorre a maior parte do controle de pragas com agrotóxicos e, conseqüentemente, a maior parte dos casos de intoxicação da causa profissional. Para se ter uma idéia do quão elevado é o uso de agrotóxicos nesta cultura, segundo Relatório Técnico de Projeto de Previsão de Safra, elaborado pelo IBGE na safra 98/99, o número médio de aplicações durante o período de cultivo era de 10,75/safra, enquanto que culturas como a soja, milho e mandioca, culturas estas concorrentes em área com o algodão, o número médio de aplicações por safra foi de 4,92, 2,02 e 1,75, respectivamente . Já a Empresa Brasileira de Pesquisa Agropecuária (EMBRAPA) Meio Ambiente, informa que em regiões como a Nordeste, Sudeste e Sul do país, são efetuadas, em média, 18 aplicações de agrotóxicos na cultura do algodão (EMBRAPA, 2005). 


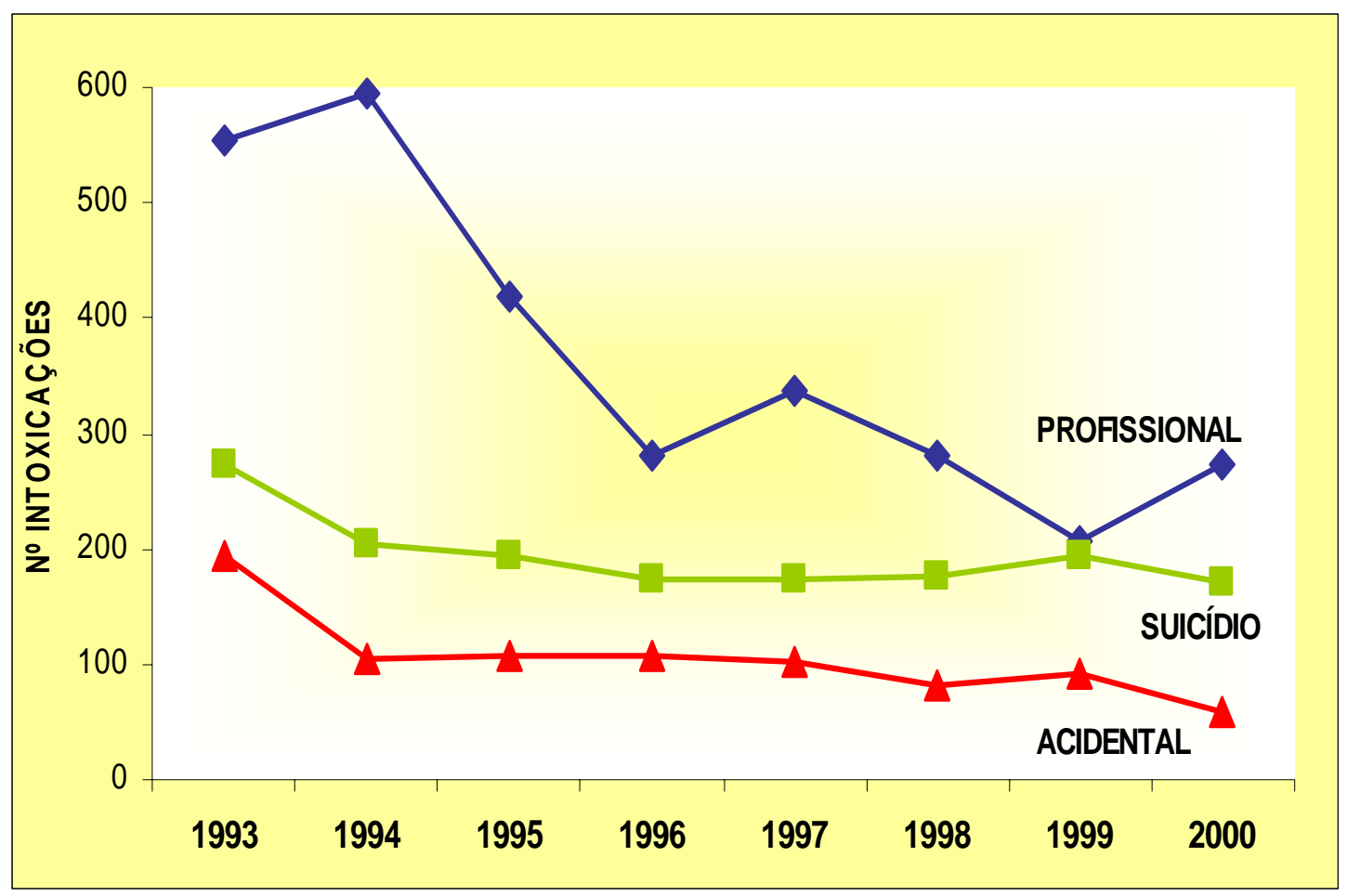

Figura 5 - Evolução dos casos de intoxicação por agrotóxicos, para as causas profissional, suicídio e acidental, ocorridos no Estado do Paraná, nos anos de 1993 a 2000

\subsection{Distribuição das intoxicações nos núcleos regionais}

Foi na região norte do estado onde se concentrou o maior número de intoxicações (43\%), tendo sido o núcleo regional de Londrina o local onde se deu o maior de intoxicações do Estado, totalizando 682, o equivalente a 12,3\% do total das intoxicações ocorridas no período estudado (Anexo B). O número de intoxicações ocorrido neste núcleo, inclusive superou os totais aferidos para as regiões centro-oeste, oeste, noroeste e sudoeste do Estado. A somatória dos percentuais das intoxicações ocorridas nos núcleos regionais de Londrina, 
Cornélio Procópio, Maringá, Cascavel e Campo Mourão, atingiram 50,3\% das ocorrências no Estado.

As demais regiões apresentaram os seguintes percentuais totais de ocorrência: região sul (20\%), centro-oeste (12\%), oeste (10\%), noroeste (10\%) e sudoeste (4\%).

A queda progressiva no número de intoxicações se deu de modo semelhante em 5 das regiões estudadas, com exceção da região sul que apresentou aumento de ocorrências a partir do ano de 1996, mas, se analisarmos o período de 1993 a 2000, todas as regiões apresentaram redução do número de intoxicações, como pode ser visualizado na Figura 6.

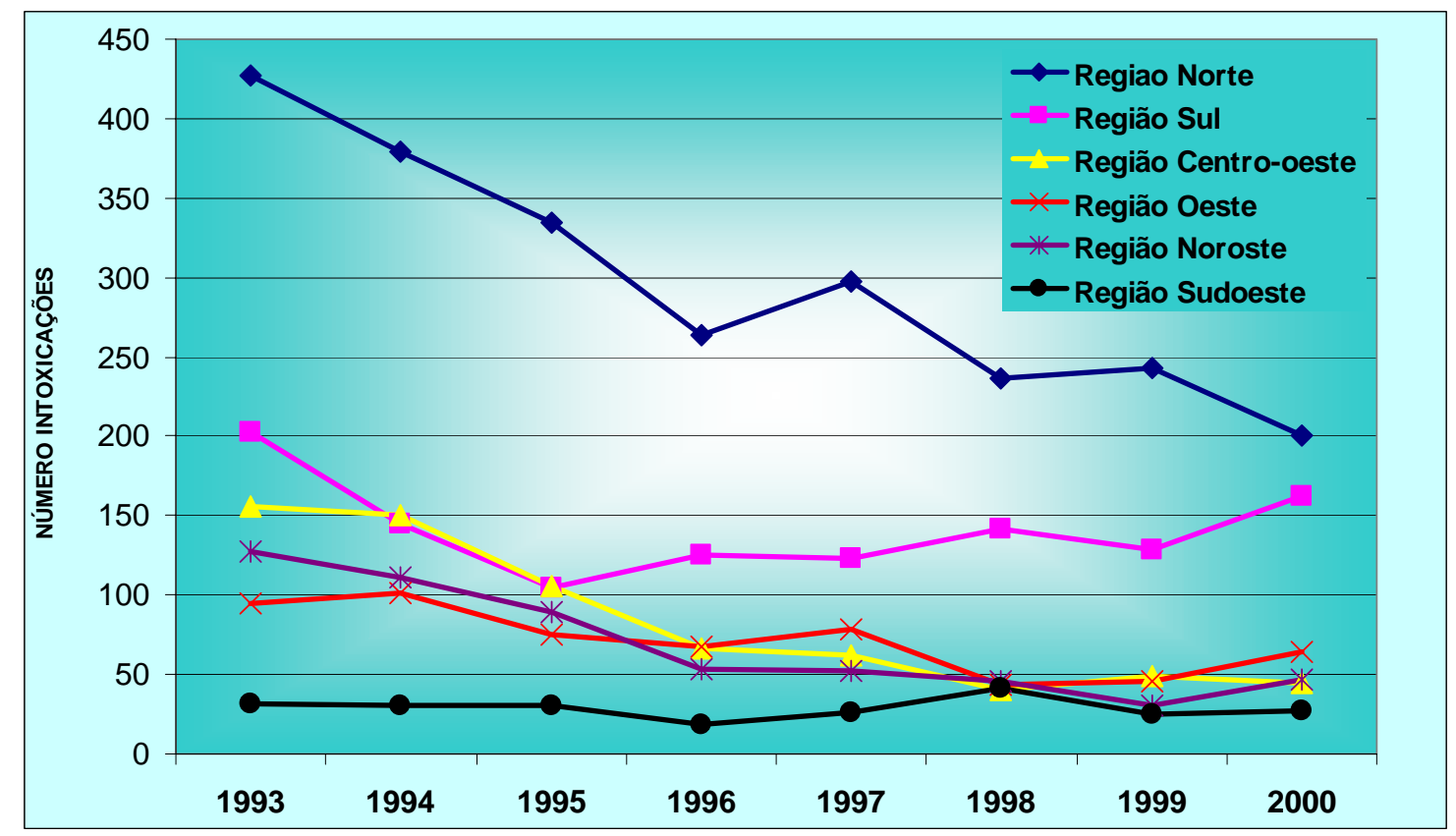

Figura 6 - Evolução dos casos de intoxicação por agrotóxicos, para as regiões norte, sul, centro-oeste, oeste, noroeste e sudoeste, ocorridos no Estado do Paraná, nos anos de 1993 a 2000 


\subsection{Intoxicações segundo as vias de contaminação}

Considerando todas as causas de intoxicação, as principais vias de intoxicação, analisadas individualmente, foram: respiratória (37,2\%), digestiva (35\%) e cutânea (8,3\%). Quando analisadas considerando suas intersecções, a respiratória continua a ser a principal via de contaminação, entretanto, 0 percentual de casos de intoxicações eleva-se de 37,2\% para 52,14\% (Tabela 5).

Tabela 5. Casos de intoxicação por agrotóxicos no Estado do Paraná, por via de contaminação, durante o período de 1993 a 2000

\begin{tabular}{ccccccccc}
\hline VIA DE & \multicolumn{2}{c}{ DIGESTVA } & \multicolumn{2}{c}{ CUTANNEA } & \multicolumn{2}{c}{ RESPIRATÓRIA } & \multicolumn{2}{c}{ IGNORADA } \\
CONTAMINACAO & $\mathrm{n}^{\circ}$ & $\%$ & $\mathrm{n}^{\circ}$ & $\%$ & $\mathrm{n}^{\circ}$ & $\%$ & $\mathrm{n}^{\circ}$ & $\%$ \\
\hline DIGESTIVA & 1.942 & $35,010 \%$ & - & - & - & - & - & - \\
CUTANAEA & 9 & $0,16 \%$ & 462 & $8,33 \%$ & - & - & - & - \\
RESPIRATÓRIA, & 27 & $0,49 \%$ & 801 & $14,44 \%$ & 2.065 & $37,22 \%$ & - & - \\
IGNORADA & - & - & - & - & - & - & 242 & $4,36 \%$ \\
TOTAL & 1.979 & $35,65 \%$ & 1.272 & $22,93 \%$ & 2.893 & $52,15 \%$ & 242 & $4,36 \%$ \\
\hline
\end{tabular}

Quando se faz o cruzamento dos dados entre as causas e vias de intoxicação, conclui-se que para as intoxicações de origem profissional, a principal via de contaminação, é a respiratória $(58,3 \%)$ e suas combinações $(82,2 \%)$ (Tabela 6). Quando a causa analisada é o suicídio, a via prioritária de contaminação é a digestiva (95,7\%), e suas combinações $(96,4 \%)$, como se pode observar na Tabela 7. Para as intoxicações originárias da causa Acidental, as vias digestiva e respiratória apresentam percentuais similares, 35,2\% e $36,7 \%$ respectivamente. Neste caso, a via respiratória supera sobremaneira as demais vias, graças às suas combinações $(49,7 \%)$ (Tabela 8). 
Tabela 6. Casos de intoxicação por agrotóxicos no Estado do Paraná, por via de contaminação, para a causa PROFISSIONAL, durante o período de 1993 a 2000

\begin{tabular}{ccccccccc}
\hline VIA DE & \multicolumn{2}{c}{ DIGESTIVA } & \multicolumn{2}{c}{ CUTANAEA } & \multicolumn{2}{c}{ RESPIRATÓRIA } & \multicolumn{2}{c}{ IGNORADA } \\
CONTAMINACGO & $n^{\circ}$ & $\%$ & $n^{\circ}$ & $\%$ & $n^{\circ}$ & $\%$ & $n^{\circ}$ & $\%$ \\
\hline DIGESTIVA & 56 & $1,90 \%$ & - & - & - & - & - & - \\
CUTANAEA & 3 & $0,10 \%$ & 370 & $12,56 \%$ & - & - & - & - \\
RESPIRATÓRIA & 12 & $0,41 \%$ & 692 & $23,49 \%$ & 1.718 & $58,32 \%$ & - & - \\
IGNORADA & - & - & - & - & - & - & 95 & $3,22 \%$ \\
TOTAL & 71 & $2,41 \%$ & 1.065 & $36,15 \%$ & 2,422 & $82,22 \%$ & 95 & $3,22 \%$ \\
\hline
\end{tabular}

Tabela 7. Casos de intoxicação por agrotóxicos no Estado do Paraná, por via de contaminação, para a causa SUICÍDIO, durante o período de 1993 a 2000

\begin{tabular}{ccccccccc}
\hline VIA DE & \multicolumn{2}{c}{ DIGESTIVA } & \multicolumn{2}{c}{ CUTANEA } & \multicolumn{2}{c}{ RESPIRATÓRIA } & \multicolumn{2}{c}{ IGNORADA } \\
CONTAMIVACAOA & $\mathrm{n}^{\circ}$ & $\%$ & $\mathrm{n}^{\circ}$ & $\%$ & $\mathrm{n}^{\circ}$ & $\%$ & $\mathrm{n}^{\circ}$ & $\%$ \\
\hline DIGESTIVA & 1.491 & $95,76 \%$ & - & - & - & - & - & - \\
CUTANAEA & 3 & $0,19 \%$ & 5 & $0,32 \%$ & - & - & - & - \\
RESPIRATORIA & 7 & $0,45 \%$ & 1 & $0,06 \%$ & 6 & $0,39 \%$ & - & - \\
IGNORADA & - & - & - & - & - & - & 44 & $2,63 \%$ \\
TOTAL & 1.501 & $96,40 \%$ & 9 & $0,57 \%$ & 14 & $0,90 \%$ & 44 & $2,83 \%$ \\
\hline
\end{tabular}

Tabela 8. Casos de intoxicação por agrotóxicos no Estado do Paraná, por via de contaminação, para a causa ACIDENTAL, durante o período de 1993 a 2000

\begin{tabular}{ccccccccc}
\hline VIA. DE & \multicolumn{2}{c}{ DIGESTIVA } & \multicolumn{2}{c}{ CUTANEA } & \multicolumn{2}{c}{ RESFIRATÓRIA } & \multicolumn{2}{c}{ IGNORADA } \\
CONTAMINACÄO & $n^{\circ}$ & $\%$ & $n^{\circ}$ & $\%$ & $n^{\circ}$ & $\%$ & $n^{\circ}$ & $\%$ \\
\hline DIGESTIVA & 297 & $35,23 \%$ & - & - & - & - & - & - \\
CUTANEA & 2 & $0,24 \%$ & 78 & $9,25 \%$ & - & - & - & - \\
RESPIRATÓRIA, & 7 & $0,83 \%$ & 102 & $12,10 \%$ & 310 & $36,77 \%$ & - & - \\
IGNORADA & - & - & - & - & - & - & 47 & $5,58 \%$ \\
TOTAL & 306 & $36,30 \%$ & 182 & $21,59 \%$ & 419 & $49,70 \%$ & 47 & $5,58 \%$ \\
\hline
\end{tabular}




\subsection{Intoxicações segundo a classe dos agrotóxicos, grupos químicos e causas de intoxicação}

Quando se faz um exame dos casos sob o aspecto dos produtos que causaram as intoxicações (Anexo E, Figura 7), observa-se que os agrotóxicos da classe dos inseticidas respondem pelo maior número de casos de intoxicação (37,9\%), seguido pelos herbicidas (17,9\%); misturas $(11,3 \%)$; fungicidas $(2,7 \%)$ e reguladores de crescimento (0,9\%). Observe-se, que desconsiderando as categorias misturas e outros, os percentuais ficariam assim distribuídos: inseticidas, 63,7\%; herbicidas, 30,2\%; fungicidas, 4,6\% e reguladores, $1,5 \%$. Os percentuais de intoxicação, segundo a classe dos agentes contaminantes varia conforme o tipo de cultura explorada, como concluiu Faria et al. (2004) em levantamento realizado na região sul do país, em áreas de cultivo de frutíferas, onde a classe dos fungicidas determinou $28 \%$, os herbicidas $16 \%$ e os inseticidas/formicidas $8 \%$. Deve-se salientar que a classe de produtos identificada como misturas, corresponde a produtos resultantes da associação de duas ou mais substâncias agrotóxicas, onde não é possível determinar qual das classes envolvidas predomina. Outro aspecto, que deve ser relatado, diz respeito à somatória total do número de casos de intoxicação (5572 casos) ser superior a somatória de casos apontada na Tabela 4 (5548 casos). Esta diferença se justifica no fato de que alguns agrotóxicos estão registrados junto ao Ministério da Agricultura, para duas classes diferentes, como é o caso do agrotóxico Baysiston GR (nome comercial), Registro M.A. $n^{\circ}$ 5989, que apresenta registro para as classes inseticida e fungicida ao mesmo tempo (BRASIL, 1998). Diante desta característica que alguns agrotóxicos apresentam, um mesmo caso de intoxicação, foi registrado, durante a fase de seleção dos dados, em classes diferentes, daí o fato da somatória total dos casos de intoxicação apontados no Anexo $E$ ser superior ao apontado na Tabela 4. 
O item outro aparece como sendo responsável por 1.629 ocorrências $(29,2 \%)$, item este, que no estudo correspondem a casos de intoxicação causados por produtos classificados como "ignorados", ou não identificados adequadamente nas Fichas de ocorrência.

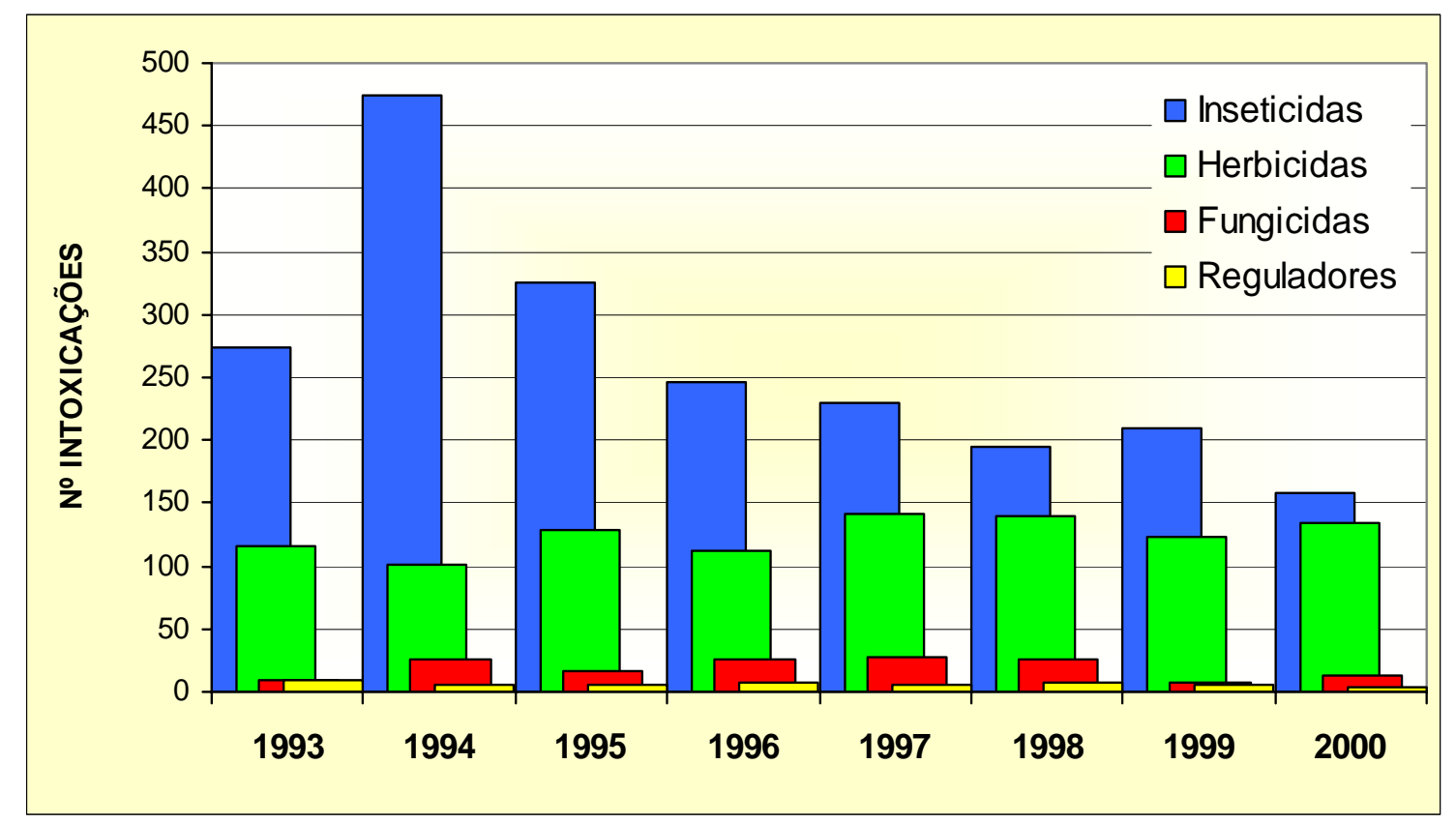

Figura 7 - Intoxicações por classes de produto, ocorridas no Estado do Paraná, durante o período de 1993 a 2000

Numa análise mais apurada, onde se buscou avaliar quais os grupos químicos que predominaram dentro das classes de agrotóxicos estudadas (Anexo E), constatou-se que dentro da classe inseticida, o principal grupo químico responsável pelas intoxicações, foram os organofosforados (60,3\%); seguido pelos carbamatos (12,6\%); piretróides (8,9\%); esteres do ASDC (Ácido Sulfuroso de um Diol Cíclico) (7,3\%) e organoclorados (3,8\%). Apesar da provável redução da área cultivada para a cultura do algodão, ocorrida no período entre os anos de 1993 e 1995, cultura onde o uso de inseticidas é 
intenso, o grupo dos organofosforados foi o responsável pelo maior número de intoxicações durante todos os anos que compõe o estudo, inclusive, quando comparado aos casos de intoxicação causados pelos principais grupos químicos pertencentes às demais classes estudadas, contudo, apesar da predominância deste grupo químico, é notável o decréscimo das intoxicações causadas por este durante o período estudado (Figura 8).

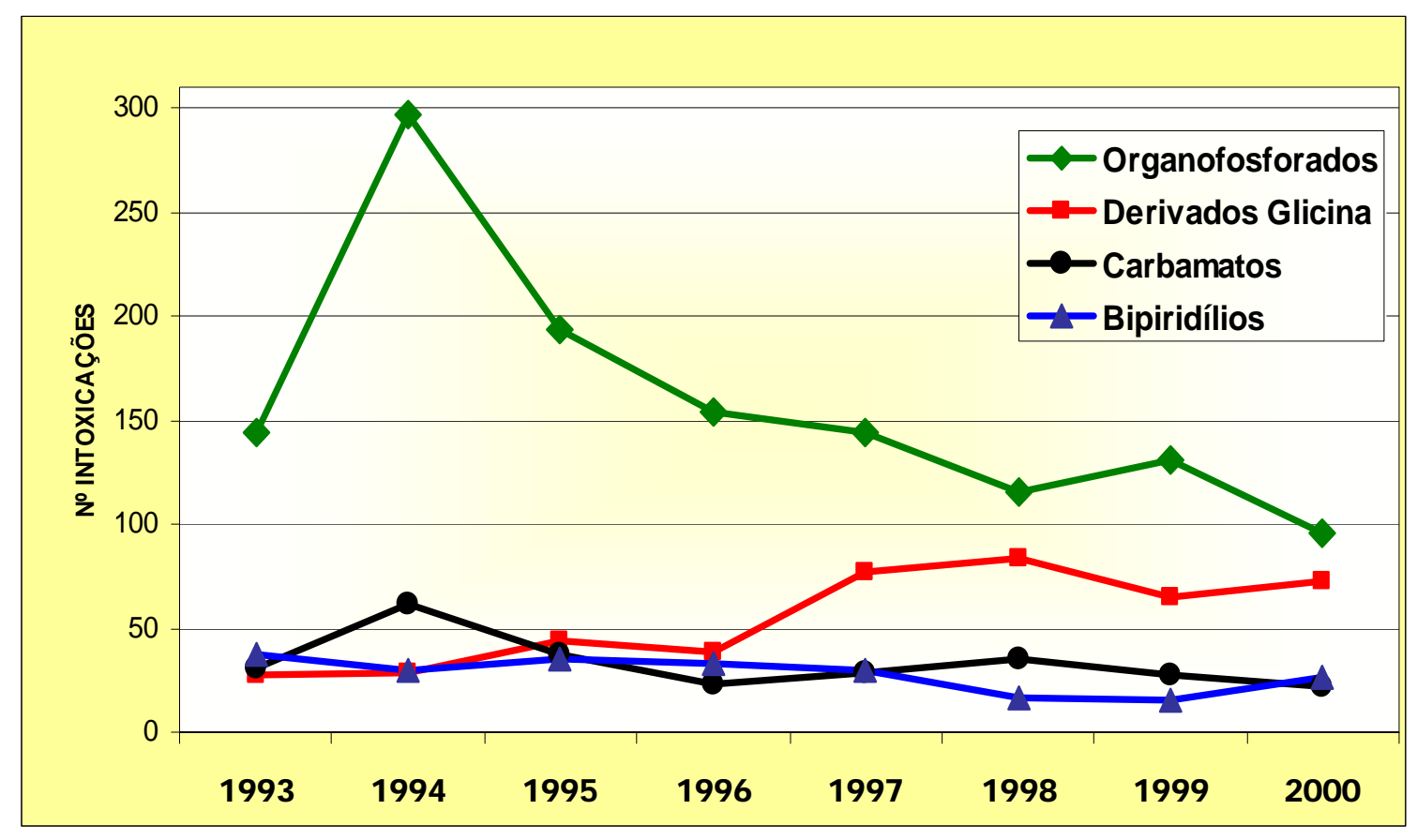

Figura 8 - Evolução do número de intoxicações causadas pelos quatro principais grupos químicos, responsáveis pelas intoxicações ocorridas no Estado do Paraná, durante o período de 1993 a 2000

A predominância do grupo químico dos organofosforados, talvez encontre justificativa no fato dos agrotóxicos que pertencem a este grupo, serem produtos compostos por ingredientes ativos antigos, como o parathion metílico, methamidophos, malathion, entre outros, produtos comercialmente baratos e pertencentes às classes toxicológicas extremamente (classe I) e 
altamente tóxicas (classe II) quando comparados a outros, compostos por ingredientes ativos de elaboração mais recente, de toxicidade mais baixa e via de regra mais caros.

O que também chama atenção na análise dos inseticidas, é a existência de casos de intoxicação resultantes do uso de organoclorados, como o BHC, Aldrin e DDT, produtos estes, que tiveram sua produção, comércio, uso e distribuição banida em 1985 por meio da Portaria Ministerial n 329/85, sendo seu uso restringido para fins de tratamento de madeiras e em campanhas de saúde pública. No presente estudo, os inseticidas organoclorados ocuparam o $5^{\circ}$ lugar dentre os principais grupos químicos causadores de intoxicações, sendo responsáveis por um total de 80 casos de contaminação, número este quase duas vezes maior do que as intoxicações causadas pelos fungicidas do grupo químico dos ditiocarbamatos (44 casos de intoxicação) que, atualmente, são agrotóxicos maciçamente utilizados na agricultura. Os casos de intoxicação constatados para o grupo químico dos organoclorados, se constituíram, na sua maioria (39 casos) em uso destinado ao suicídio, e os demais, através da causa acidental (21 casos), profissional (13 casos), ambiental (5 casos) e de origem ignorada ( 2 casos) (Anexo F). Por termo, chega-se a infeliz conclusão de que apesar das medidas proibitivas de uso destes produtos e de todo esclarecimento acerca de suas características ambientais negativas, eles ainda continuam a ser utilizados, e para os mais diversos fins. Carvalho (2000), em matéria sobre as conseqüências decorrentes do uso de agrotóxicos, relata que os organofosforados comportam-se como os principais grupos químicos causadores de intoxicações e que os organoclorados ainda são responsáveis por muitos acidentes.

Ainda em análise ao Anexo $\mathrm{E}$ outro aspecto que também chama a atenção é o elevado número de intoxicações causadas por agrotóxicos 
pertencentes ao grupo químico dos derivados da glicina, na sua maioria agrotóxicos compostos pelo ingrediente ativo glifosato. Estes, num total de 438 ocorrências de intoxicação, representaram, dentro da classe dos herbicidas, 43,9\% dos casos, número superior ao do grupo dos bipiridílios (paraquat, por exemplo). O número de casos registrados para os produtos derivados da glicina, mostrou um crescimento expressivo durante o decorrer do período estudado, tendo apresentado do início ao final do período estudado, um aumento percentual da ordem de $68,4 \%$, motivado principalmente pelo surgimento de diversos produtos comerciais, pela eficiência do produto e pelo fácil acesso (baixo preço). Dentro do grupo químico dos fungicidas, os ditiocarbamatos foram os principais causadores de intoxicações, sendo responsáveis por 29,1\% dos casos, seguidos dos triazóis (19,2\%), benzimidazóis $(9,9 \%)$, cúpricos $(9,3 \%)$ e triazóis + organofosforados $(8,6 \%)$.

Quando se analisam as causas de intoxicação sob o enfoque dos principais grupos químicos, selecionados por meio do número de ocorrências, conclui-se que, tanto para a causa profissional, suicídio e acidental, os principais agentes de intoxicação foram os inseticidas organofosforados (profissional: 543 casos; suicídio: 524 casos; acidental: 168 casos) seguido pelos herbicidas derivados da glicina (profissional: 204 casos; suicídio: 135 casos; acidental: 90). Como o terceiro e quarto grupos químicos causadores de intoxicações figuram os inseticidas carbamatos, para as causas profissional (192 casos) e acidental (41 casos), e os herbicidas bipiridílios (93 casos), para a causa do suicídio, respectivamente (Anexo F, Figura 9).

Ciciolli (2004), relatou que em estudo realizado pela Escola de Saúde Pública de Berkeley, nos Estados Unidos, demonstrou-se que o glifosato, ingrediente ativo pertencente ao grupo químico dos derivados da glicina, é o maior responsável pela maioria das doenças relativas a pesticidas em 
jardineiros da Califórnia e o terceiro pesticida causador de doenças em trabalhadores agrícolas. Quevedo \& Corriols (1999), estudando focos de intoxicação do tipo aguda na Nicaragua, apuraram que os inseticidas organofosforados e carbamatos e os herbicidas foram os agentes de maior importância, dentro dos 406 casos de intoxicação investigados.

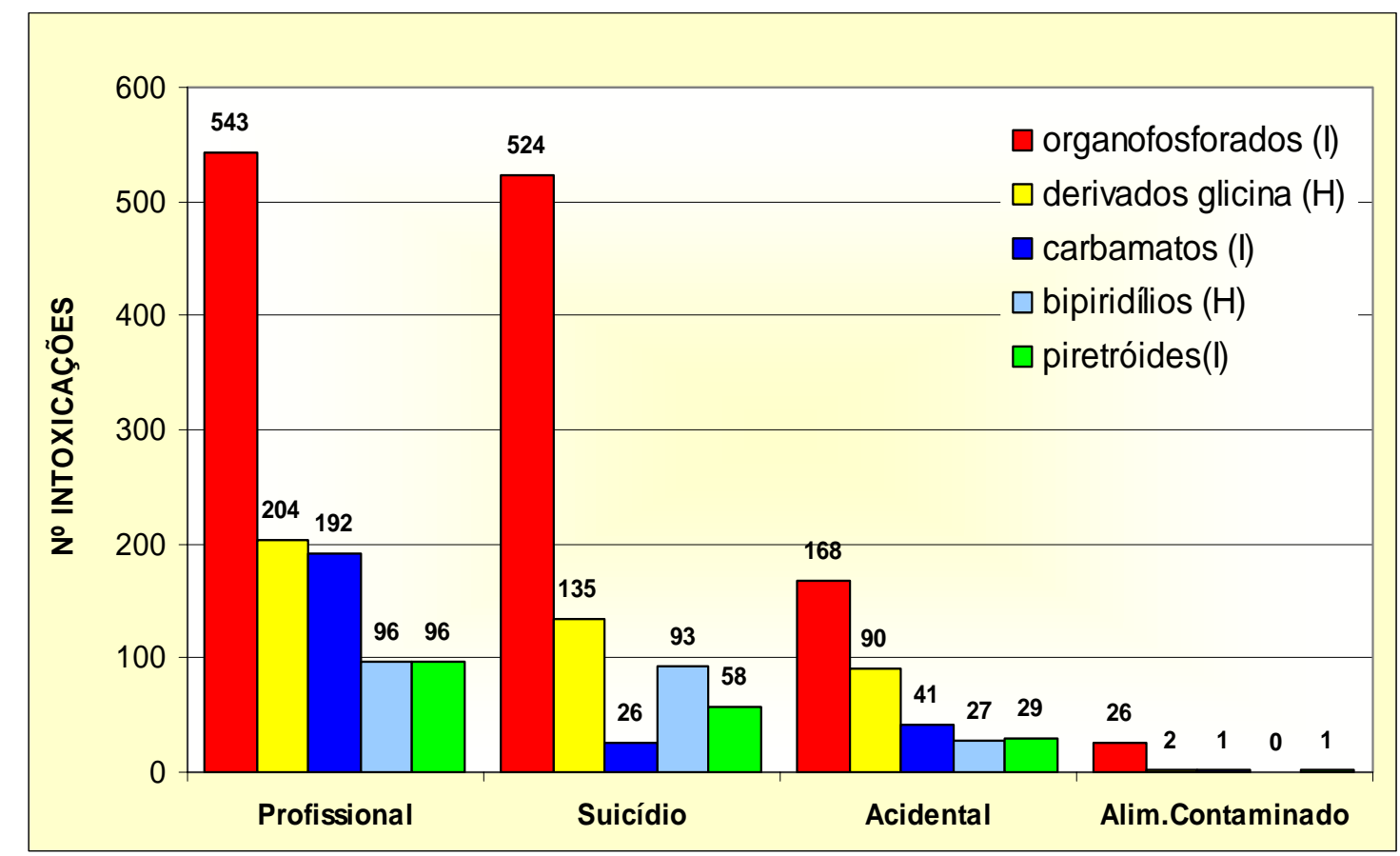

Figura 9 - Principais causas e grupos químicos, responsáveis pelas intoxicações ocorridas no Estado do Paraná, durante o período de 1993 a 2000

No México, Duran-Nah \& Colli-Quintal (2000) em um estudo epidemiológico, contendo um total de 33 casos de pacientes que sofreram intoxicações agudas, apuraram que $82 \%$ dos intoxicados eram homens, e que as intoxicações eram na sua maioria (79\%) oriundas da tentativa de suicídio. Neste estudo, a causa profissional representou $21 \%$ das ocorrências, sendo os 
grupos químicos dos organofosforados, carbamatos e bipiridílios, responsáveis por 33\%, 27\% e 18\% das intoxicações, respectivamente.

Um número muito grande de trabalhos de pesquisa faz alusão aos efeitos crônicos decorrentes da exposição prolongada aos agrotóxicos, em especial, os pertencentes ao grupo químico dos organofosforados. Acredita-se que o citado grupo químico seja um potencial agente causador de distúrbios neurocomportamentais, sendo eles de ordem passageira ou permanente. Entre estes distúrbios, figuram neuropatias como a ansiedade e depressão, que podem, inclusive, redundar em casos de suicídio, naqueles indivíduos expostos ou intoxicados por agrotóxicos deste grupo, conforme relatam alguns autores (Assunção \& Ribeiro, 2004; Bueno, 2004; Levigard, 2004; OPAS, 2002; Pires et al., 2005 e Trapé, 2004).

\subsection{Intoxicações segundo a classe, grupo químico e vias de contaminação}

A principais vias de contaminação constatadas no estudo, quando analisadas individualmente, foram a respiratória (37,2\%); digestiva (34,9\%) e cutânea (8,4\%), sendo a somatória destas, equivalente a 80,5\% do total de ocorrências notificadas no período estudado. Quando analisadas através de suas combinações, a ordem classificatória das vias de contaminação permaneceu inalterada, tendo a via respiratória representado 52\% dos casos, seguido pela digestiva $(35,5 \%)$ e cutânea $(22,9 \%)$. Importante observar que a via cutânea + respiratória representou 14,4\% dos casos, tendo superado, inclusive, a via cutânea (Anexo G).

Os inseticidas organofosforados foram os principais agentes responsáveis pelas intoxicações que ocorreram através das vias respiratória, 
digestiva, cutânea e cutânea+respiratória, atribuindo a estas, a ocorrência de 413, 611, 52 e 159 casos, respectivamente. Os herbicidas derivados da glicina, se situaram como o segundo agente de intoxicações, conferindo às vias respiratória, digestiva, cutânea e cutânea+respiratória, o equivalente a 144, 172, 34 e 70 casos de intoxicação, respectivamente.

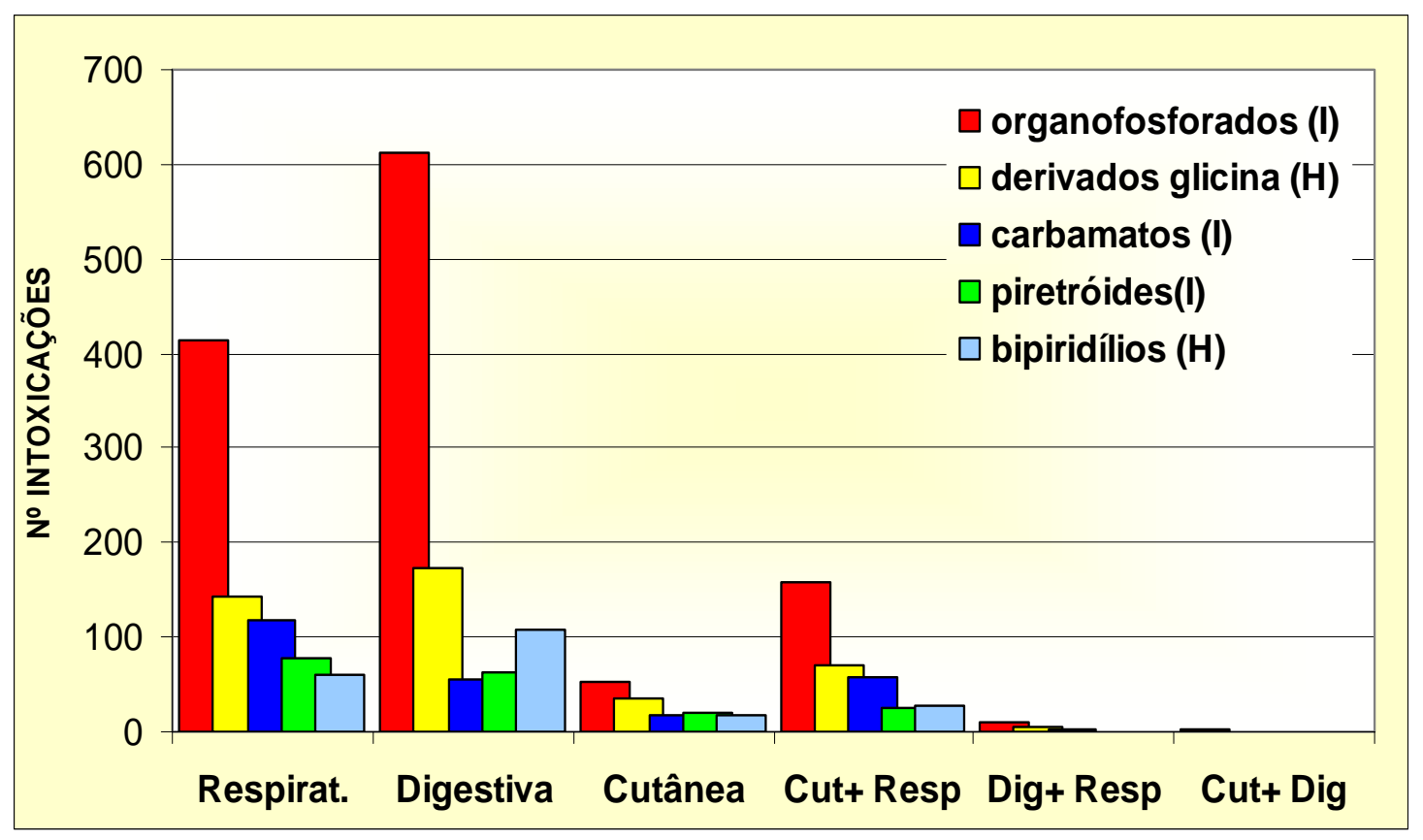

Figura 10 - Principais vias de intoxicação e grupos químicos, responsáveis pelas intoxicações ocorridas no Estado do Paraná, no período de 1993 a 2000

\subsection{Intoxicações através das diferentes faixas de idade}

Para se analisar em qual faixa etária ocorreram as intoxicações, foram criadas classes de idade com amplitude de 6 anos. 0 intuito desta segmentação reside na intenção de se isolar o grupo de indivíduos com idades entre 0 e 17 anos, faixa de idade onde, sob o aspecto legal, é proibido o 
trabalho em atividades comprovadamente insalubres, como é o caso do manuseio e aplicação de agrotóxicos. Tal proibição encontra amparo legal no art. 67, incisos II e III, da Lei no 8.069/1990, que dispõe sobre o Estatuto da Criança e do Adolescente (BRASIL, 2005), bem como no art. 405, inciso I da Consolidação das Leis do Trabalho (CLT).

Tabela 9. Casos de intoxicação por agrotóxicos no Estado do Paraná, por causa e faixas etárias, durante o período de 1993 a 2000

\begin{tabular}{|c|c|c|c|c|c|c|c|c|c|c|c|c|c|}
\hline \multirow{2}{*}{ CAUSADA INTOXICACAOO } & \multicolumn{12}{|c|}{ CLASSE DE IDADE } & \multirow{2}{*}{ TOTAL } \\
\hline & 0 a 5 & $6 a 11$ & $12 a 17$ & 18 a 23 & 24 a 29 & 30 a 35 & 36 a 41 & 42 a 47 & 48 a 53 & 54 a 59 & $>=60$ & IGNOR:DOD & \\
\hline PROF|SS|ONAL & & 20 & 292 & 691 & 591 & 453 & 311 & 233 & 159 & 97 & 78 & 21 & 2.946 \\
\hline SULICIO & 1 & 7 & 196 & 336 & 259 & 237 & 177 & 122 & 75 & 69 & 64 & 14 & 1.557 \\
\hline ACIDENTAL & 183 & 89 & 95 & 112 & 89 & 80 & 62 & 42 & 35 & 18 & 36 & 2 & 843 \\
\hline |G|VORADO & 9 & 1 & 13 & 25 & 24 & 13 & 8 & 8 & 7 & 8 & 6 & 1 & 123 \\
\hline ALIMENTO CONTAMINADO & 15 & 14 & 4 & 3 & 3 & - & - & 2 & 2 & 1 & 1 & - & 45 \\
\hline AMEIENTAL & 4 & 5 & - & 4 & 2 & 1 & 4 & 1 & 1 & - & - & - & 22 \\
\hline CFIN\|NOSA & 2 & - & 1 & 1 & - & 4 & 2 & 1 & 1 & - & - & - & 12 \\
\hline \multirow{2}{*}{ TOTAL } & 214 & 136 & 601 & 1.172 & 968 & 788 & 564 & 409 & 280 & 193 & 185 & 38 & 5.548 \\
\hline & $3,9 \%$ & $2,5 \%$ & $10,8 \%$ & $21,1 \%$ & $17,4 \%$ & $14,2 \%$ & $10,2 \%$ & $7,4 \%$ & $5,0 \%$ & $3,5 \%$ & $3,3 \%$ & $0,7 \%$ & $100,0 \%$ \\
\hline
\end{tabular}

As faixas de idade onde ocorreu o maior número de intoxicações foram aquelas compreendidas entre as idades de 18 a 35 anos, respondendo por um percentual de $52,7 \%$ do total. Individualmente, a faixa de idades onde predominaram as ocorrências foi a compreendida entre 18 e 23 anos, tendo a somatória destas correspondido a $21,1 \%$ dos casos registrados para o período estudado (Tabela 9). Foram nestas faixas de idade onde ocorreram os maiores números de intoxicações para as causas, profissional e suicídio, durante todo o período estudado. Os Anuários do SINITOX, referentes aos anos de 1997 (FIOCRUZ, 1998) e 1999 (FIOCRUZ, 2000), relataram que a faixa de idade onde ocorreu o maior número de intoxicações foi aquela compreendida entre os 20 e 29 anos, tendo apresentado, respectivamente, 17,2\% e 16,99\% do total de intoxicações por agrotóxicos ocorridas no país. 


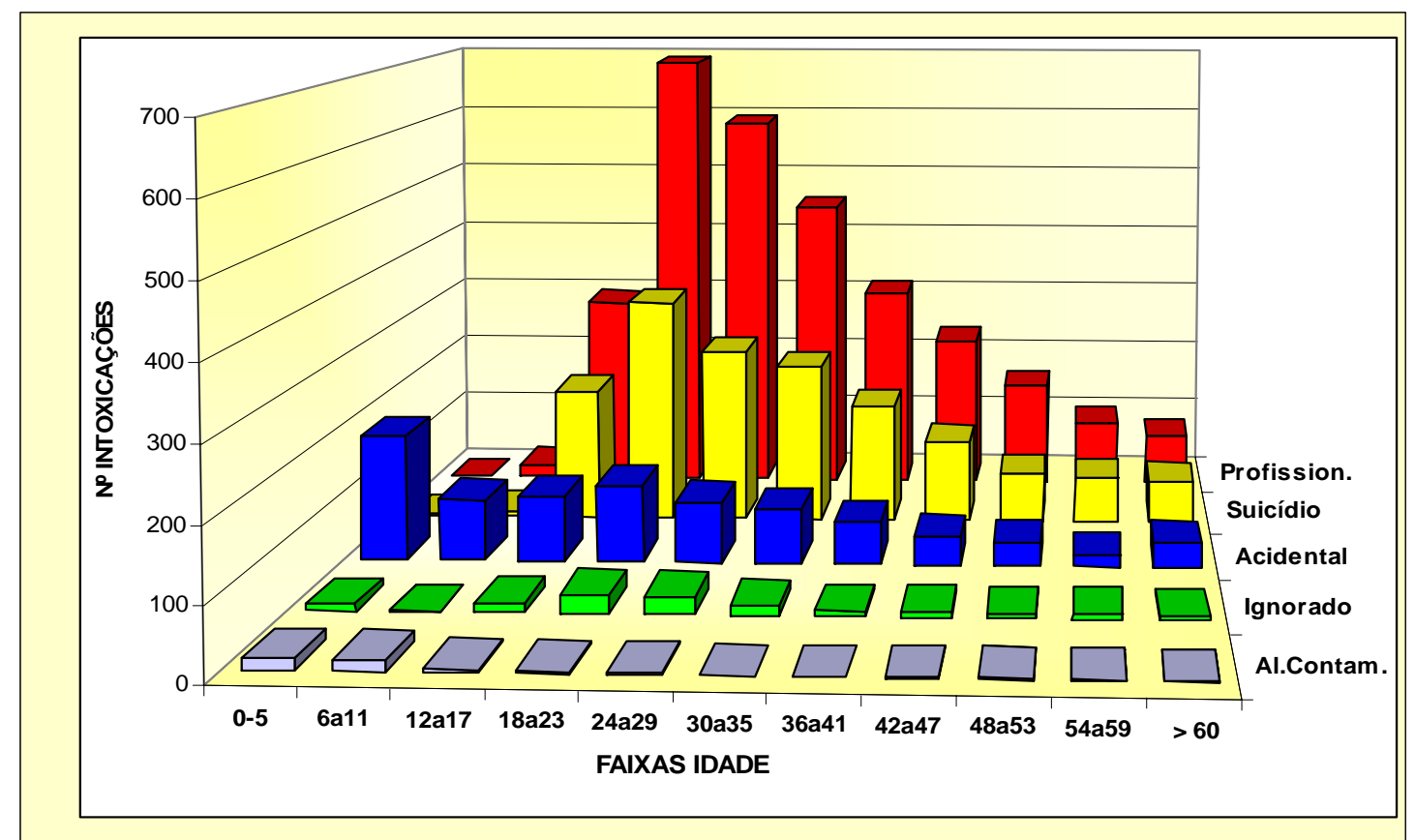

Figura 11 - Distribuição das intoxicações para as causas profissional, suicídio, acidental, ignorada e alimentos contaminados, dentro das faixas de idade, ocorridas no Estado do Paraná, durante o período de 1993 a 2000

Para a causa acidental, o maior número de ocorrências (183) se deu na faixa de idade entre 0 e 5 anos, denotando a existência de acidentes domésticos, provavelmente pelo inadequado armazenamento dos agrotóxicos. Importante ressaltar o número total de intoxicações, resultante da somatória destas três causas, ocorridas com indivíduos pertencentes a faixa entre 0 e 17 anos, que atingiu um total de 951 casos (17,2\%). Tais indivíduos, pertencentes a uma faixa etária, que sabidamente, não poderiam, de modo algum ou com qualquer objetivo que fosse, estar em contato com tais produtos. Desta feita se enseja duas conclusões: menores de idade estão ingressando prematuramente nas atividades relacionadas ao uso e aplicação de agrotóxicos, e os produtos estão sendo armazenados em locais de fácil acesso, visto o sucesso obtido 
pelos menores nas tentativas de suicídio (204 casos) e o número de ocorrências relacionadas à causa acidental (Tabela 9).

O presente estudo também apurou que, do total de 5.548 casos de intoxicação, 1.125 (20,2\%) delas ocorreram em indivíduos do sexo feminino e $4.423(79,8 \%)$ em indivíduos do sexo masculino. No ano de 2000 a OPAS (2002) apurou que em alguns países da América central, 70\% das intoxicações ocorrem em homens. A faixa de idades onde ocorreu o maior número de intoxicações, tanto homens quanto em mulheres, foi aquela compreendida entre 18 e 23 anos, totalizando 966 e 206 casos, respectivamente.

\subsection{Número de óbitos}

A Tabela 10 apresenta os óbitos ocorridos, segundo a causa de intoxicação, faixas de idade e sexo das vítimas. Nela, se observa que a maioria dos casos de óbitos são oriundos da tentativa de suicídio (86 \%) (Figura 13), percentual este, inclusive, próximo ao apurado pelo SINITOX (FIOCRUZ, 1998, p.21), que em levantamento realizado em todo país durante o ano de 1997, apurou um percentual de 82,5\% para os casos de óbitos, decorrentes do uso de agrotóxicos. Consideradas as demais causas de intoxicação, as que apresentaram maior número de casos registrados, foram, a causa profissional (5\%); ignorado (5,7\%); acidental $(2,6 \%)$ e criminosa $(0,47 \%)$. 
Tabela 10. Óbitos causados pela intoxicação por agrotóxicos no Estado do Paraná, por sexo, classe de idade e causa, durante o período de 1993 a 2000

\begin{tabular}{|c|c|c|c|c|c|c|c|c|c|c|c|c|c|c|c|c|c|c|c|c|c|c|c|c|c|}
\hline \multirow{3}{*}{$\begin{array}{l}\text { CAUSA.DA } \\
\text { INTOXICACGAOO }\end{array}$} & \multicolumn{25}{|c|}{ CLASSE DE IDADE } \\
\hline & & & & 11 & & 17 & & 23 & $24 a$ & & $30 \mathrm{a}$ & & $36 a$ & & 42 & & 48 & & 54 & & $p=$ & 60 & IGNOF & $A 00^{\circ}$ & TOTAL \\
\hline & $r$ & M & $\mathrm{F}$ & M & $F$ & M & $F$ & $\mathrm{M}$ & $F$ & $M$ & $\mathrm{~F}$ & M & $\mathrm{F}$ & M & $\mathrm{F}$ & M & $\mathrm{F}$ & M & $\mathrm{F}$ & M & $\mathrm{F}$ & M & $\mathrm{F}$ & M & \\
\hline SUICLI0 & 1 & 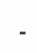 & 2 & & 25 & 15 & 29 & 59 & 20 & 61 & 16 & 60 & 14 & 54 & 13 & 39 & 12 & 29 & 6 & 37 & 6 & 40 & 2 & 4 & 544 \\
\hline PROFISSIONALL & & - & - & & & 1 & 2 & 5 & 1 & 6 & & 5 & & 2 & & 3 & & 2 & & 5 & - & - & - & 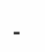 & 32 \\
\hline ACIDENTAL & 2 & 6 & 1 & & - & - & - & 1 & & - & - & 1 & 1 & 2 & - & 1 & - & 1 & - & - & - & 1 & - & - & 17 \\
\hline CFIMNOOSA & - & - & - & - & - & - & - & - & - & - & 2 & - & - & & - & - & - & 1 & - & - & - & - & - & - & 3 \\
\hline IGNORADO & - & 1 & - & - & - & 1 & - & 4 & 1 & 7 & - & 5 & - & 2 & - & 3 & - & 3 & 1 & 3 & 1 & 4 & - & - & 36 \\
\hline TOTAL & 3 & 7 & 3 & 0 & 25 & 17 & 31 & 69 & 22 & 74 & 18 & 71 & 15 & 60 & 13 & 46 & 12 & 36 & 7 & 45 & 7 & 45 & 2 & 4 & 632 \\
\hline
\end{tabular}

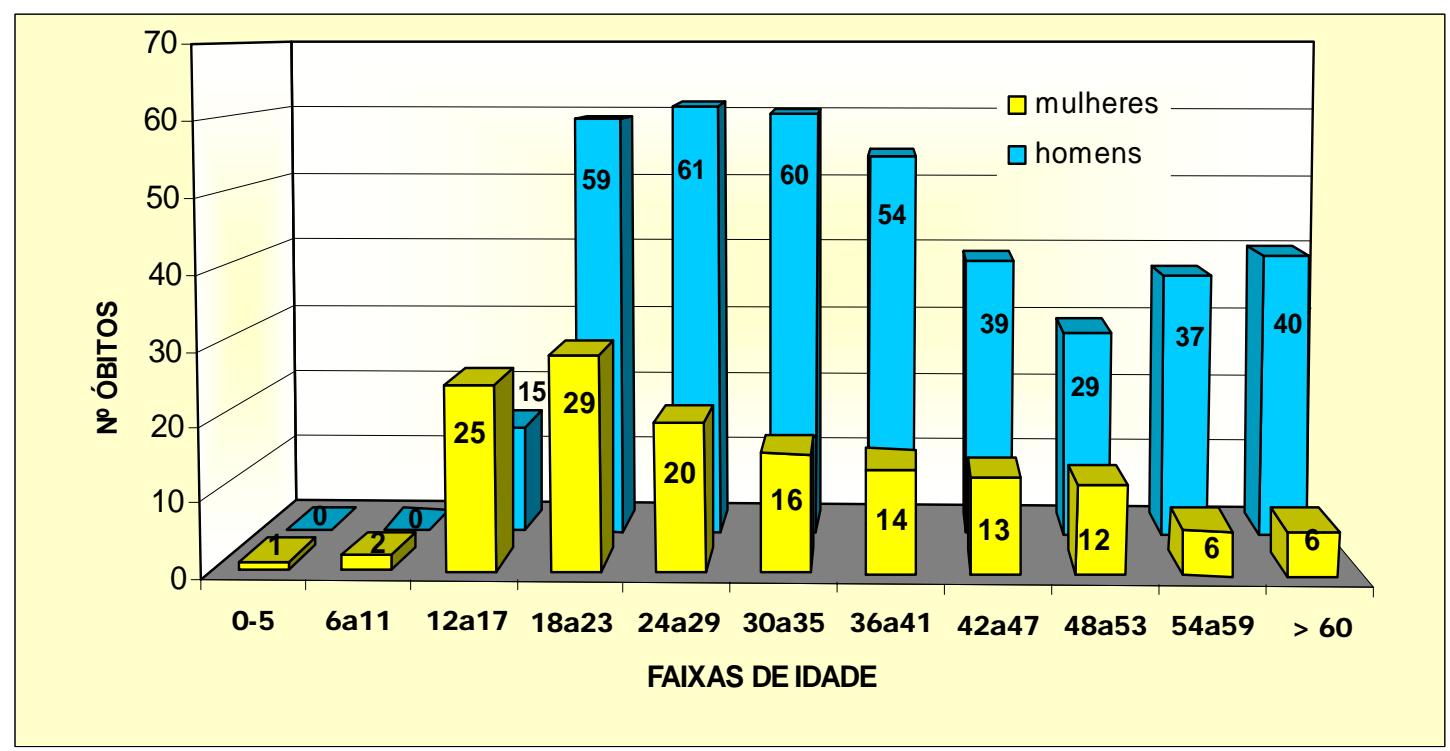

Figura 12 - Distribuição do número de óbitos entre homens e mulheres, nas diversas faixas de idade estudadas, segundo a causa suicídio, no Estado do Paraná, durante o período de 1993 a 2000 


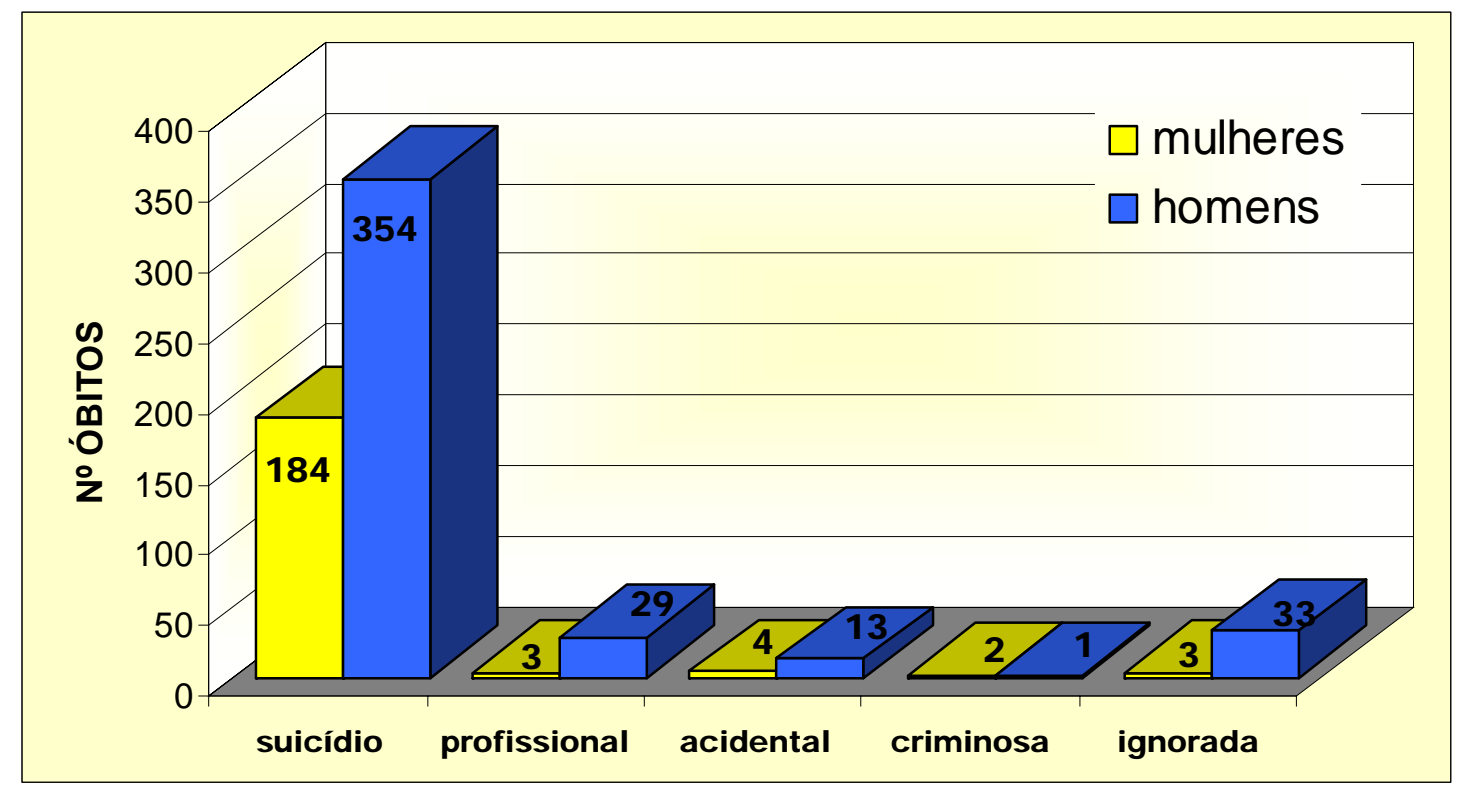

Figura 13 - Distribuição do número de óbitos, por causa de intoxicação para homens e mulheres, no Estado do Paraná, durante o período de 1993 a 2000

À semelhança do que foi apontado na Tabela 9, foi entre as faixas de idades compreendidas entre os 18 e 35 anos, onde ocorreu o maior número de óbitos (285 casos), o equivalente a um percentual de 45\% em relação ao período total estudado. Analisadas individualmente, a faixa de idade onde ocorreu o maior número de óbitos foi a compreendida entre os 18 e 23 anos, apresentando um total de 100 ocorrências (15,8\%), sendo 69 casos para o sexo masculino e 31, para o feminino (Figura 14). Do número total de casos de óbito (632 óbitos), 158 deles se deram em mulheres (25\%) e 474 (75\%), em homens. Segundo Trapé (2004), esta diferença expressiva entre o número de vítimas masculinas e femininas é decorrente do fato da cota de homens envolvidos na atividade agrícola ser superior ao das mulheres, e também por executarem tarefas onde a exposição aos produtos é maior. 


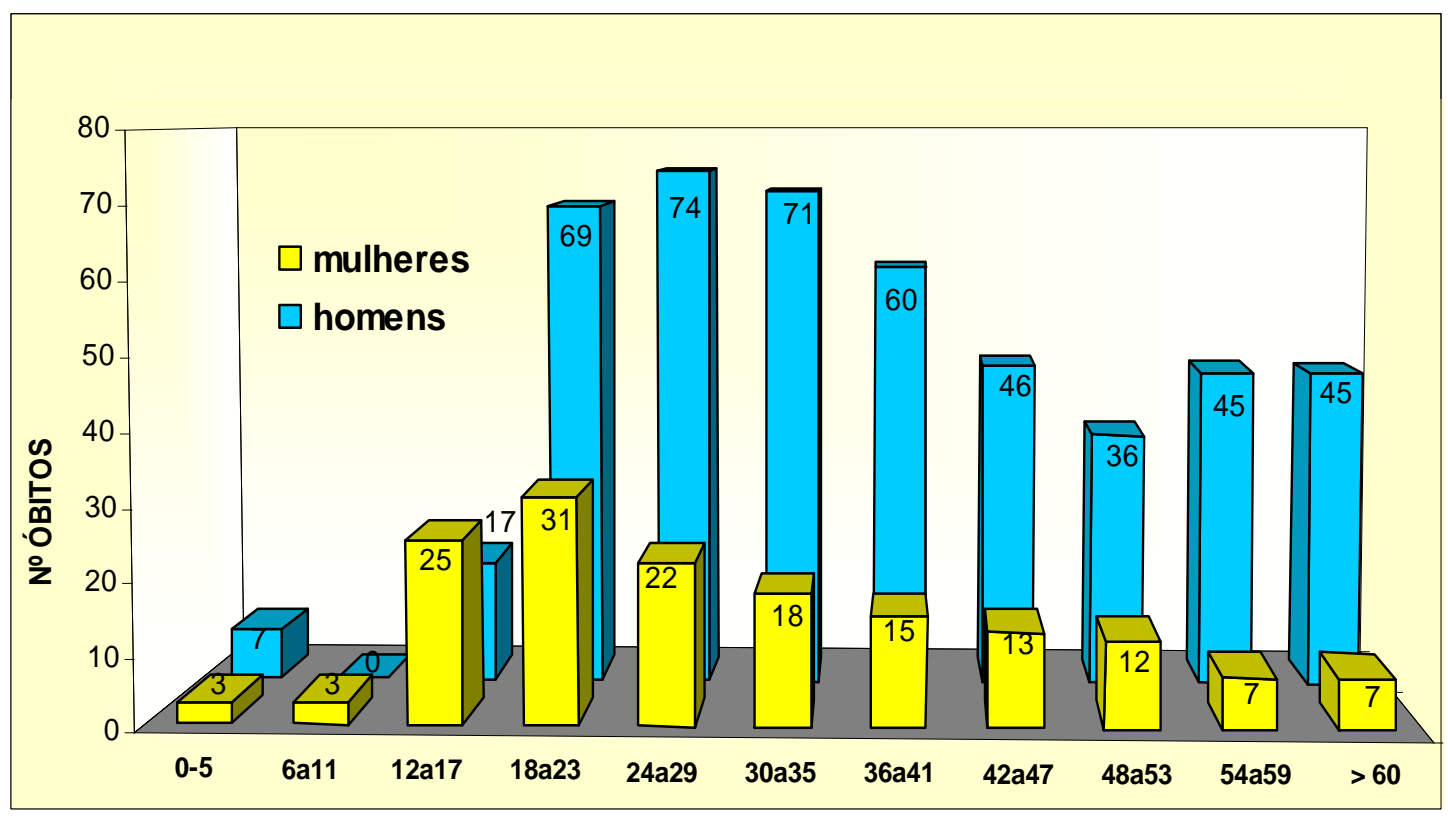

Figura 14 - Distribuição do número de óbitos entre homens e mulheres, dentro das diversas faixas de idade, ocorridas no Estado do Paraná, durante o período de 1993 a 2000

A OMS, através de relatório publicado em 1990, estimou que 7,3\% dos casos de intoxicações causadas por agrotóxicos se convertem em óbitos (World Health Organization, 1990). No presente estudo, onde foram notificadas um total de 5.548 ocorrências de intoxicação, o percentual de casos de óbitos atingiu a cifra de $11,4 \%$. Percentual semelhante foi obtido por Pires et al. (2005), que avaliando 1355 notificações de intoxicação, ocorridas no período de 1992 a 2002, onde constataram que a causa suicídio representou 36,9\% do total de casos, tendo $27,7 \%$ destes evoluídos a óbito. O total de óbitos equivaleu a $10 \%$ do total de casos notificados no período de estudo.

A Organização Pan-americana de Saúde (2002), em levantamento realizado em alguns países da América Central, quais sejam: Belice, Costa Rica, El Salvador, Guatemala, Honduras, Nicaragua e Panamá, constatou um 
percentual de óbitos equivalente a 11\%, em relação às intoxicações notificadas no ano de 2000.

\subsection{Relação entre intoxicações, regiões e respectivas áreas de cultivo}

Como não foi possível correlacionar as ocorrências de intoxicação às eventuais culturas onde as mesmas possam ter ocorrido, em função destas informações não estarem disponíveis no banco de dados disponibilizado pela SESA, uma das alternativas buscadas neste estudo foi relacionar as intoxicações às áreas de cultivos, aqui organizadas por meio de grupos de cultivo, que predominam nos municípios e regiões onde as intoxicações ocorreram.

Mesmo que nem todos os agrotóxicos, objetos causadores das intoxicações, estivessem condicionados ao uso expressamente agrícola, a maioria esteve sim, relacionada aos atos de aquisição, uso e armazenamento, para tal fim, como pode ser observado na Tabela 4, onde se apurou que as causas, profissional, suicídio e acidental determinaram $96,4 \%$ dos casos de intoxicação. Desta feita, o relacionamento dos casos de intoxicação às aptidões agrícolas de cada região, é uma das poucas formas de se identificar e estudar quais as regiões geográficas do Estado demandam maior atenção e análises mais profundas no que diz respeito ao comércio de agrotóxicos.

A região norte é responsável, em termos de área, pela maior atividade agrícola, ocupando $29 \%$ do total explorado. As regiões sul, oeste, centro-oeste, sudoeste e noroeste ocupam 25\%, 20\%, 12\%, 11\% e 4\% da área agrícola, respectivamente (Anexo D). Em qualquer uma das seis regiões que compõe o Estado, o grupo culturas de verão foi o que deteve a maior parte das 
áreas de exploração agrícola (86\%), sendo sucedida pelo grupo culturas Inverno (9,0\%). A exceção desta conclusão coube a região noroeste, onde o grupo outros ocupou a segunda maior área de cultivo $(22,9 \%)$ provavelmente pela grande concentração de culturas relacionadas à bovinocultura de corte pastagens e capineiras (Anexos $\mathrm{G}$ e $\mathrm{H}$ ).

Foi na região norte do Estado foi onde ocorreu a maior parte das intoxicações, detendo um percentual de $43 \%$ das ocorrências totais, sendo sucedida pelas regiões sul, centro-oeste, oeste, noroeste e sudoeste, que apresentaram percentuais de $20 \%, 12 \%, 10 \%, 10 \%$ e $4 \%$, respectivamente (Anexo B).

Todavia, quando se analisa o índice de intoxicações por área, aqui expresso pelo quociente: Índice $=\frac{\text { número de intoxicações }}{\text { área plantada }} \times 10.000$, a região noroeste, que ocupou apenas 4\% da área cultivada no Estado, passou a ser considerada a mais preocupante, pois apontou o maior índice de intoxicações $(2,39)$, haja vista que o índice médio apurado para o Estado foi de 1,0, ou seja, uma intoxicação anual a cada 10 mil hectares cultivados. As regiões norte e centro-oeste também apontaram índices superiores ao do Estado, tendo apresentado, 1,49 e 1,09, respectivamente (Anexo D).

Dos seis núcleos regionais que compõe a região norte, quatro deles apresentaram índice de intoxicação superiores à média inferida para o Estado: Londrina (2,23), Cornélio Procópio $(1,63)$, Maringá $(1,66)$ e Apucarana $(1,86)$ (Anexo D).

Na região sul, apresentaram índices de intoxicação acima da média estadual, os núcleos de Curitiba $(1,63)$, Irati $(1,45)$, União da Vitória $(2,31)$ e 
Paranaguá (8,37), este último, o maior índice de todo o Estado. O N.R. Paranaguá, onde a atividade agrícola predominante é a fruticultura, e apesar desta ter ocupado, durante o período estudado, a quarta área (19.379 ha) mais extensa do grupo de cultivo frutas, dentro deste núcleo ela correspondeu a 43,9\% da área agrícola total (Anexo D).

Os Núcleos Regionais de Campo Mourão, Paranavaí e Umuarama, também apresentaram índices de intoxicação acima da média estadual (Anexo D).

À exceção do N.R. Apucarana, onde prevaleceram as intoxicações motivadas pela causa suicídio, todos os núcleos cujo índice de intoxicação foi superior à média estadual, a principal causa de contaminação foi a profissional (Anexo $\mathrm{C}$ ), tendo os inseticidas como principal agente destas intoxicações. Com exceção do N.R. Paranaguá, onde predominaram os inseticidas do grupo químico dos carbamatos, nos demais núcleos foi o grupo químico dos organofosforados que causou a maior parte das contaminações (Anexo H).

Em outra análise, onde se buscou relacionar a evolução do número de intoxicações e das áreas ocupadas pelos seis grupos de culturas estudados durante o período de estudo, concluiu-se que a do grupo culturas de verão foi o que melhor concatenou número de intoxicações e áreas (extensão) de cultivo (Figura 18). Os demais grupos de culturas estudados apresentaram relação gráfica inversa entre intoxicações e áreas de cultivo (Figuras 15, 16, 17, 18 e 19). A Figura 21, que representa a relação entre o número total de intoxicações e a área total de exploração agrícola, também não apresentou relação aparente entre estas duas variáveis, dando indícios de que as ocorrências toxicológicas não estão, pelo menos aparentemente, diretamente relacionadas à expansão ou retração das áreas cultivadas. 


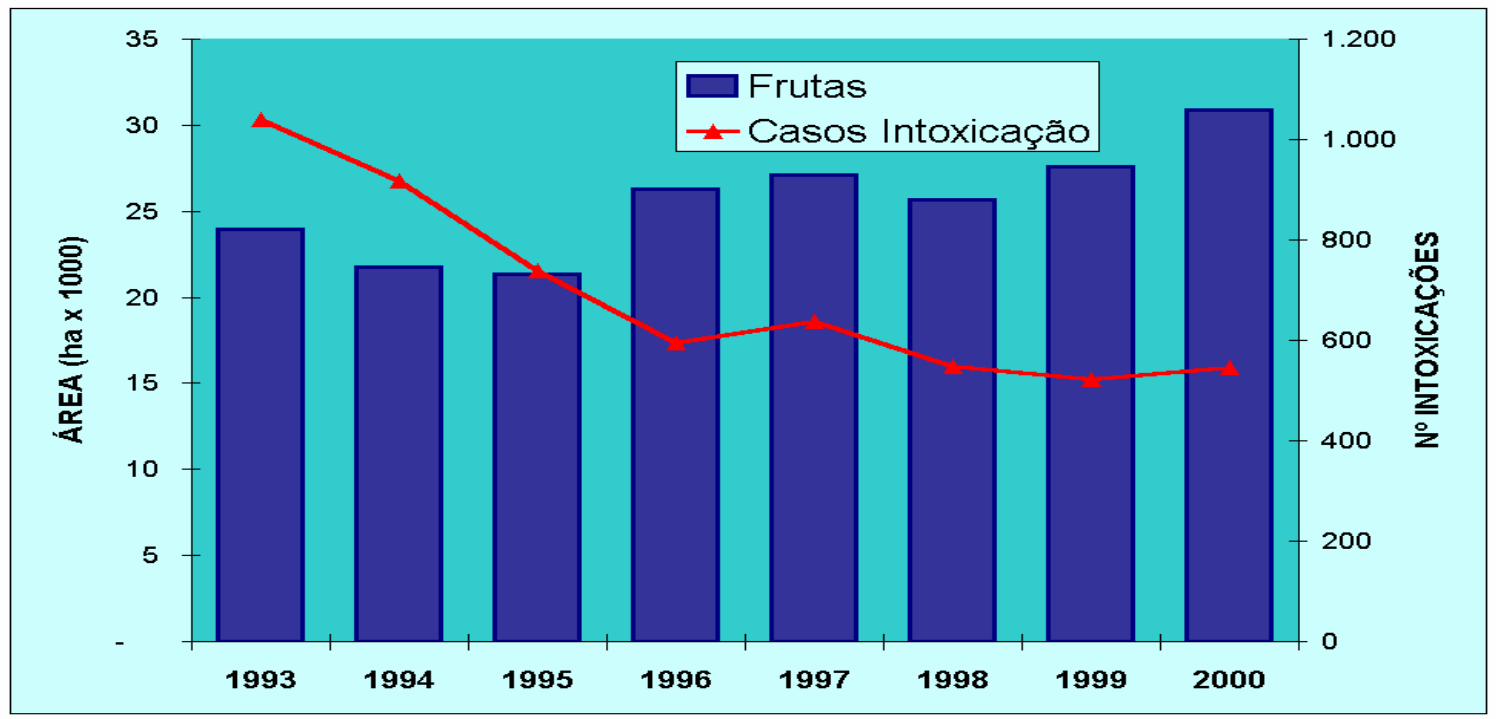

Figura 15 - Evolução do número de casos de intoxicação e das áreas de cultivo do grupo de cultivos de frutas, no Estado do Paraná, durante o período de 1993 a 2000

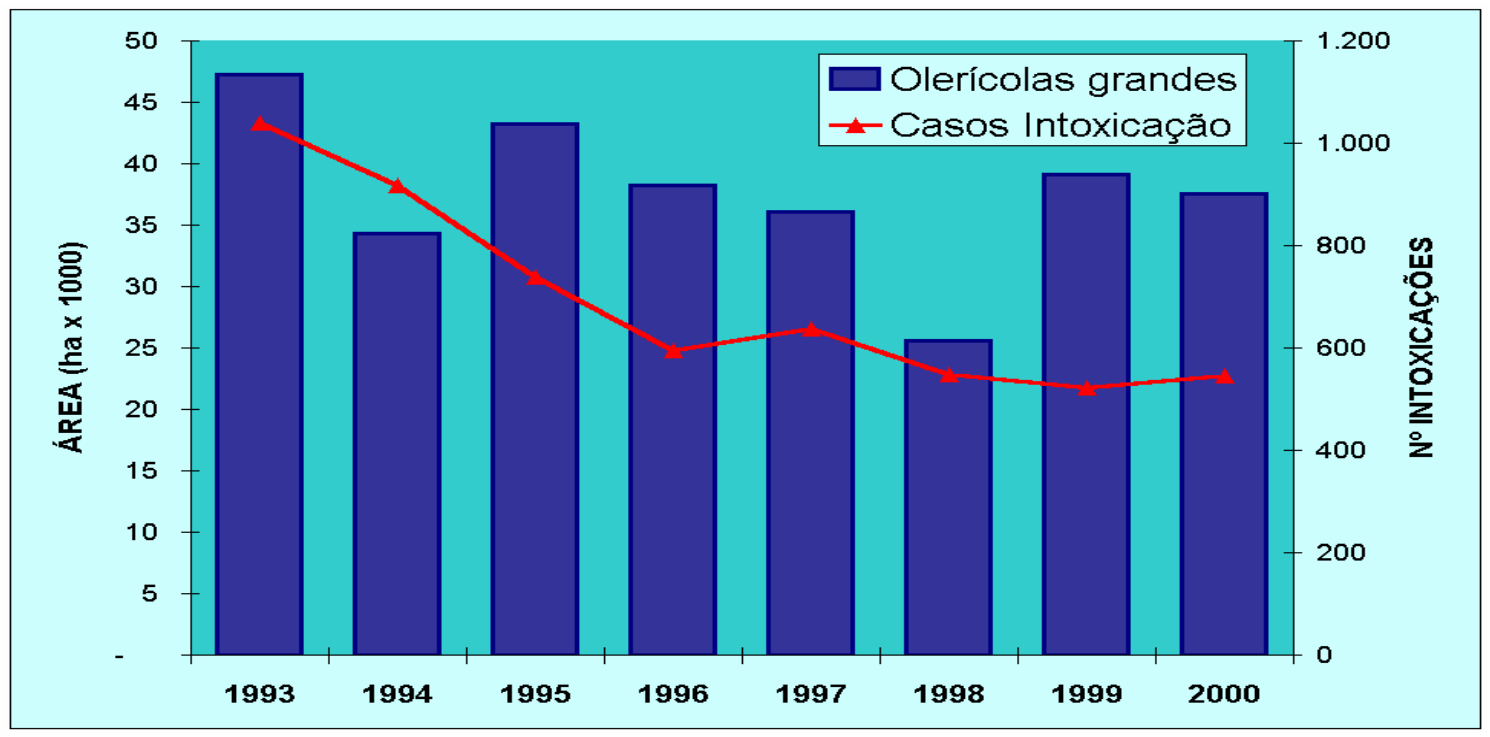

Figura 16 - Evolução do número de casos de intoxicação e das áreas de cultivo do grupo de cultivos de olerícolas grandes, no Estado do Paraná, durante o período de 1993 a 2000 


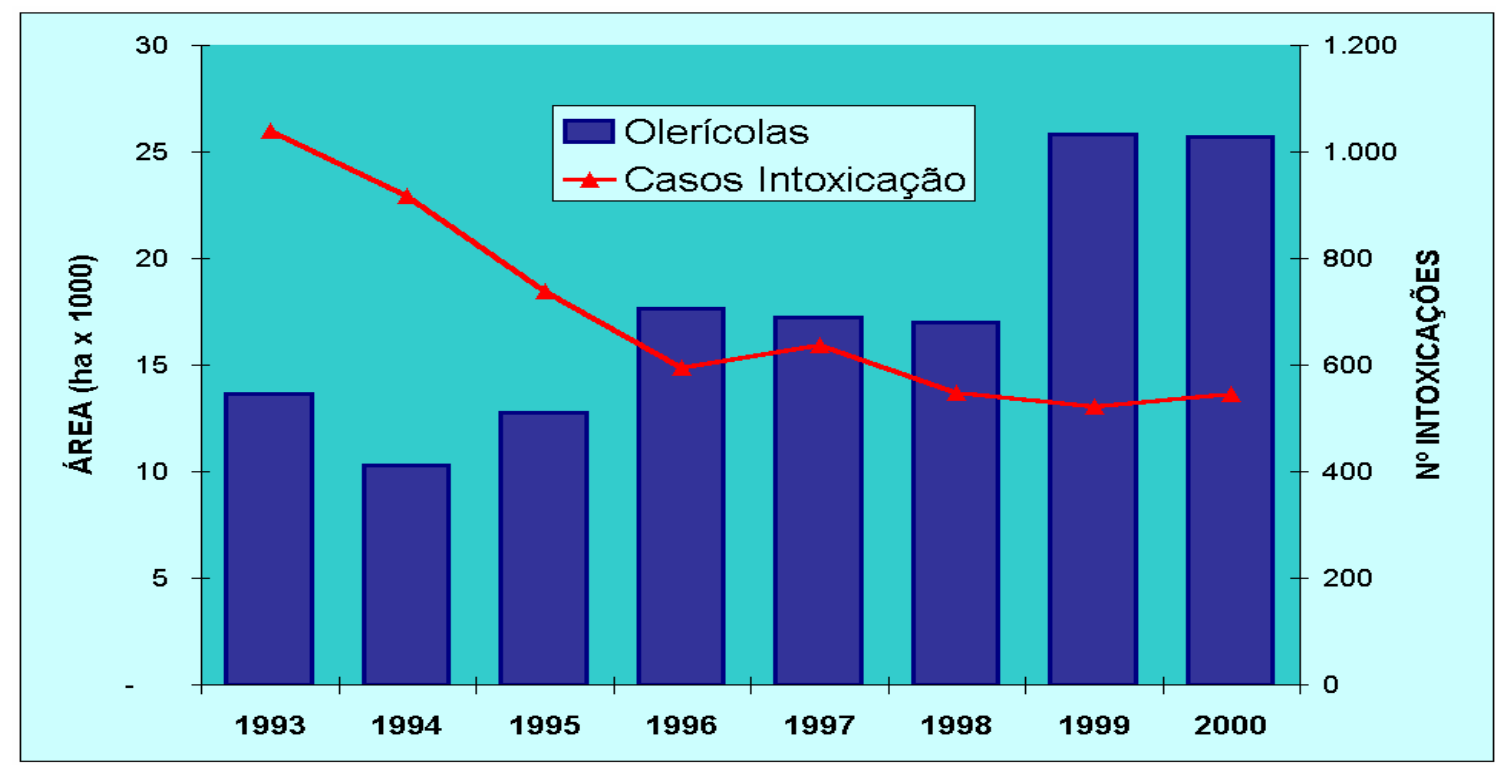

Figura 17 - Evolução do número de casos de intoxicação e das áreas de cultivo do grupo de cultivos de olerícolas, no Estado do Paraná, durante o período de 1993 a 2000

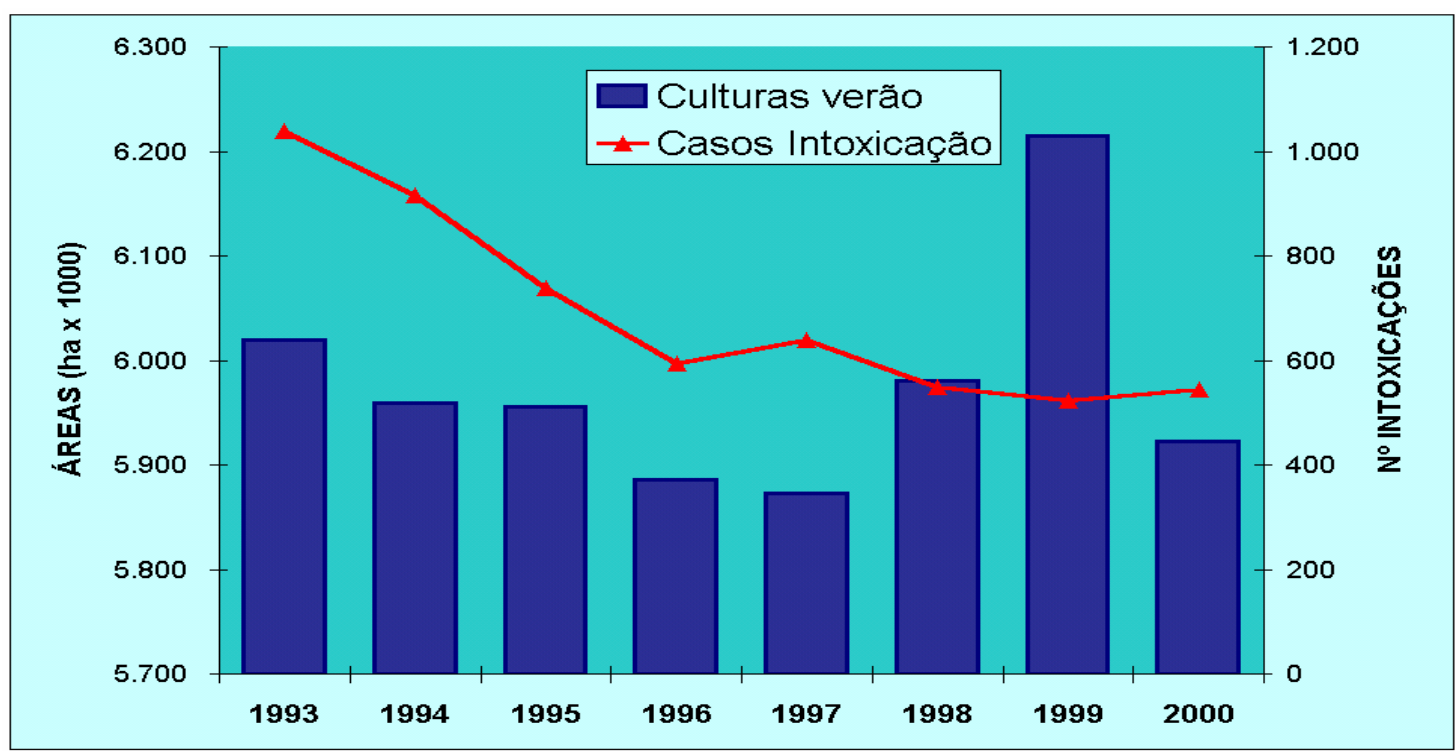

Figura 18 - Evolução do número de casos de intoxicação e das áreas de cultivo do grupo de cultivos de verão, no Estado do Paraná, durante o período de 1993 a 2000 


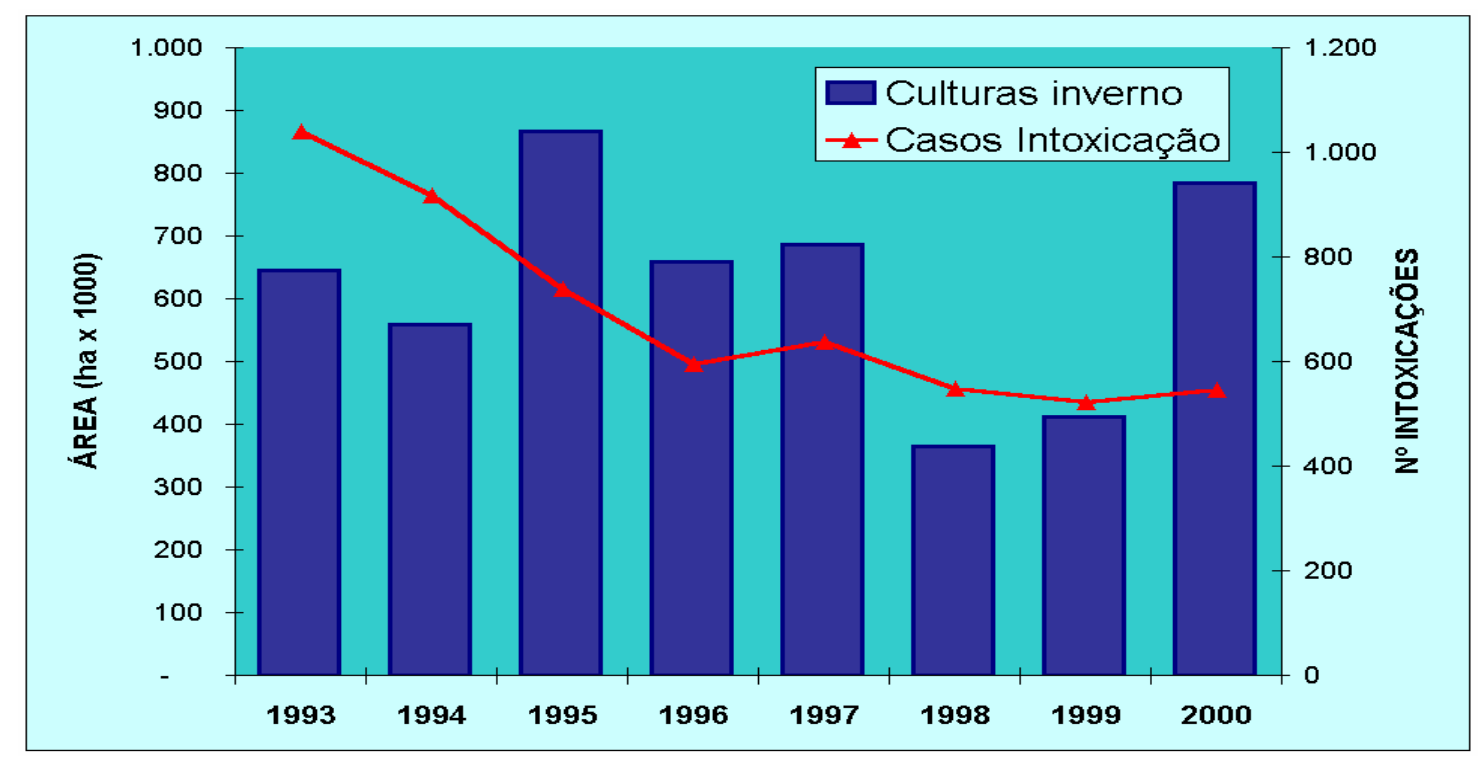

Figura 19 - Evolução do número de casos de intoxicação e das áreas de cultivo do grupo de cultivos de inverno, no Estado do Paraná, durante o período de 1993 a 2000

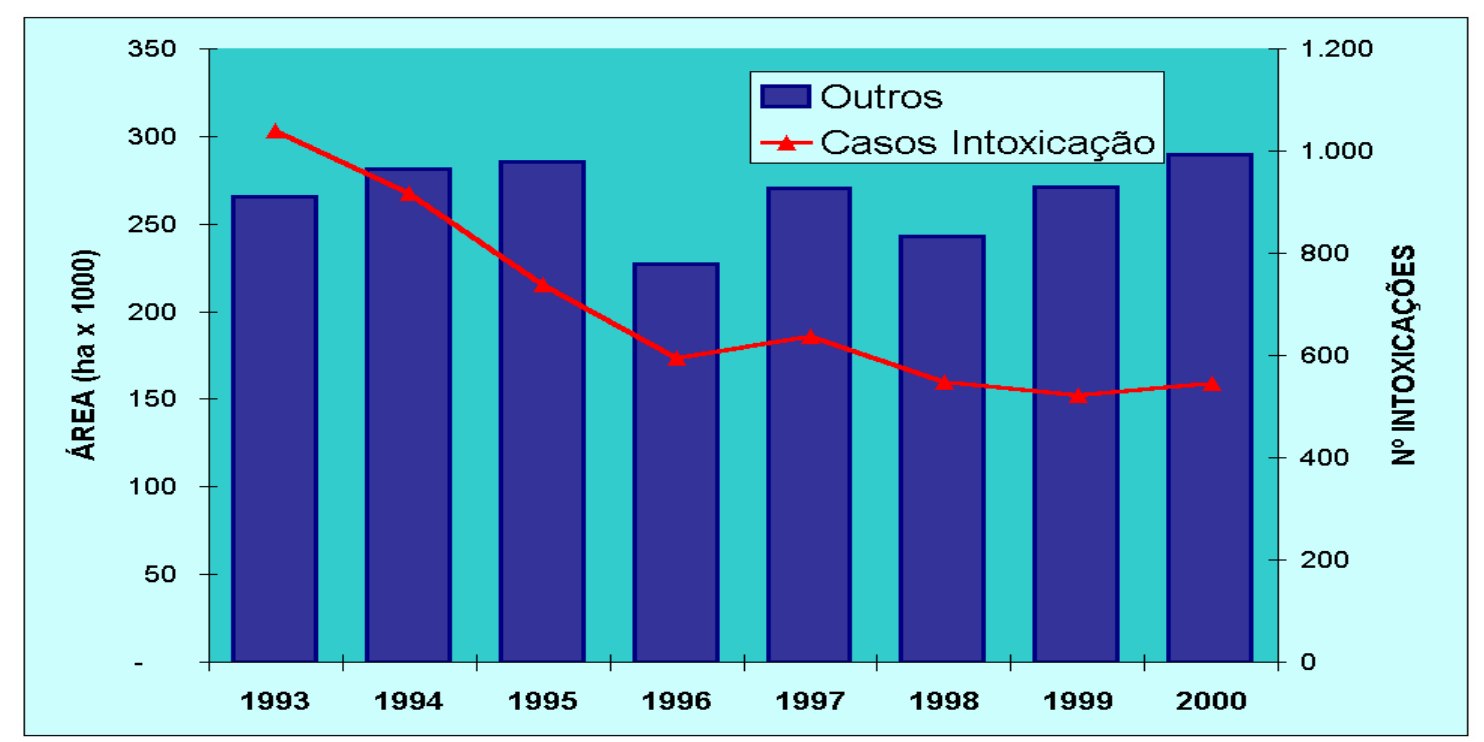

Figura 20 - Evolução do número de casos de intoxicação e das áreas de cultivo do grupo de outros cultivos, no Estado do Paraná, durante o período de 1993 a 2000 


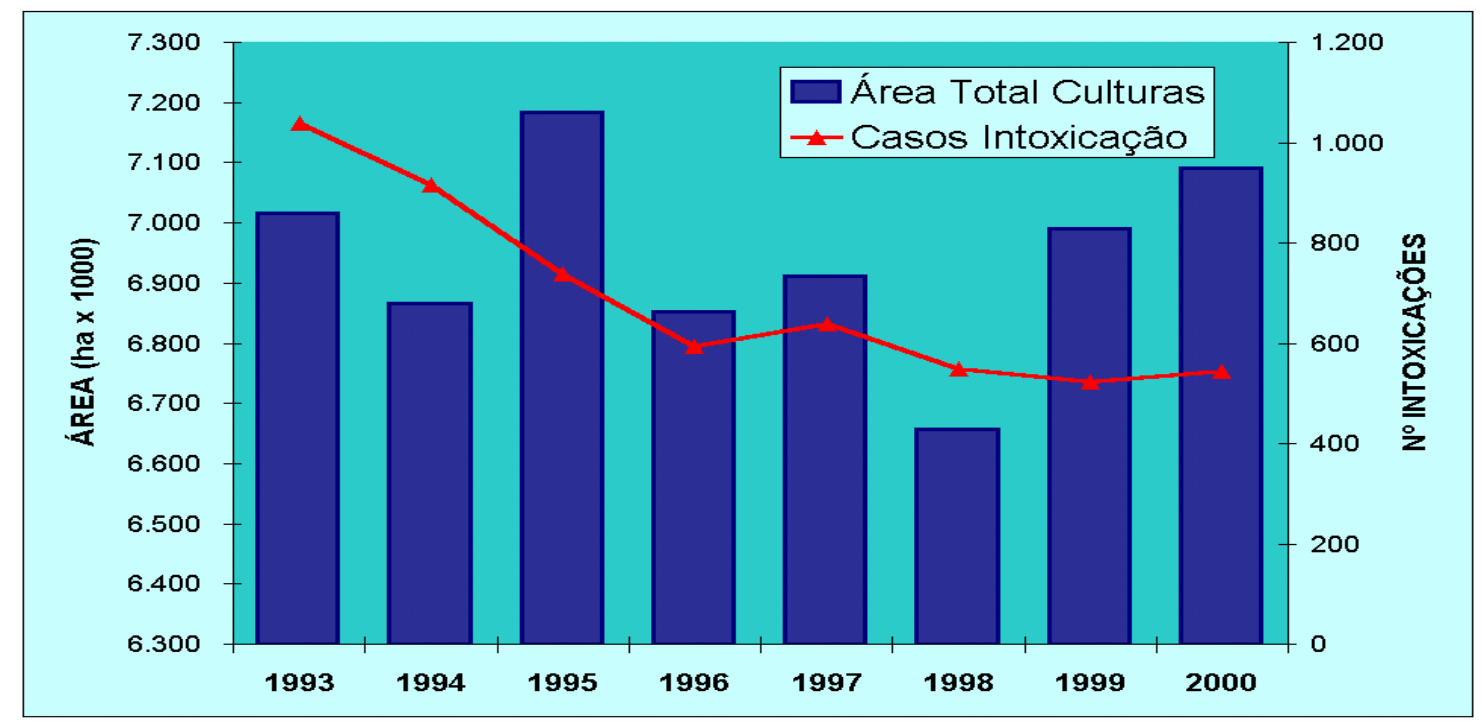

Figura 21 - Evolução do número de casos de intoxicação e das áreas totais de grupos de cultivo, no Estado do Paraná, durante o período de 1993 a 2000

Nos grupos de cultivos olerícolas (Figura 17) e olerícolas grandes (Figura 16), onde a freqüência, bem como a intensidade do uso de agrotóxicos são comprovadamente elevadas, os equipamentos de aplicação são de qualidade e estado de uso, precários e, por conseguinte, a exposição dos aplicadores a estes produtos acaba sendo maior do que nos demais grupos de cultivos analisados, não ficou evidenciado, durante os anos analisados, relação condizente entre a evolução dos números de intoxicações e respectivas áreas de exploração. Para o grupo olerícolas a relação gráfica entre as intoxicações e áreas implantadas, inclusive, foi inversa.

No grupo de cultivo frutas, à semelhança dos grupos relativos ao cultivo olerícolas, onde o uso de agrotóxicos sujeita-se a características análogas, a relação entre as variáveis intoxicação e áreas cultivadas, também foi contrária (Figura 15). 
Como complemento às análises descritivas anteriores, foi feita análise de Correlação entre as variáveis "número de intoxicações" e "área cultivada" para os seis grupos de culturas. Para isto considerou-se, para cada ano estudado, todos os municípios do Estado que tenham apresentado algum caso de intoxicação, totalizando 1360 dados.

Os resultados, apresentados na Tabela 11, mostram correlações estatisticamente significativas entre as variáveis "Número de intoxicações" e as áreas cultivadas de "culturas de inverno", "frutas", "culturas de verão" e olerícolas, todas positivas, denotando uma relação positiva entre área cultivada e número de casos de intoxicação.

Tabela 11. Análise de correlação entre as variáveis, grupos de cultura e Intoxicações

\begin{tabular}{lcccc}
\hline \multicolumn{1}{c}{ GRuPos } & $\mathbf{r}_{(\boldsymbol{x}, \boldsymbol{y})}$ & $\mathbf{t}$ & $\mathbf{P}$ & $\mathbf{N}$ \\
\hline Culturas de Inverno & 0,1357 & 5,05 & $5,12.10^{-7}$ & 1360 \\
Frutas & 0,1417 & 5,27 & $1,54.10^{-7}$ & 1360 \\
Culturas de Verä口 & 0,1739 & 6,51 & $1,06.10^{-10}$ & 1360 \\
Olericolas & 0,1541 & 5,75 & $1,11.10^{-8}$ & 1360 \\
Olerícolas Grandes & 0,0018 & 0,07 & 0,94 & 1360 \\
Outras & $-0,0263$ & $-0,97$ & 0,33 & 1360 \\
\hline
\end{tabular}

Uma análise de correlação não comprova a relação causa/efeito entre as variáveis, até porquê os casos de intoxicação não puderam ser identificados como oriundos de determinada cultura. O que ela mostra é a existência de um padrão, que pode ser resultante da relação causa/efeito, estatisticamente significativo entre elas. 


\subsection{Intoxicações segundo o local da ocorrência}

O local de ocorrência rural foi onde ocorreu o maior número de intoxicações, totalizando $65 \%$ das ocorrências, no período estudado. Os locais de intoxicações denominados como outro, urbano e ignorado, apresentaram percentuais de ocorrências iguais a: 25,6\%, 6,0\% e 3,4\%, respectivamente (Tabela 12). Os percentuais das ocorrências de intoxicações para o local rural, diferentemente dos demais locais avaliados, apresentaram durante o decorrer dos anos estudados, pequenas oscilações percentuais, conforme pode ser observado na Figura 22.

No que tange ao local de ocorrência das intoxicações, o Anuário SINITOX (FIOCRUZ, 2000), que considera apenas três zonas: urbana, rural e ignorada, relatou percentuais distintos daqueles obtidos neste trabalho. Neste, a zona rural apresentou 42,5\% das intoxicações, enquanto a urbana, 54,5\%.

Cabe aqui, observar que à época da coleta das informações que compõe o banco de dados empregado neste estudo, o Sistema de saúde do Paraná utilizava duas fichas distintas na coleta das informações referentes às ocorrências. Em uma delas, a Ficha Epidemiológica de Ocorrência Toxicológica (Apêndice 1), as informações sobre o local de ocorrência eram armazenadas em seu campo de $\mathrm{n}^{\circ} 14$, onde, neste, havia cinco opções de preenchimento, quais sejam: urbana, rural, trabalho, residência e outro. Considerando que na ocasião do preenchimento, o funcionário deveria anotar o local genérico (urbano ou rural) da ocorrência e o específico (se residência, trabalho ou outro), devido à falta de divisão física do citado campo, e obviamente pela falta de preparo de alguns que executavam esta tarefa, todos os locais se referiam a locais genéricos, além daqueles já relatados, como por exemplo: lazer, escola, lavoura, entre outros. Com isto, muitas ocorrências, que provavelmente, 
aconteceram em ambientes rurais ou urbanos, foram agrupadas em outros lugares, aumentando sobremaneira o número de locais de ocorrência, e conseqüentemente comprometendo a análise segundo esta variável.

Tabela 12. Número de intoxicações segundo o local de ocorrência, durante o período de 1993 a 2000

\begin{tabular}{|c|c|c|c|c|c|c|c|c|c|}
\hline \multirow{2}{*}{ Local } & \multicolumn{8}{|c|}{ Ano } & \multirow{2}{*}{ TOTAL } \\
\hline & 1993 & 1994 & 1995 & 1996 & 1997 & 1998 & 1999 & 2000 & \\
\hline RURAL & 626 & 565 & 496 & 396 & 444 & 382 & 324 & 373 & 3.606 \\
\hline OUTRO & 398 & 352 & 121 & 122 & 145 & 62 & 131 & 90 & 1.421 \\
\hline UREANO & 9 & - & 90 & 55 & 32 & 57 & 25 & 63 & 331 \\
\hline IGNORADO & 7 & - & 33 & 22 & 17 & 48 & 43 & 20 & 190 \\
\hline TOTAL & 1.040 & 917 & 740 & 595 & 638 & 549 & 523 & 546 & 5.548 \\
\hline
\end{tabular}

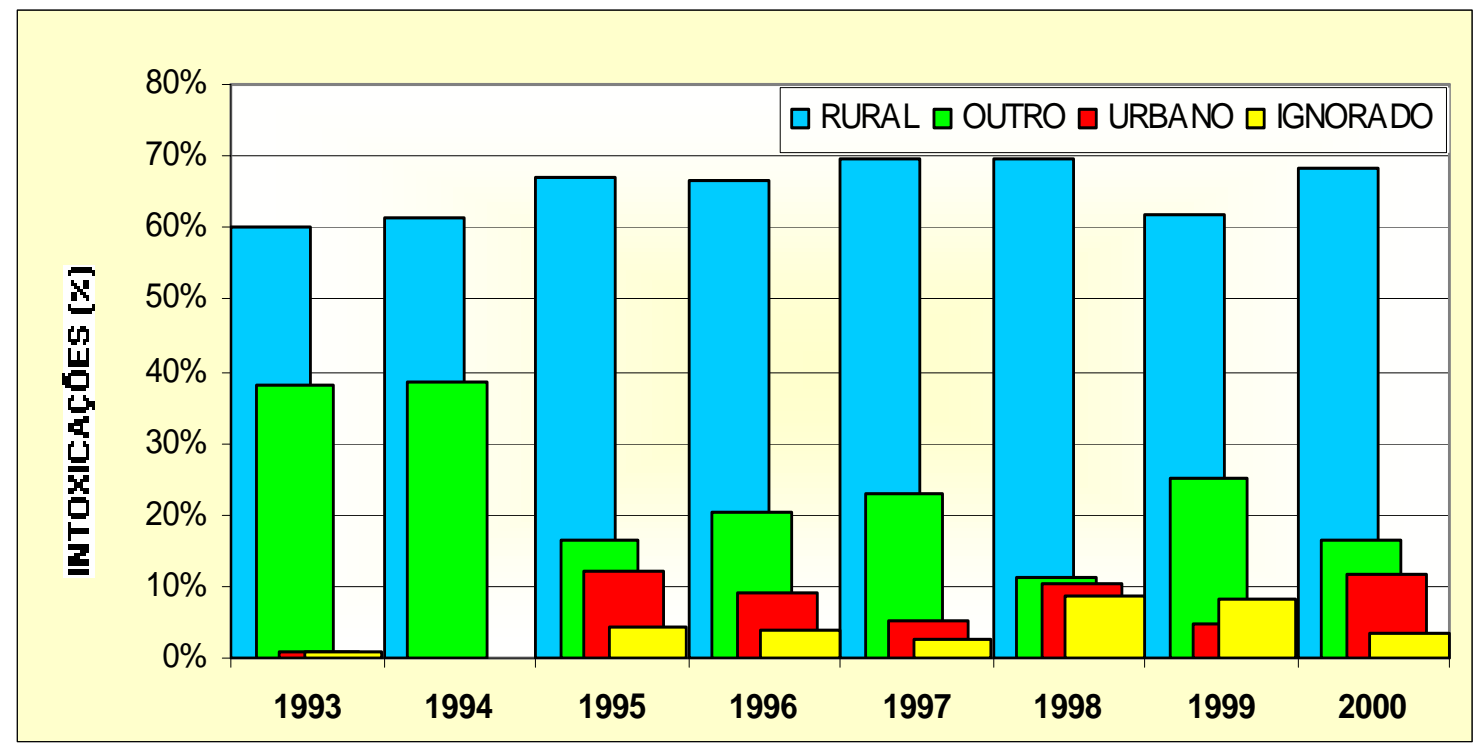

Figura 22 - Evolução dos percentuais de intoxicação, segundo o local de ocorrência, durante o período de 1993 a 2000 
$\mathrm{Na}$ Tabela 13, onde as intoxicações foram analisadas segundo o cruzamento das informações relativas a local de ocorrência e causa de contaminação, observa-se que a maioria das ocorrências referentes ao local rural tiveram cunho profissional (72\%), seguida das causas suicídio (15\%) e acidental (10\%), enquanto que os percentuais referentes às demais causas, somados não totalizaram 2\% (Tabela 13).

Duran-Nah \& Colli-Quintal (2000) num estudo epidemiológico realizado no México apuraram que $70 \%$ dos casos estudados pertenciam ao meio rural, apesar das intoxicações, na sua maioria suicídios, não estarem relacionadas à prática da atividade agrícola.

Tabela 13. Número total de intoxicações segundo as causas de contaminação e locais de ocorrência, para o período de 1993 a 2000

\begin{tabular}{lcccccccc}
\hline \multicolumn{8}{c}{ Causa de Contaminação } \\
Local & Profissional & Suicidio & Acidental & Ignorado & $\begin{array}{c}\text { Alimento } \\
\text { Contaminado }\end{array}$ & Ambiental & Criminosa & TOTAL \\
\hline RURAL & 2609 & 557 & 370 & 47 & 13 & 5 & 5 & 3.606 \\
OUTRO & 232 & 744 & 361 & 37 & 29 & 12 & 6 & 1.421 \\
UREANO & 79 & 151 & 77 & 16 & 2 & 5 & 1 & 331 \\
IGNORADO & 26 & 105 & 35 & 23 & 1 & - & - & 190 \\
TOTAL & 2.946 & 1.557 & 843 & 123 & 45 & 22 & 12 & 5.548 \\
\hline
\end{tabular}

Já para o local denominado como outro, local este onde foram agrupadas intoxicações ocorridas em residência, e que, face a ausência de informações oferecidas pelo banco de dados não foi possível precisar se o local estava circunscrito ao ambiente urbano ou rural, a maioria das ocorrências, teve no Suicídio a principal causa, tendo conferido a esta o percentual de 52\%. Para 
este mesmo local, as causas acidental e profissional apresentaram percentuais de ocorrência iguais a $25 \%$ e $16 \%$, respectivamente. No local urbano também predominaram as intoxicações motivadas pela causa suicídio (46\%), seguidas pela causa profissional (24\%) e acidental (23\%) (Tabela 13).

Em análise às principais causas de contaminação, a causa profissional atingiu sua maior expressão no local rural, inferindo a esta o percentual de 89\%. Já a causa acidental, apresentou percentuais de ocorrências de intoxicação semelhantes, tanto para os locais rural (44\%), como o local outro (43\%). Para a causa suicídio, as intoxicações predominaram no local outro (48\%), seguido do rural (36\%) (Tabela 13).

Em efeito, fica patente que as intoxicações decorrentes da atividade trabalhista, ocorrem, preferencialmente no ambiente rural, local este, onde a priori, os agrotóxicos tem sua utilização consumada. Nas intoxicações cuja motivação tiveram como causa a intenção do suicídio, aconteceram principalmente no ambiente residencial, que neste estudo está relacionado ao local outro, e também no ambiente rural, onde o acesso aos agrotóxicos é facilitado.

$\mathrm{Na}$ análise dos locais, tendo em vista as vias de contaminação, concluiu-se que para as intoxicações ocorridas no ambiente rural, a principal via de contaminação foi a respiratória (47\%), enquanto que àquelas referentes ao ambiente outro (onde estão inclusas intoxicações sofridas em residências), predominou a via digestiva (67\%) (Tabela 14), que este estudo provou serem procedentes da prática do suicídio (76,6\%) (Tabela 7). No urbano, à semelhança do ocorrido no ambiente denominado como ignorado, a via digestiva figurou como o principal meio das intoxicações relatadas, tendo sido aferido para estas, $56 \%$ e $57 \%$ (Tabela 14), onde provavelmente estejam 
contidas intoxicações ocorridas no ambiente residencial, porém não declaradas a ponto de serem registradas nas fichas de notificação.

Tabela 14. Número de intoxicações segundo o local de ocorrência e via de contaminação, durante o período de 1993 a 2000

\begin{tabular}{lcccccccc}
\hline Local & Respiratória & Digestiva & $\begin{array}{c}\text { Cutânea }+ \\
\text { Respiratória }\end{array}$ & Cutânea & Ignnorada & $\begin{array}{c}\text { Digestiva }+ \\
\text { Respiratória }\end{array}$ & Cigestiva + + & TOTAL \\
\hline RURAL & 1.710 & 698 & 681 & 392 & 99 & 20 & 6 & 3.606 \\
OUTRO & 284 & 950 & 73 & 47 & 60 & 4 & 3 & 1.421 \\
URBANO & 66 & 186 & 42 & 20 & 14 & 3 & - & 331 \\
IGNORADO & 5 & 108 & 5 & 3 & 69 & - & - & 190 \\
TOTAL & 2.065 & 1.942 & 801 & 462 & 242 & 27 & 9 & 5.548 \\
\hline
\end{tabular}

\subsection{Intoxicações segundo a ocupação}

No presente estudo, as ocupações foram agrupadas segundo a natureza da atividade, de modo a minimizar o número de itens para análise, em sendo assim, foram criados quatro ocupações: agricultor (composto por indivíduos relacionados à atividade agrícola, tais como: agricultores, proprietários, arrendatários, bóias-frias, etc.), estudante, doméstica e outra (composta por ocupações que não se enquadram nas ocupações anteriores).

Foi na ocupação agricultor onde ocorreu o maior número de intoxicações (3504 casos), num equivalente percentual de 63\% (Tabela 15). E tais intoxicações ocorreram na sua quase totalidade, no ambiente rural (89\%) (Tabela 15). A ocupação outra totalizou 32\% dos casos de intoxicação notificados, e se deram no local aqui denominado como outro. As intoxicações 
ocorridas em indivíduos cuja ocupação foi registrada como sendo doméstica, representaram 208 casos e aconteceram, na sua maioria (138 casos), no local outro, que neste estudo, agrupou notificações ocorridas em residências (Tabela 15). A ocupação estudante, que no total, expressou um número de 86 intoxicações, o equivalente a $2 \%$ dos casos, se deu principalmente nos locais outro (50\%) e rural (31\%), sendo que os casos ocorridos neste último ambiente, denotam a presença de indivíduos, ainda na idade jovem, envolvidos em funções relacionadas à atividades agrícolas (Tabela 15).

Tabela 15. Número de intoxicações segundo o local de ocorrência e a ocupação dos intoxicados

\begin{tabular}{lccccc}
\hline \multirow{2}{*}{ Ocupação } & \multicolumn{5}{c}{ Local } \\
& Rural & Outro & Urbano & lgnorado & TOTAL \\
\hline AGRICULTOR & 3.122 & 308 & 66 & 8 & 3.504 \\
OUTRA & 423 & 932 & 226 & 169 & 1.750 \\
IOMESTICA & 34 & 138 & 26 & 10 & 208 \\
ESTUDANTE & 27 & 43 & 13 & 3 & 86 \\
TOTAL & 3.606 & 1.421 & 331 & 190 & 5.548 \\
\hline
\end{tabular}

\subsection{Intoxicações nas regiões e núcleos regionais, segundo a classe e respectivos grupos químicos dos agrotóxicos}

Cada uma das seis regiões estudadas apresentaram provavelmente em função das características agrícolas locais, tais como culturas predominantes e respectivas extensões das áreas cultivadas (Anexo D), quadros de intoxicação particularizados, resultantes da exposição a diferentes classes e grupos químicos. Todavia, os agrotóxicos da classe Inseticida 
produziram intoxicações com maior intensidade, atingindo o número de 2.113 casos (37,9\%), sendo acompanhado pelos herbicidas (997 casos), fungicidas (151casos) e reguladores (51 casos) (Tabela 16). As misturas, resultante da mescla de agrotóxicos pertencentes a diferentes classes, representaram 11,3\% dos casos notificados (Anexo E).

Num total de 2.400 ocorrências, o equivalente a $43,1 \%$ do total registrado para o período estudado, foi na região norte em que se deu o maior número de intoxicações. Ainda para esta mesma região, cabe observar que a mesma apresentou o maior número de intoxicações em qualquer uma das classes de agrotóxicos avaliadas. As regiões sul, centro-oeste, oeste, noroeste e sudoeste apresentaram percentuais, em relação ao total de casos apurados, iguais a $20,4 \%, 12,1 \%, 10,3 \%, 10 \%$ e 4,1\%, respectivamente (Tabela 16).

A exceção da região sudoeste, onde predominaram os agrotóxicos da classe herbicidas, nas demais regiões foi por intermédio dos Inseticidas que ocorreram o maior número de intoxicações. Na região sudoeste os herbicidas causaram 43,3\% das ocorrências, tendo como principal responsável pelas mesmas, aqueles pertencentes ao grupo químico dos derivados da glicina, que representaram $17,3 \%$ do total das intoxicações registradas nesta região. Das intoxicações ocorridas nas regiões norte, sul, centro-oeste e noroeste, predominaram absolutos os inseticidas, determinando a estas percentuais de intoxicação iguais a: 42,5\%, 23,9\%, 43,8\%, 33,7\% e 49,6\%, respectivamente. Em qualquer uma destas cinco regiões, foi o grupo químico dos organofosforados o principal causador das ocorrências registradas (Tabela 16).

Dentro da classe dos Inseticidas, foi no N.R. Campo Mourão onde ocorreu o maior percentual de intoxicações, totalizando $14,0 \%$ dos casos 
registrados no Estado. Dos cinco principais grupos químicos avaliados nesta classe, o N.R. Londrina apresentou os maiores percentuais de intoxicação em três deles: carbamatos (15,8\%), piretróides (20,2\%) e organoclorados (25,0\%). O grupo químico dos organofosforados atingiu seu maior percentual $(14,4 \%)$ no N.R. Cornélio Procópio. Já os inseticidas pertencentes ao grupo químico dos esteres do ASDC, apresentaram seu percentual mais elevado $(27,1 \%)$ no N.R. Campo Mourão (Anexo H).

$\mathrm{Na}$ categoria dos herbicidas, o maior número de intoxicações, 145 casos, se deu no N.R. Londrina, o equivalente a 14,5\% do total de ocorrências. Neste mesmo núcleo também se deram os maiores percentuais de intoxicação para os herbicidas dos grupos químicos dos derivados da glicina $(20,1 \%)$ e fenoxiacéticos (20,0\%). Já os grupos dos bipiridílios, dinitroanilinas, e fenoxiacéticos + derivados do ácido picolínico, apresentaram os mais elevados percentuais nos núcleos regionais de Pato Branco (16,6\%), Campo Mourão $(20,3 \%)$ e Cascavel (35,7\%), respectivamente (Anexo H).

Dos cinco grupos químicos relacionados na classe dos fungicidas, o N.R. Londrina apresentou os maiores percentuais em quatro deles: triazóis $(17,2 \%)$, benzimidazóis $(20,0 \%)$, cúpricos $(21,4 \%)$ e triazóis + organofosforados (53,8\%). O N.R. Cornélio Procópio apresentou percentuais idênticos para o grupo dos triazóis e benzimidazóis. Os grupo dos ditiocarbamatos expressou seu maior percentual no N.R. União da Vitória (25,0\%). No cômputo geral, o maior número de intoxicações originadas pelos fungicidas se deu no N.R. Londrina, totalizando 31 casos (Tabela 17).

Para a categoria dos reguladores de crescimento, o N.R. Curitiba deteve o maior número de intoxicações (11 casos), o equivalente a 21,6\% em relação ao apresentado pelos demais núcleos, como também apresentou o 
maior percentual com relação ao grupo químico das dinitroanilinas (45,8\%). O grupo das cianamidas encontrou seu maior percentual $(37,0 \%)$ nos núcleos regionais de Cornélio Procópio e Maringá (Anexo H).

O N.R. Campo Mourão apresentou o maior percentual de intoxicação na classe denominada outro. As intoxicações originadas através da exposição às misturas ocorreram em maior proporção no N.R. União da Vitória, atingindo $21,2 \%$ do total de casos (Anexo $\mathrm{H})$.

Tabela 16. Número de intoxicações por regiões, segundo a classe e principais grupos químicos de agrotóxicos, ocorridas durante o período de 1993 a 2000

\begin{tabular}{|c|c|c|c|c|c|c|c|}
\hline \multirow[b]{2}{*}{ CLASSE DE PRODUTO } & \multicolumn{6}{|c|}{ REGIÕES } & \multirow[b]{2}{*}{ TOTAL } \\
\hline & Norte & Sul & $\begin{array}{c}\text { Centro } \\
\text { Oeste }\end{array}$ & Oeste & Noroeste & Sudoeste & \\
\hline INSETICIDA & 1.019 & 271 & 296 & 193 & 277 & 57 & 2.113 \\
\hline ORGMNOFOSFORADO & 603 & 179 & 173 & 141 & 136 & 43 & 1.275 \\
\hline CAREAMATO & 135 & 48 & 33 & 18 & 29 & 3 & 266 \\
\hline FIRETROIDE & 89 & 16 & $2 \mathrm{~g}$ & 15 & 39 & 3 & 188 \\
\hline ESTER DO ASDC & 66 & 0 & 42 & 8 & 38 & 1 & 155 \\
\hline ORGMNOCLORMDO & 48 & 8 & 1 & 4 & 17 & 2 & 80 \\
\hline HERBICIDA & 408 & 250 & 67 & 124 & 48 & 100 & 997 \\
\hline DERIVADO DA GLICINA & 223 & 78 & 24 & 51 & 22 & 40 & 438 \\
\hline EIFIFIDILIOS & 60 & 95 & 10 & 17 & 2 & 39 & 223 \\
\hline DINUITROANULIVAS & 27 & 16 & 15 & 8 & 5 & 3 & 74 \\
\hline FENOXIACETICO + DER. AC. PICOLINICO & 22 & 5 & 2 & 27 & 9 & 5 & 70 \\
\hline FENOXIACETICO & 17 & 8 & 4 & 8 & 0 & 3 & 40 \\
\hline FUNGICIDA & 88 & 36 & 11 & 5 & 7 & 4 & 151 \\
\hline DITIOCAREAMATO & 16 & 26 & 1 & 0 & 0 & 1 & 44 \\
\hline TRIAZIS & 17 & 1 & 5 & 2 & 3 & 1 & 29 \\
\hline EENZZIMIDAZOL & 10 & 0 & 1 & 2 & 0 & 2 & 15 \\
\hline CUPRICO & 9 & 2 & 1 & 0 & 2 & 0 & 14 \\
\hline TRIAZZOIS + ORG,ANOFOSFORADO & 11 & 0 & 1 & 0 & 1 & 0 & 13 \\
\hline REGULADORES & 27 & 21 & 0 & 0 & 0 & $\mathbf{3}$ & 51 \\
\hline GANAMIDA. & 27 & 0 & 0 & 0 & 0 & 0 & 27 \\
\hline DINITROANILINAS & 0 & 21 & 0 & 0 & 0 & 3 & 24 \\
\hline MISTURAS & 205 & 205 & 63 & 81 & 61 & 16 & 631 \\
\hline OUTROS & 653 & 352 & 239 & 169 & 165 & 51 & 1.629 \\
\hline TOTAL & 2.400 & 1.135 & 676 & 572 & 558 & 231 & 5.572 \\
\hline
\end{tabular}




\subsubsection{Região norte}

Foi na região norte, composta pelos núcleos regionais de Londrina, Cornélio Procópio, Maringá, Apucarana, Ivaiporã e Jacarezinho, onde ocorreram 2.400 intoxicações (Tabela 17), o equivalente a 43,1\% dos casos notificados para todo o Estado durante o período estudado (Anexo $\mathrm{H}$ ).

Tabela 17. Número de intoxicações entre os núcleos regionais da região norte, por classe e principais grupos químicos ocorridas durante o período de 1993 a 2000

\begin{tabular}{|c|c|c|c|c|c|c|c|}
\hline \multirow[b]{2}{*}{ CLASSE DE PRODUTO } & \multicolumn{6}{|c|}{ NÚCLEOS REGIONAIS } & \multirow[b]{2}{*}{ TOTAL } \\
\hline & Londrina & $\begin{array}{l}\text { Cornélio } \\
\text { Procópio }\end{array}$ & Maringá & Apucarana & Ivaiporã & Jacarezinho & \\
\hline INSETICIDA & 293 & 280 & 204 & 98 & 79 & 65 & 1.019 \\
\hline ORGANOFOSFORADO & 139 & 184 & 118 & 64 & 59 & 39 & 603 \\
\hline CAREMMMTO & 42 & 37 & 31 & 16 & 2 & 7 & 135 \\
\hline PIRETROIDE & 30 & 22 & 17 & 1 & 4 & 7 & 89 \\
\hline ESTER DO ASDC & 11 & 21 & 16 & 3 & 10 & 5 & 66 \\
\hline ORGANOCLORADO & 20 & 8 & 11 & 7 & 2 & - & 48 \\
\hline HERBICIDA & 145 & 55 & 72 & 39 & 55 & 42 & 408 \\
\hline DERIYADO DA GLIINMA & 86 & 26 & 43 & 29 & 14 & 23 & 223 \\
\hline EIPREIIILIOS & 20 & & 4 & 3 & 28 & 5 & 60 \\
\hline DINITROMNNINAS & 5 & 7 & 11 & 3 & 1 & - & 27 \\
\hline FENOK|ACETICO + DER. AC. PICOLINICO & 11 & 5 & 3 & - & - & 3 & 22 \\
\hline FENOX|ACETICO & 8 & 5 & 3 & & 1 & - & 17 \\
\hline FUNGICIDA & 31 & 23 & 11 & 9 & 4 & 10 & 80 \\
\hline DITOCAREAMATO & 4 & 5 & 4 & 1 & 1 & 1 & 16 \\
\hline TFlaZZIS & 5 & 5 & 2 & 3 & - & 2 & 17 \\
\hline BENIIMIDAZZOL & 3 & 3 & - & 2 & 2 & & 10 \\
\hline CUPRICO & 3 & 1 & 1 & 1 & 1 & 2 & 9 \\
\hline TFIAZOIS + ORGANOFOSFORADO & 7 & 1 & - & - & - & 3 & 11 \\
\hline REGULADORES & 7 & 10 & 10 & - & - & - & 27 \\
\hline CIAMAMDA & 7 & 10 & 10 & - & - & - & 27 \\
\hline DINUTROMMULINASS & & & & & - & - & 0 \\
\hline MISTURAS & 64 & 53 & 49 & 8 & 20 & 11 & 205 \\
\hline OUTROS & 154 & 162 & 148 & 85 & 61 & 43 & 653 \\
\hline TOTAL & 694 & 583 & 494 & 239 & 219 & 171 & 2.400 \\
\hline
\end{tabular}

Dentre os núcleos que compõe tal região, foi o núcleo regional de Londrina que apresentou o maior número de intoxicações, num total de 694 casos (28,9\%), representando o equivalente a 12,5\% (Anexo $\mathrm{H}$ ) das intoxicações ocorridas em todo o Estado, durante o período estudado. Os núcleos regionais de Cornélio Procópio, Maringá, Apucarana, Ivaiporã e 
Jacarezinho apresentaram percentuais de intoxicação iguais a 24,3\%, 20,6\%, $10 \%, 9,1 \%$ e $7,1 \%$, respectivamente (Anexo $\mathrm{H}$ ).

Como se observa claramente na Figura 23, nesta região a maior parte das intoxicações aconteceu através da exposição a inseticidas (42,5\%), enquanto que a classe dos herbicidas, fungicidas e reguladores, inferiu, respectivamente, percentuais de $17 \%, 3,7 \%$ e $1,1 \%$, do total de casos notificados (Anexo $\mathrm{H}$ ).

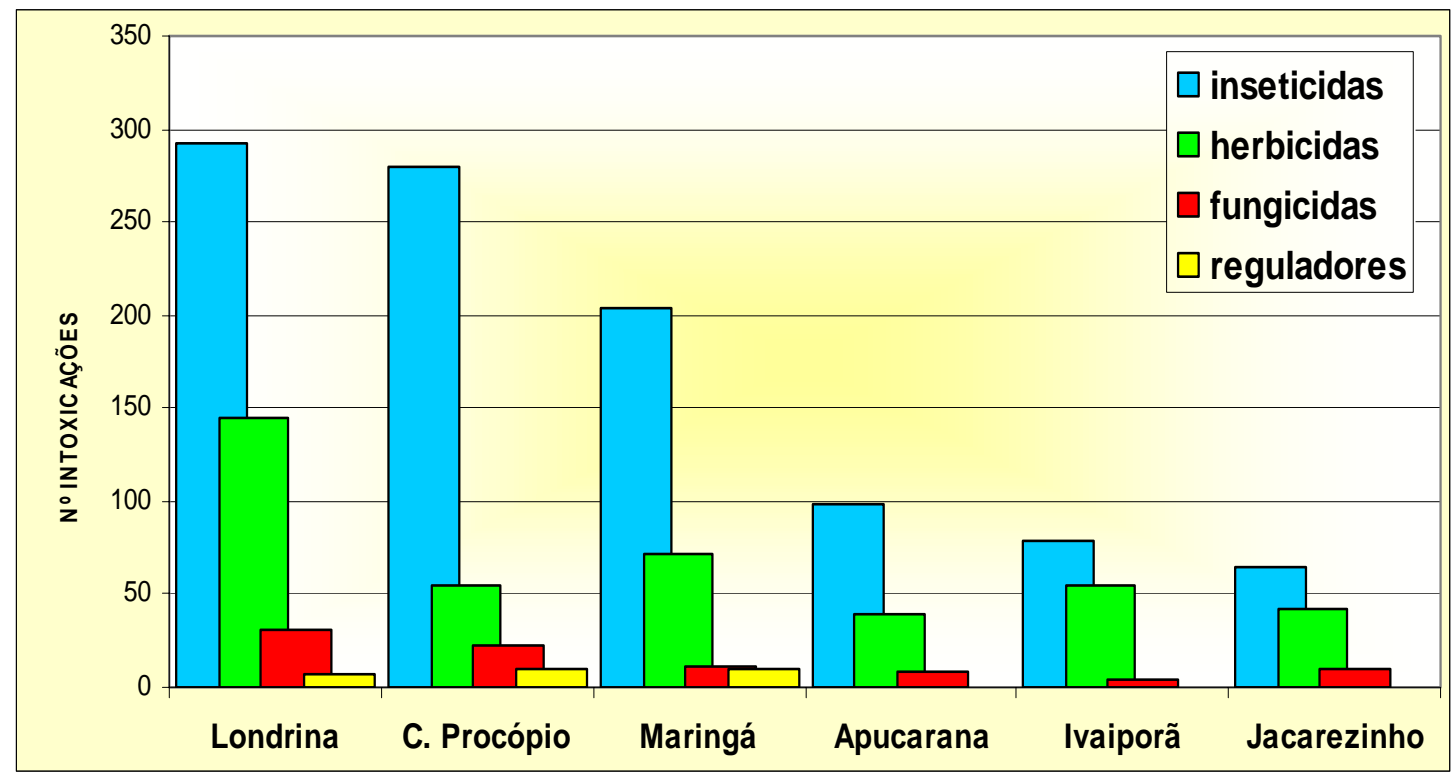

Figura 23 - Número de intoxicações nos núcleos regionais da região norte, segundo a classe dos agrotóxicos, durante o período de 1993 a 2000

Foram 17 os grupos químicos considerados como principais e relacionados no estudo, pois através destes se consumaram 53\% das intoxicações ocorridas no período estudado. Em dez destes grupos químicos (carbamatos, piretróides, organoclorados, derivados da glicina, fenoxiacético + 
derivados do ácido picolínico, fenoxiacético, triazóis, benzimidazóis, cúpricos e triazóis + organofosforados) o núcleo regional de Londrina deteve os maiores percentuais de intoxicações, quando comparado aos percentuais apresentados pelos mesmos grupos, nos demais núcleos regionais que compõe a região norte. O núcleo regional de Cornélio Procópio também obteve posição de destaque, tendo apresentado os maiores percentuais de intoxicação em 6 dos grupos químicos relacionados no estudo (organofosforados, éster do ASDC, ditiocarbamatos, triazóis, benzimidazóis e cianamida) (Anexo H).

No Anexo $\mathrm{H}$ pode-se observar que em todos os seis núcleos regionais analisados, os inseticidas pertencentes ao grupo químico dos organofosforados foram os principais responsáveis pela maioria das intoxicações, chegando a atingir índices bastante elevados, como foi o caso do N.R. Ivaiporã $(74,7 \%)$.

Importante observar que as intoxicações causadas por inseticidas pertencentes ao grupo químico dos organoclorados (Aldrin e BHC, na sua grande maioria), tiveram sua maior expressão no N.R. Londrina, onde representaram percentual de $41,7 \%$ em relação aos outros núcleos da região norte, e $25 \%$ dos casos, quando comparado aos demais núcleos que compõe o quadro geral do Estado (Anexo $\mathrm{H}$ ).

Chamou também a atenção a ocorrência do elevado número de intoxicações causadas pelos herbicidas pertencentes ao grupo químico dos bipiridílios (paraquat) no N.R. Ivaiporã, na sua quase totalidade tendo como causa a atividade profissional. Neste mesmo núcleo, o citado grupo químico atingiu o percentual de 46,7\% (Anexo $\mathrm{H}$ ) em relação ao total deste grupo na região norte, e 12,6\% em relação ao total do Estado, sendo superado apenas pelo N.R. de Pato Branco, que apresentou percentual global de 16,6\%. 
A classe dos herbicidas teve como principal causador de intoxicação o grupo químico dos derivados da glicina (54,7\%), seguido pelos bipiridílios $(14,7 \%)$, dinitroanilinas $(6,6 \%)$, fenoxiacético + derivados do ácido picolínico $(5,4 \%)$ e fenoxiacéticos (4,2\%) (Anexo H). À exceção do N.R. Ivaiporã, como foi dito anteriormente, nos demais núcleos regionais houve o prevalecimento dos derivados da glicina como principais agentes intoxicantes. Importante observar aqui, o ocorrido no N.R. Apucarana, onde as ocorrências relacionadas a este grupo químico atingiram o percentual de $74,4 \%$. Para se ter uma noção da dimensão deste evento, este foi o maior percentual de intoxicação obtido por um herbicida em qualquer das regiões avaliadas, durante o período estudado.

$\mathrm{Na}$ classe dos fungicidas, prevaleceram as intoxicações causadas pelos triazóis $(19,3 \%)$. Já os reguladores de crescimento inferiram o percentual de intoxicação igual a 1,1\%, sendo as cianamidas, o único grupo químico responsável pelas ocorrências (Anexo H).

\subsubsection{Região sul}

De modo análogo ao ocorrido na região norte, os percentuais de intoxicação, segundo a variável classe do agrotóxico, obedeceram ao mesmo ordenamento, porém em proporções diferentes. Nesta região, os inseticidas apresentaram percentual de $23,9 \%$, enquanto que os herbicidas, $22 \%$. Os fungicidas e reguladores, apresentaram, respectivamente, percentuais de 3,2 e 1,9 em relação ao total de casos notificados para a região (Tabela 18).

Dentro da classe dos inseticidas, os organofosforados foram os maiores responsáveis pelas intoxicações, inferindo a estes o percentual de $66,1 \%$ dos casos. Na classe dos herbicidas, o grupo químico dos bipiridílios foi 
o principal causador de intoxicações (38\% dos casos), diferenciando assim, do observado nas demais regiões componentes do Estado do Paraná (Anexo H), onde os herbicidas do grupo químico dos derivados da glicina predominaram. Dentro da classe dos fungicidas, o grupo químico dos ditiocarbamatos preponderou sobremaneira em relação aos demais grupos, tendo causado $72,2 \%$ das intoxicações (Tabela 18).

Tabela 18. Número de intoxicações entre os núcleos regionais da região sul, por classe e principais grupos químicos ocorridas durante o período de 1993 a 2000

\begin{tabular}{|c|c|c|c|c|c|c|c|c|}
\hline \multirow[b]{2}{*}{ CLASSE DE PRODUTO } & \multicolumn{7}{|c|}{ NÚCLEOS REGIONAIS } & \multirow[b]{2}{*}{ TOTAL } \\
\hline & Curitiba & Irati & $\begin{array}{l}\text { Uniăo da } \\
\text { Vitória }\end{array}$ & $\begin{array}{l}\text { Ponta } \\
\text { Grossa }\end{array}$ & Guarapuava & $\begin{array}{c}\text { Laranjeiras } \\
\text { do Sul }\end{array}$ & Paranaguá & \\
\hline INSETICIDA & 83 & 86 & 22 & 40 & 22 & 9 & 9 & 271 \\
\hline ORGANOFOSFORADO & 66 & 46 & 16 & 29 & 15 & 3 & 4 & 179 \\
\hline CAREMATO & 6 & 25 & 2 & 5 & 4 & 1 & 5 & 48 \\
\hline $\begin{array}{l}\text { PIRETRODE } \\
\text { PIDE }\end{array}$ & 5 & 6 & 1 & 3 & - & 1 & - & 16 \\
\hline ESTER DOASOC & - & . & - & . & - & . & - & 0 \\
\hline ORGANOCLORADO & 3 & . & 1 & 2 & 1 & 1 & - & 8 \\
\hline HERBICIDA & 65 & 44 & 27 & 28 & 40 & 39 & 7 & 250 \\
\hline DERIWADO DA GLCINM & 21 & 15 & 7 & 9 & 7 & 15 & 4 & 78 \\
\hline EIFIFIILIOS & 26 & 13 & 9 & 14 & 21 & 11 & 1 & 95 \\
\hline 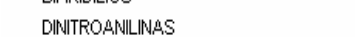 & 4 & 6 & 5 & 1 & 21 & . & - & 16 \\
\hline FENOX|ACETICO + DER. AC. FICOLINICO & 1 & . & - & 1 & - & 3 & - & 5 \\
\hline FENOX|MCETTCO & 4 & 1 & - & . & - & 2 & 1 & $\theta$ \\
\hline $\begin{array}{l}\text { FUNGICIDA } \\
\text { Fus }\end{array}$ & 13 & 3 & 11 & - & 4 & 1 & 4 & 36 \\
\hline DITOCAREAMATO & 8 & 2 & 11 & . & - & 1 & 4 & 26 \\
\hline TFIALZIS & - & . & - & . & 1 & . & - & 1 \\
\hline EENIMMIOAZOL & - & . & - & . & - & . & - & 0 \\
\hline Cuprico & 1 & 1 & - & . & - & . & - & 2 \\
\hline TFIAZOLS + ORGMNOFOSFORADO & - & - & - & & - & . & & 0 \\
\hline REGULADORES & 11 & 8 & 1 & - & - & 1 & - & 21 \\
\hline CIMNAMAM & - & & - & . & - & . & - & 0 \\
\hline DINUITROANULINUS & 11 & 8 & 1 & - & - & 1 & - & 21 \\
\hline MISTURAS & 25 & 21 & 134 & 9 & 7 & 6 & 3 & 205 \\
\hline OUTROS & 129 & 64 & 31 & 51 & 39 & 24 & 14 & 352 \\
\hline TOTAL & 326 & 226 & 226 & 128 & 112 & 80 & 37 & 1.135 \\
\hline
\end{tabular}

O predomínio dos inseticidas, como principal agente de intoxicação, ocorreu nos núcleos regionais de Curitiba, Irati, Ponta Grossa e Paranaguá, ao passo que nos núcleos regionais de União da Vitória, Guarapuava e Laranjeiras 
do Sul, a classe dos herbicidas prevaleceu como o principal agente de intoxicações (Tabela 18).

Nesta região, o N.R. Curitiba foi o que apresentou o maior número de intoxicações (326 casos), o equivalente a $28,6 \%$ do total de intoxicações da região sul, enquanto que o N.R. Paranaguá, apresentou o menor percentual $(3,5 \%)$.

Aspecto interessante ocorreu no N.R. União da Vitória, que apresentou o maior percentual de intoxicação na classe misturas, o equivalente a $21,2 \%$ do total de ocorrências registradas para esta classe em todo o Estado (Anexo H). Nesta classe, este regional exibiu um percentual de 59,3\% em relação às demais classes avaliadas (Anexo $H$ ) e 65,4\% quando confrontado com os demais núcleos que compõe a região sul (Tabela 18).

\subsubsection{Região centro-oeste}

Esta região, composta apenas pelo N.R. Campo Mourão apresentou o segundo maior número de intoxicações do Estado, num total de 676 ocorrências $(12,1 \%)$ (Tabela 19, Anexo H). Nesta, os agrotóxicos pertencentes à classe dos inseticidas predominaram como os maiores agentes intoxicantes, conferindo a estes o percentual de $43,8 \%$ em relação às demais classes avaliadas. 
Tabela 19. Número de intoxicações entre os núcleos regionais das regiões centro-oeste e oeste, por classe e principais grupos químicos ocorridas durante o período de 1993 a 2000

\begin{tabular}{|c|c|c|c|c|c|}
\hline \multirow{2}{*}{ CLASSE DE PRODUTO } & \multicolumn{2}{|c|}{ REGIÃO CENTRO-OESTE } & \multicolumn{2}{|c|}{ REGIÄO OESTE } & \multirow[b]{2}{*}{ TOTAL } \\
\hline & Campo Mourão & TOTAL & Cascavel & Toledo & \\
\hline INSETICIDA & 296 & 296 & 111 & 82 & 193 \\
\hline ORGANOFOSFORADO & 173 & 173 & 85 & 56 & 141 \\
\hline CAREMMATO & 33 & 33 & 7 & 11 & 18 \\
\hline PIRETROIDE & 26 & 26 & 8 & 7 & 15 \\
\hline ESTER DO ASDC & 42 & 42 & 5 & 3 & 8 \\
\hline ORGANOCLORADO & 1 & 1 & 1 & 3 & 4 \\
\hline HERBICIDA & 67 & 67 & 96 & 28 & 124 \\
\hline DERIYADO DA GLICINA & 24 & 24 & 39 & 12 & 51 \\
\hline EIFIFIDILIOS & 10 & 10 & 12 & 5 & 17 \\
\hline DINUTROMANLINAS & 15 & 15 & 6 & 2 & 8 \\
\hline FENOKIACETICO + DER. AC. FICOLINICO & 2 & 2 & 25 & 2 & 27 \\
\hline FENOKIACETICO & 4 & 4 & 6 & 2 & 8 \\
\hline FUNGICIDA & 11 & 11 & 2 & 3 & 5 \\
\hline DITIOCAREAMATO & 1 & 1 & - & - & 0 \\
\hline TRlAZZZIS & 5 & 5 & - & 2 & 2 \\
\hline EENZZIMID,AZZLL & 1 & 1 & 2 & - & 2 \\
\hline CLPRICO & 1 & 1 & - & - & 0 \\
\hline TFIAZZIS + OROANOFOSFORADO & 1 & 1 & - & - & 0 \\
\hline REGULADORES & - & - & - & - & 0 \\
\hline CMNAMDA & - & - & - & - & 0 \\
\hline DINUTROANULINAS & - & - & - & - & 0 \\
\hline MISTURAS & 63 & 63 & 36 & 45 & 81 \\
\hline OUTROS & 239 & 239 & 112 & 57 & 169 \\
\hline TOTAL & 676 & 676 & 357 & 215 & 572 \\
\hline
\end{tabular}

As classes dos herbicidas e fungicidas apresentaram percentuais de intoxicação iguais a 9,9\% e 1,6\%, respectivamente. Nesta região não ocorreram intoxicações resultantes da exposição a reguladores de crescimento.

$\mathrm{Na}$ classe dos inseticidas houve o predomínio de intoxicações decorrentes do uso de organofosforados (58,4\%), enquanto na dos herbicidas prevaleceu os derivados da glicina (35,8\%). Já na classe dos fungicidas, os agrotóxicos pertencentes ao grupo químico dos triazóis foram os principais agentes intoxicantes, inferindo a estes o percentual de $45,5 \%$ em relação aos demais fungicidas avaliados. 


\subsubsection{Região oeste}

A região oeste respondeu por $10,3 \%$ do total de intoxicações ocorridas no Estado durante o período referente ao presente estudo (Anexo H). Nesta, a maioria das intoxicações foi resultante da exposição a agrotóxicos da classe inseticida (33,7\%), em especial aos organofosforados, que representaram $73,1 \%$ dos casos notificados (Tabela 19). Os herbicidas representaram $21,7 \%$ dos casos de intoxicação, tendo sido os produtos pertencentes ao grupo químico dos derivados da glicina os principais responsáveis pelo maior percentual de intoxicações $(41,1 \%)$. Nesta região do Estado os fungicidas foram responsáveis por apenas 0,9\% dos casos de intoxicação; saliente-se que para a classe dos fungicidas, este percentual foi o menor dentre os obtidos nas demais regiões estudadas. À semelhança do ocorrido na região centro-oeste, nesta região do estado também não foram registrados casos de intoxicação pela exposição a reguladores de crescimento.

\subsubsection{Região noroeste}

A região noroeste representou $10 \%$ dos casos de intoxicação notificados para o Estado (Anexo $\mathrm{H}$ ). Nesta, os inseticidas foram os principais causadores de intoxicação, representando $49,6 \%$ dos casos, enquanto que os herbicidas representaram $8,6 \%$ e os fungicidas 1,3\% (Tabela 20). De modo análogo ao ocorrido nas regiões oeste e centro-oeste, também não foram registradas intoxicações decorrentes da exposição a reguladores de crescimento. 
Os inseticidas organofosforados, herbicidas derivados da glicina e fungicidas triazóis foram os grupos químicos onde figuraram os maiores percentuais de intoxicação, em suas respectivas classes.

Tabela 20. Número de intoxicações entre os núcleos regionais das regiões noroeste e sudoeste, por classe e principais grupos químicos, ocorridas durante o período de 1993 a 2000

\begin{tabular}{|c|c|c|c|c|c|c|}
\hline \multirow{3}{*}{ CLASSE DE PRODUTO } & \multirow{2}{*}{\multicolumn{2}{|c|}{ REGIÄO NOROESTE }} & \multirow[b]{3}{*}{ TOTAL } & \multirow{2}{*}{\multicolumn{2}{|c|}{$\begin{array}{l}\text { REGIÃO SUDOSTE } \\
\text { Pato } \quad \text { Francisco }\end{array}$}} & \multirow[b]{3}{*}{ TOTAL } \\
\hline & & & & & & \\
\hline & Paranavaí & Umuarama & & Branco & Beltrăo & \\
\hline INSETICIDA & 151 & 126 & 277 & 30 & 27 & 57 \\
\hline ORGANOFOSFORADO & 77 & 59 & 136 & 22 & 21 & 43 \\
\hline CAREMMATO & 18 & 11 & 29 & 2 & 1 & 3 \\
\hline PIRETROIDE & 20 & 19 & 39 & 2 & 1 & 3 \\
\hline ESTER DO ASOC & 17 & 21 & 38 & - & 1 & 1 \\
\hline ORGANOCLORADO & 8 & 9 & 17 & 2 & - & 2 \\
\hline HERBICIDA & 31 & 17 & 48 & 85 & 15 & 100 \\
\hline DERIVADOOAM GLINNA & 15 & 7 & 22 & 33 & 7 & 40 \\
\hline EIPIRIDLIOS & 1 & 1 & 2 & 37 & 2 & 39 \\
\hline DINUTROMNULINAS & 3 & 2 & 5 & 1 & 2 & 3 \\
\hline FENOXIACETICO + DER. AC. FICOLINICO & 5 & 4 & 9 & 4 & 1 & 5 \\
\hline FENOKIACETCO & & & 0 & 2 & 1 & 3 \\
\hline FUNGICIDA & 3 & 4 & 7 & 4 & - & 4 \\
\hline DITOCAREAMATO & & & 0 & 1 & - & 1 \\
\hline TFild.7015 & 1 & 2 & 3 & 1 & - & 1 \\
\hline EENZIMMDAZZLL & - & & 0 & 2 & - & 2 \\
\hline CUPRICO & 1 & 1 & 2 & - & - & a \\
\hline TRIAZZOS + ORGANOFOSFORADO & - & 1 & 1 & - & - & 0 \\
\hline REGULADORES & - & - & 0 & 1 & 2 & 3 \\
\hline CINAMDM & - & - & 0 & - & & a \\
\hline DINUTROANULINAS & - & - & 0 & 1 & 2 & 3 \\
\hline MISTURAS & 22 & 39 & 61 & 15 & 1 & 16 \\
\hline OUTROS & 90 & 75 & 165 & 27 & 24 & 51 \\
\hline TOTAL & 297 & 261 & 558 & 162 & 69 & 231 \\
\hline
\end{tabular}

\subsubsection{Região sudoeste}

As intoxicações ocorridas na região sudoeste foram responsáveis por 4,1\% do total apurado para o Estado do Paraná, portanto, o menor percentual dentre as regiões (Anexo $\mathrm{H}$ ). Nesta, diferente das demais estudadas, a classe dos inseticidas, que atingiu $24,7 \%$ dos casos, não acumulou o maior percentual de intoxicações, este atributo coube à classe dos herbicidas, que redundou em 
43,3\% das intoxicações ocorridas, tendo tais intoxicações se concentrado nos grupos químicos referentes aos derivados da glicina e bipiridílios, que inferiram, dentro desta classe de agrotóxicos, percentuais iguais a $40 \%$ e $39 \%$, respectivamente (Anexo $\mathrm{H}$ ). Os fungicidas e reguladores foram responsáveis por $1,7 \%$ e $1,3 \%$ dos casos, respectivamente. Importante salientar que os núcleos regionais que compõe esta região, a saber, Pato Branco e Francisco Beltrão, apresentaram comportamento distinto quanto a distribuição dos casos de intoxicação entre as classes de agrotóxicos estudadas. No N.R. Pato Branco a maioria das intoxicações se concentrou na classe dos herbicidas (52,5\%), em especial os do grupo dos bipiridílios (43,5\%), ao passo que no N.R. Francisco Beltrão o maior número de intoxicações se deu principalmente na classe dos inseticidas $(39,1 \%)$, mais precisamente no grupo dos organofosforados $(77,8 \%)$. Este comportamento díspar pode ser claramente observado na Figura 24.

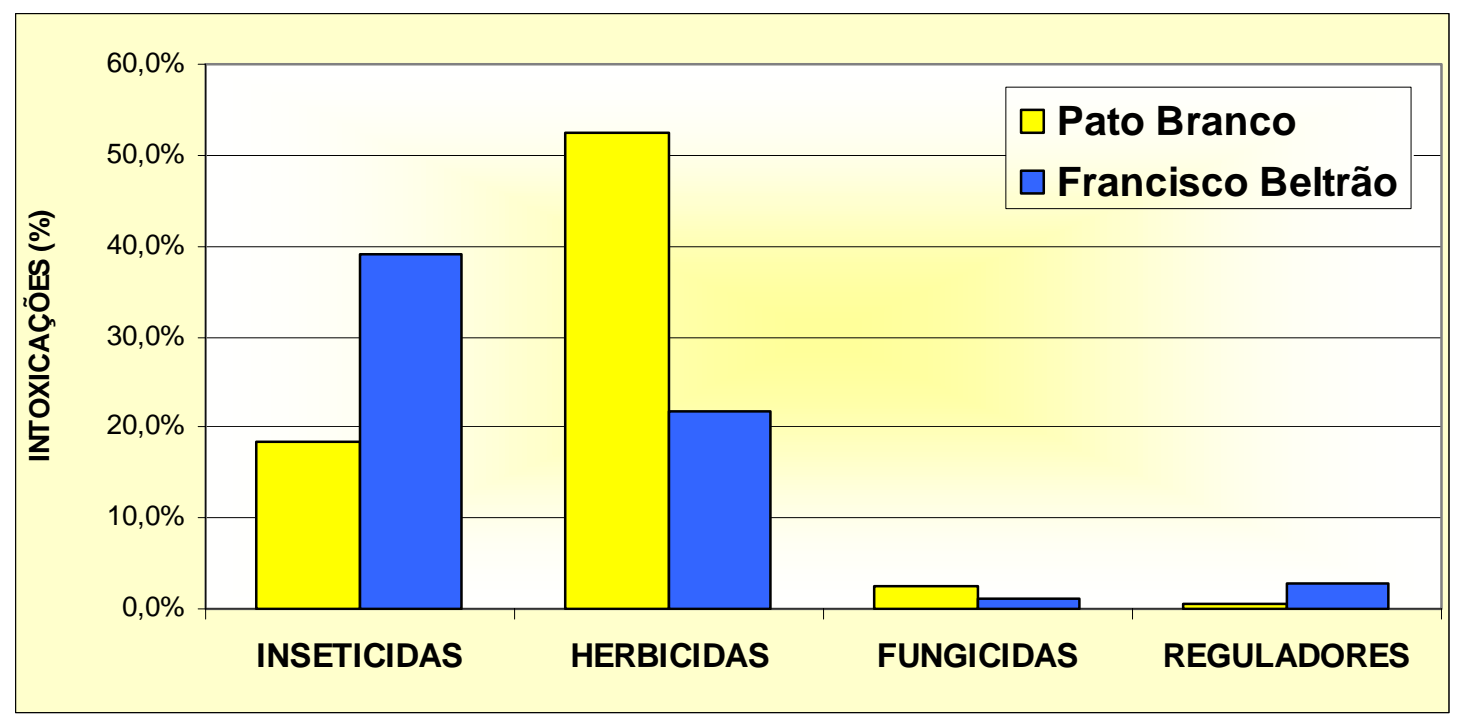

Figura 24 - Percentual das intoxicações segundo a classe dos agrotóxicos, na região sudoeste, durante o período de 1993 a 2000 


\subsection{2 Óbitos segundo as classes e principais grupos químicos dos agrotóxicos, dentro das regiões e núcleos regionais}

As ocorrências de intoxicação que se consumaram em casos de óbito tiveram, durante o decorrer do período analisado, uma evolução semelhante àquela apresentada para o total de casos de intoxicação, como se pode observar na Figura 25. No ano de 1993 foi quando ocorreu o maior número de óbitos, 106 casos (16,8\%), enquanto que o menor número (62 casos) ocorreu no ano de 1998 (Tabela 21).

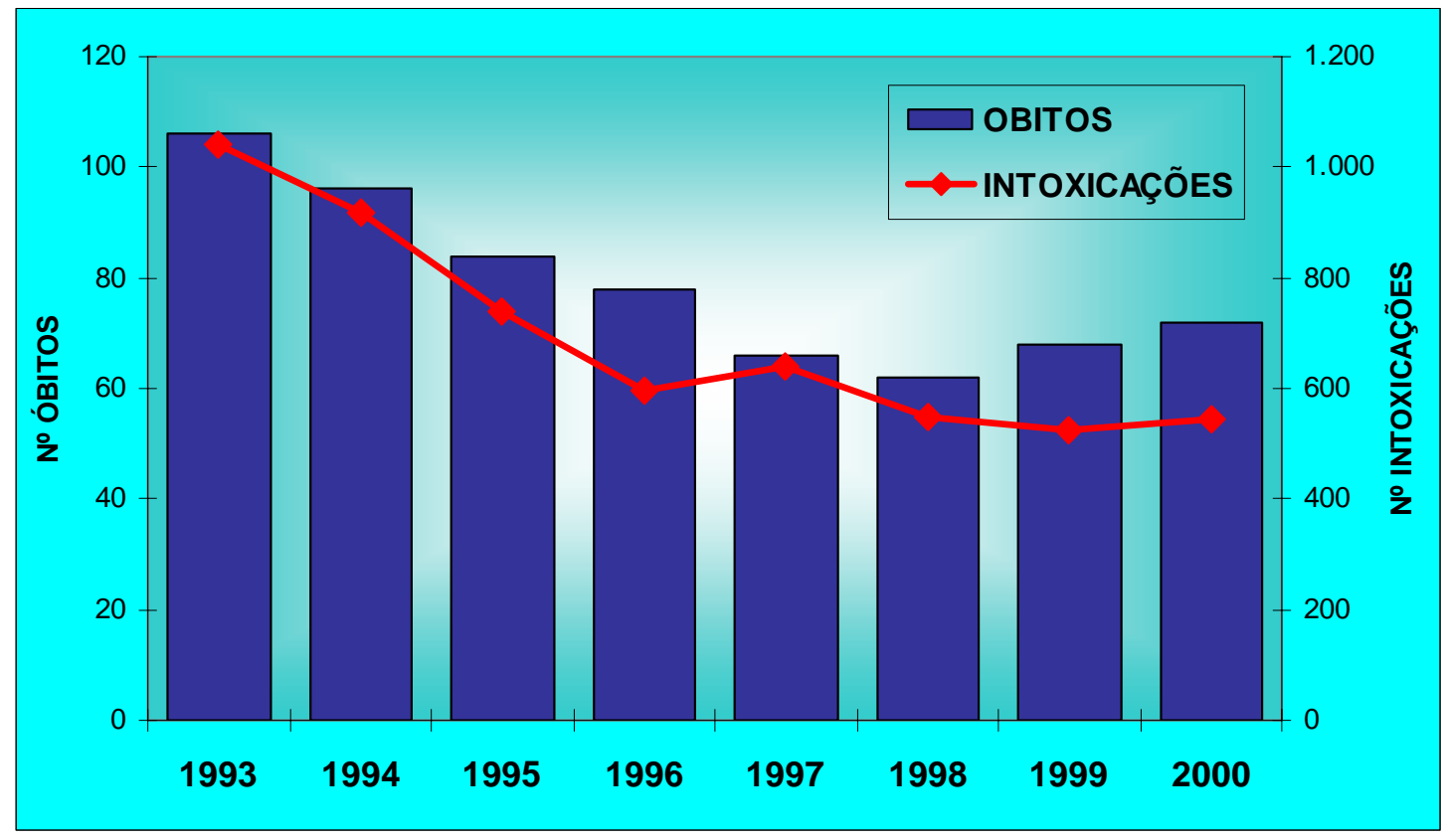

Figura 25 - Evolução dos casos de intoxicação e óbito, durante os anos de 1993 a 2000

A maior parte dos óbitos teve como agente causador os Inseticidas $(42,2 \%)$, enquanto que os herbicidas foram responsáveis por $16,8 \%$ dos casos, os fungicidas $0,3 \%$ e os reguladores de crescimento $0,5 \%$ (Tabela 21). 
Desconsiderando as categorias misturas e outros, ter-se-ia os óbitos sido causados por inseticidas, herbicidas, fungicidas e reguladores nas proporções respectivas de 70,6\%, 28,0\%, 0,5\% e 0,8\%. Em todos os anos avaliados, os Inseticidas prevaleceram em relação às demais classes de agrotóxicos, como o principal agente responsável pelos óbitos, tendo sido os inseticidas organofosforados o principal grupo químico, em qualquer dos anos estudados (Tabela 21). Os organofosforados foram responsáveis, dentro da classe dos inseticidas, por $77,2 \%$ dos óbitos ocorridos. Já na classe dos herbicidas, predominaram os óbitos decorrentes do uso dos bipiridílios (62,3\%), ficando os herbicidas pertencentes ao grupo químico dos derivados da glicina relegados ao segundo lugar. A categoria outros foi responsável por um total de 230 casos, o equivalente a $36,4 \%$ do total de óbitos apurados para o período analisado.

Dos 632 óbitos registrados no período estudado, a maior parte se deu na região norte (37\%). As regiões sul, centro-oeste, oeste, noroeste e sudoeste apresentaram, respectivamente, percentuais iguais a 22\%, 17\%, 10\%, 9\% e $6 \%$, com relação ao total apurado para o Estado (Anexo I).

Os Núcleos Regionais de Campo Mourão, Cornélio Procópio, Ivaiporã, Cascavel e Guarapuava, tendo apresentado, respectivamente, número de óbitos iguais a 105, 78, 57, 38 e 37, representaram, em relação ao total de casos registrados no Estado, percentual equivalente a 49,8\% (Anexo I). Com exceção do N.R. Guarapuava, onde prevaleceram os óbitos relacionados aos agrotóxicos da classe herbicida (bipiridílios, em especial), nos demais predominaram os óbitos determinados pelo uso de agrotóxicos Inseticidas, sendo que em todos houve o predomínio do grupo químico dos organofosforados. 
Tabela 21. Número de óbitos, segundo as classes e principais grupos químicos dos agrotóxicos, ocorridos durante os anos de 1993 a 2000

\begin{tabular}{|c|c|c|c|c|c|c|c|c|c|}
\hline \multirow{2}{*}{ CLASSE DE PRODUTO } & \multicolumn{8}{|c|}{ ANO } & \multirow{2}{*}{ TOTAL } \\
\hline & 1993 & 1994 & 1995 & 1996 & 1997 & 1998 & 1999 & 2000 & \\
\hline INSETICIDA & 32 & 41 & 36 & 35 & 31 & 26 & 40 & 26 & 267 \\
\hline ORGANOFOSFORADO & 19 & 30 & 24 & 30 & 24 & 24 & 32 & 23 & 206 \\
\hline CAREMMTO & & 3 & 3 & - & - & 1 & 1 & - & 8 \\
\hline FIRETROIDE & 1 & - & 3 & - & 1 & - & - & - & 5 \\
\hline ESTER DO ASOC & 8 & 6 & 5 & 4 & 4 & 1 & 5 & 3 & 36 \\
\hline ORGANOCLORADO & 2 & - & - & 1 & 1 & - & 1 & - & 5 \\
\hline HERBICIDA & 11 & 11 & 16 & 17 & 12 & 11 & 13 & 15 & 106 \\
\hline DEFIVADO DA GLIOINA & - & 2 & 2 & 2 & 2 & 1 & 3 & 4 & 16 \\
\hline EPRR:DLLOS & 10 & 8 & 12 & 12 & 8 & 4 & 3 & 9 & 66 \\
\hline DINITROMNULINAS & - & 1 & - & 2 & 1 & 1 & 1 & - & 6 \\
\hline FENOK|ACETCO + DER AC. FICOLINICO & - & - & - & - & 1 & 5 & 2 & 1 & 9 \\
\hline FENOXIACETICO & - & - & - & - & - & - & 1 & - & 1 \\
\hline FUNGICIDA & - & 1 & - & 1 & - & . & - & - & 2 \\
\hline DITOCAREAMATO & - & 1 & - & - & - & - & - & - & 1 \\
\hline TRIAZOIS & - & - & - & - & - & - & - & - & - \\
\hline EENZZMMID,AZOL & & - & - & 1 & - & - & - & - & 1 \\
\hline CUPRICO & - & - & - & - & - & - & - & - & - \\
\hline TRIAZZOS + ORGANOFOSFORADO & - & - & & - & - & - & - & - & - \\
\hline REGULADORES & - & - & 1 & - & 1 & - & 1 & - & $\mathbf{3}$ \\
\hline CMNAMA & - & - & 1 & - & 1 & - & - & - & 2 \\
\hline DINUTROANMLINAS & - & - & - & - & - & - & 1 & - & 1 \\
\hline MISTURAS & 3 & 3 & 5 & 5 & 3 & - & 2 & 3 & 24 \\
\hline OUTROS & 60 & 40 & 26 & 20 & 19 & 25 & 12 & 28 & 230 \\
\hline TOTAL & 106 & 96 & 84 & 78 & 66 & 62 & 68 & 72 & 632 \\
\hline
\end{tabular}

\subsection{3 Óbitos segundo as classes e principais grupos químicos dos agrotóxicos, entre as classes de idade e sexo}

Quando a classe analisada foi a inseticida, com exceção das classes de idade, 6 a 11 anos e ignorado, nas demais classes houve o predomínio dos organofosforados como principal agente causador de óbitos, tendo este grupo químico vitimado 55 mulheres e 151 homens. Já na classe dos herbicidas prevaleceram os agrotóxicos do grupo dos bipiridílios, que causaram a morte de 13 mulheres e 53 homens. O grupo químico do organofosforados causou o maior número de mortes na classe de idade compreendida entre 18 e 23 anos, já os bipiridílios, na faixa de idade entre 30 e 35 anos. Tais grupos causaram, 
nas respectivas faixas de idade, 32 (organofosforados) e 14 (bipiridílios) óbitos (Anexo J).

Importante observar o fato de que os agrotóxicos pertencentes ao grupo químico dos bipiridílios (agrotóxicos a base dos princípios ativos paraquat e diquat), que causaram, no período estudado, o equivalente a 223 intoxicações (Anexo E) e conseqüentes 66 óbitos, tinham à época, por força da Portaria Ministerial $n^{0}$ 329/85, seu comércio submetido à emissão de um documento denominado "Guia de Aplicação - Venda aplicada" que, acompanhado do Receituário Agronômico, restringia a aplicação deste grupo, e de suas combinações a outros princípios ativos, mediante ao acompanhamento de um técnico responsável (engenheiro agrônomo), devidamente cadastrado (Registro de Prestador de Serviços Fitossanitários, emitido pela SEAB) para tal fim, junto a firma vendedora de tais agrotóxicos. Consideradas as intoxicações causadas por estes agrotóxicos, qualquer que fossem suas causas de contaminação, ou motivações, fica patente, à semelhança do que ocorre por longa data ao Receituário Agronômico, a ineficácia da citada Portaria no que tange ao controle e utilidade da aplicação de tais produtos. Atualmente por força de uma avaliação jurídica, que ocorreu após a reavaliação toxicológica sofrida pelos bipiridílios (Gramoxone 200, Gramocil e Reglone; nomes comerciais) nos Ministérios da Saúde e Agricultura, quando passaram da classe toxicológica I para a III, estes deixaram de ter sua venda condicionada a aplicação acompanhada. 


\section{CONCLUSÕES}

A ocorrência de intoxicações esteve relacionada ao cultivo de culturas de inverno, verão, frutíferas e olerícolas.

O acesso fácil, associado ao armazenamento inadequado dos agrotóxicos, assim como a participação prematura em atividades agrícolas resultou na ocorrência de intoxicações e óbitos em indivíduos menores de idade.

O Receituário agronômico associado a Guia de aplicação para a aquisição de agrotóxicos sujeitos à venda aplicada, não impediram a ocorrência de intoxicações e óbitos causados por herbicidas bipiridílios. 


\section{Sugestões de medidas futuras}

Medidas fiscalizatórias devem ser implementadas pelos órgãos competentes visando coibir a participação de menores em atividades insalubres, como aquelas relacionadas ao uso de agrotóxicos.

A prescrição e armazenagem de produtos agrotóxicos, assim como a fiscalização destas duas etapas pelos órgãos correlatos, deve ser mais intensa e criteriosa visando minimizar intoxicações de caráter acidental e suicida, principalmente entre crianças. 
ANEXOS 


\section{Anexo A. Relação dos municípios que compõe os núcleos regionais da SEAB}

\begin{tabular}{|c|c|c|c|}
\hline N.R. Apucarana & \multirow[b]{2}{*}{ MARILANDIA DO SUL } & N.R. Cascavel & \multirow[b]{2}{*}{ ITAIPULANDIA } \\
\hline APUCARANA & & ANAHY & \\
\hline ARAPONGAS & MARUMBI & BOA VISTA DA APARECIDA & LINDOESTE \\
\hline BOM SUCESSO & MAUA DA SERRA & BRAGANEY & MATELANDIA \\
\hline CALIFORNIA & NOVO ITACOLOMI & CAFELANDIA & MEDIANEIRA \\
\hline CAMBIRA & RIO BOM & CAMPO BONITO & MISSAL \\
\hline JANDAIA DO SUL & SABAUDIA & CAP. LEONIDAS MARQUES & NOVA AURORA \\
\hline \multicolumn{2}{|l|}{ KALORE } & CASCAVEL & RAMILANDIA \\
\hline N.R. Campo Mourão & & CATANDUVAS & SANTA LUCIA \\
\hline ALTAMIRA DO PARANA & JURANDA & CEU AZUL & SANTA TEREZA DO OESTE \\
\hline ARARUNA & LUIZIANA & CORBELIA & SANTA TEREZINHA DO ITAIPU \\
\hline BARBOSA FERRAZ & MAMBORE & DIAMANTE D'OESTE & SAO MIGUEL DO IGUACU \\
\hline BOA ESPERANCA & MOREIRA SALES & FOZ DO IGUACU & SERRANOPOLIS DO IGUACU \\
\hline CAMPINA DA LAGOA & NOVA CANTU & IBEMA & TRES BARRAS DO PARANA \\
\hline CAMPO MOURAO & PEABIRU & IGUATU & VERA CRUZ DO OESTE \\
\hline CORUMBATAI DO SUL & QUARTO CENTENARIO & N.R.Cornélio Procópio & \\
\hline ENGENHEIRO BELTRAO & QUINTA DO SOL & ABATIA & RANCHO ALEGRE \\
\hline FAROL & RANCHO ALEGRE DO OESTE & ANDIRA & RIBEIRAO DO PINHAL \\
\hline FENIX & RONCADOR & ASSAI & SANTA AMELIA \\
\hline GOIOERE & TERRA BOA & BANDEIRANTES & SANTA CECILIA DO PAVAO \\
\hline IRETAMA & UBIRATA & CONGONHINHAS & SANTA MARIANA \\
\hline \multicolumn{2}{|l|}{ JANIOPOLIS } & CORNELIO PROCOPIO & SANTO ANTONIO DO PARAISO \\
\hline N.R. Pato Branco & & ITAMBARACA & SAO JERONIMO DA SERRA \\
\hline BOM SUCESSO DO SUL & MARIOPOLIS & JATAIZINHO & SAO SEBASTIAO AMOREIRA \\
\hline CHOPINZINHO & PALMAS & LEOPOLIS & SAPOPEMA \\
\hline CLEVELANDIA & PATO BRANCO & NOVA AMERICA DA COLINA & SERTANEJA \\
\hline \multicolumn{2}{|c|}{ CORONEL DOMINGOS SOAF SAO JOAO } & NOVA FATIMA & URAI \\
\hline CORONEL VIVIDA & SAUDADES DO IGUACU & NOVA SANTA BARBARA & \\
\hline HONORIO SERPA & SULINA & N.R. Guarapuava & \\
\hline ITAPEJARA DO OESTE & VITORINO & CAMPINA DO SIMAO & LARANJAL \\
\hline \multicolumn{2}{|l|}{ MANGUEIRINHA } & CANDOI & PALMITAL \\
\hline N.R. Curitiba & & CANTAGALO & PINHAO \\
\hline A.DRIANOPOLIS & FAZENDA RIO GRANDE & FOZ DO JORDAO & PRUDENTOPOLIS \\
\hline AGUDOS DO SUL & ITAPERUCU & GOIOXIM & RESERVA DO IGUACU \\
\hline \multirow{2}{*}{$\begin{array}{l}\text { ALMIRANTE TAMANDARE } \\
\text { ARAUCARIA }\end{array}$} & \multirow{2}{*}{$\begin{array}{l}\text { LAPA } \\
\text { MANDIRITUBA }\end{array}$} & GUARAPUAVA & TURVO \\
\hline & & N.R. Irati & \\
\hline BALSA NOVA & PIEN & FERNANDES PINHEIRO & MALLEET \\
\hline BOCAIUVA DO SUL & PINHAIS & GUAMIRANGA & REBOUCAS \\
\hline CAMPINA GRANDE DO SUL & PIRAQUARA & IMBITUVA & RIO AZUL \\
\hline CAMPO DO TENENTE & QUATRO BARRAS & INACIO MARTINS & TEIXEIRA SOARES \\
\hline \multirow{2}{*}{$\begin{array}{l}\text { CAMPO LARGO } \\
\text { CAMPO MAGRO }\end{array}$} & \multirow{2}{*}{$\begin{array}{l}\text { QUITANDINHA } \\
\text { RIO BRANCO DO SUL }\end{array}$} & IRATI & \\
\hline & & N.R. Jacarezinho & \\
\hline CERRO AZUL & RIO NEGRO & BARRA DO JACARE & JUNDIAI DO SUL \\
\hline COLOMBO & SAO JOSE DOS PINHAIS & CAMBARA & PINHALAO \\
\hline CONTENDA & TIJUCAS DO SUL & CARLOPOLIS & QUATIGUA \\
\hline CURITIBA & TUNAS DO PARANA & CONSELHEIRO MAIRINCK & RIBEIRAO CLARO \\
\hline \multicolumn{2}{|l|}{ DOUTOR ULYSSES } & CURIUVA & SALTO DO ITARARE \\
\hline N.R. Francisco Beltrão & & FIGUEIRA & SANTANA DO ITARARE \\
\hline AMPERE & NOVA PRATA DO IGUACU & GUAPIRAMA & SANTO ANTONIO DA PLATINA \\
\hline BARRACAO & PEROLA DO OESTE & IBAITI & SAO JOSE DA BOA VISTA \\
\hline BELA VISTA DA CAROBA & PINHAL DE SAO BENTO & JABOTI & SIQUEIRA CAMPOS \\
\hline \multicolumn{2}{|c|}{ BOA. ESPERANCA DO IGUACPLANALTO } & JACAREZINHO & TOMAZINA \\
\hline BOM JESUS DO SUL & PRANCHITA & JAPIRA & WENCESLAU BRAZ \\
\hline \multirow{2}{*}{$\begin{array}{l}\text { CAPANEMA } \\
\text { CRUZEIRO DO IGUACU }\end{array}$} & \multirow{2}{*}{$\begin{array}{l}\text { REALEZA } \\
\text { RENASCENCA }\end{array}$} & JOAQUIM TAVORA & \\
\hline & & N.R. Laranjeiras do Sul & \\
\hline DOIS VIZINHOS & SALGADO FILHO & DIAMANTE DO SUL & NOVA LARANJJEIRAS \\
\hline ENEAS MARQUES & SALTO DO LONTRA & ESPIGAO ALTO DO IGUACU & PORTO BARREIRO \\
\hline FLOR DA SERRA DO SUL & SANTA IZABEL DO OESTE & GUARANIACU & QUEDAS DO IGUACU \\
\hline FRANCISCO BELTRAO & SANTO ANTONIO DO SUDOESTE & LARANJEIRAS DO SUL & RIO BONITO DO IGUACU \\
\hline MANFRINOPOLIS & SAO JORGE DO OESTE & MARQUINHO & VIRMOND \\
\hline & VERE & & \\
\hline NOVA ESPERANCA SUDOE: & ESTE & & \\
\hline
\end{tabular}




\section{Anexo A. Relação dos municípios que compõe os núcleos regionais da SEAB}

\begin{tabular}{|c|c|c|c|}
\hline \multicolumn{2}{|l|}{ N.R. Paranavaí } & \multicolumn{2}{|l|}{ N.R. Maringá } \\
\hline ALTO PARANA & PARANAPOEMA & ANGULO & MARIALVA \\
\hline AMAPORA & PARANAVAI & ASTORGA & MARINGA \\
\hline CRUZEIRO DO SUL & PLANALTINA DO PARANA & ATALAIA & MUNHOZ DE MELO \\
\hline DIAMANTE DO NORTE & PORTO RICO & COLORADO & NOSSA SENHORA DAS GRACAS \\
\hline GUAIRACA & QUERENCIA DO NORTE & DOUTOR CAMARGO & NOVA ESPERANCA \\
\hline INA,JA & SANTA CRUZ MONTE CASTELO & FLORAI & OURIZONA \\
\hline ITAUNA DO SUL & SANTA IZABEL DO IVAI & FLORESTA & PAICANDU \\
\hline JARDIM OLINDA & SANTA MONICA & FLORIDA & PRESIDENTE CASTELO BRANCO \\
\hline LOANDA & SANTO ANTONIO DO CAIUA & IGUARACU & SANTAFE \\
\hline MARILENA & SAO CARLOS DO IVAI & ITAGUAJJE & SANTA INES \\
\hline MIRADOR & SAO JOAO DO CAIUA & ITAMBE & SANTO INACIO \\
\hline NOVA ALIANCA DO IVAI & SAO PEDRO DO PARANA & IVATUBA & SAO JORGE DO IVAI \\
\hline NOVA LONDRINA & TAMBOARA & LOBATO & SARANDI \\
\hline PARAISO DO NORTE & TERRA RICA & MANDAGUACU & UNIFLOR \\
\hline \multicolumn{2}{|l|}{ PARANACITY } & \multicolumn{2}{|l|}{ MANDAGUARI } \\
\hline N.R. Ivaiporã & & N.R. Londrina & \\
\hline ARAPUAN & LIDIANOPOLIS & ALVORADA DO SUL & LUPIONOPOLIS \\
\hline ARIRANHA DO IVAI & LUNARDELLI & BELA VISTA DO PARAISO & MIRASELVA \\
\hline \multicolumn{2}{|c|}{ BOA VENTURA DE SAO ROG MANOEL RIBAS } & CAFEARA & PITANGUEIRAS \\
\hline BORRAZOPOLIS & MATO RICO & CAMBE & PORECATU \\
\hline CANDIDO DE ABREU & NOVA TEBAS & CENTENARIO DO SUL & PRADO FERREIRA \\
\hline CRUZMALTINA & PITANGA & FLORESTOPOLIS & PRIMEIRO DE MAIO \\
\hline FAXINAL & RIO BRANCO DO IVAI & GUARACl & ROLANDIA \\
\hline GODOY MOREIRA & ROSARIO DO IVAI & IBIPORA & SERTANOPOLIS \\
\hline GRANDES RIOS & SANTA MARIA DO OESTE & JAGUAPITA & TAMARANA \\
\hline IVAIPORA & SAO JOAO DO IVAI & \multicolumn{2}{|l|}{ LONDRINA } \\
\hline JARDIM ALEGRE & SAO PEDRO DO IVAI & N.R. Paranaguá & \\
\hline \multicolumn{2}{|l|}{ N.R. Umuarama } & ANTONINA & MORRETES \\
\hline ALTO PIQUIRI & JUSSARA & GUARAQUECABA & PARANAGUA \\
\hline ALTONIA & MARIA HELENA & GUARATUBA & PONTAL DO PARANA \\
\hline BRASILANDIA DO SUL & MARILUZ & \multicolumn{2}{|l|}{ MATINHOS } \\
\hline CAFEZAL DO SUL & NOVA OLIMPIA & \multicolumn{2}{|l|}{ N.R. Ponta Grossa } \\
\hline CIANORTE & PEROBAL & ARAPOTI & PIRAI DO SUL \\
\hline CIDADE GAUCHA & PEROLA & CARAMBEI & PONTA GROSSA \\
\hline CRUZEIRO DO OESTE & RONDON & CASTRO & PORTO AMAZONAS \\
\hline DOURADINA & SAO JORGE DO PATROCINIO & IMBAU & RESERVA \\
\hline ESPERANCA NOVA & SAO MANOEL DO PARANA & IPIRANGA & SAO JOAO DO TRIUNFO \\
\hline FRANCISCO ALVES & SAO TOME & IVAl & SENGES \\
\hline GUAPOREMA & TAPEJARA & JAGUARIAIVA & TELEMACO BORBA \\
\hline ICARAIMA & TAPIRA & ORTIGUEIRA & TIBAGI \\
\hline \multirow{2}{*}{$\begin{array}{l}\text { INDIANOPOLIS } \\
\text { IPORA }\end{array}$} & \multirow{2}{*}{$\begin{array}{l}\text { TUNEIRAS DO OESTE } \\
\text { UMUARAMA }\end{array}$} & PALMEIRA & VENTANIA \\
\hline & & \multicolumn{2}{|l|}{ N.R. Toledo } \\
\hline IVATE & VILA ALTA & ASSIS CHATEAUBRIAND & OURO VERDE DO OESTE \\
\hline JAPURA & XAMBRE & \multirow{2}{*}{$\begin{array}{l}\text { ENTRE RIOS DO OESTE } \\
\text { FORMOSA DO OESTE }\end{array}$} & PALOTINA \\
\hline \multicolumn{2}{|l|}{ N.R. União da Vitória } & & PATO BRAGADO \\
\hline \multirow{7}{*}{$\begin{array}{l}\text { ANTONIO OLINTO } \\
\text { BITURUNA } \\
\text { CRUZ MACHADO } \\
\text { GENERAL CARNEIRO } \\
\text { PAULA FREITAS }\end{array}$} & PAULO FRONTIN & GUAIRA & QUATRO PONTES \\
\hline & PORTO VITORIA & IRACEMA DO OESTE & SANTA HELENA \\
\hline & SAO MATEUS DO SUL & JESUITAS & SAO JOSE DAS PALMEIRAS \\
\hline & UNIAO DA VITORIA & \multicolumn{2}{|c|}{ MARECHAL CANDIDO RONDISAO PEDRO DO IGUACU } \\
\hline & & MARIPA & TERRA ROXA \\
\hline & & MERCEDES & TOLEDO \\
\hline & & NOVA SANTA ROSA & TUPASSI \\
\hline
\end{tabular}


Anexo B. Número de intoxicações nos diferentes núcleos regionais da SEAB, durante os anos de 1993 a 2000

\begin{tabular}{|c|c|c|c|c|c|c|c|c|c|c|}
\hline NÚCLEO REGIONAL & 1993 & 1994 & 1995 & 1996 & 1997 & 1998 & 1999 & 2000 & TOTAL & $(\%)$ \\
\hline LONDRINA & 78 & 77 & 90 & 103 & 91 & 83 & 87 & 75 & 684 & $12,3 \%$ \\
\hline CORNELIO PROCOPIO & 109 & 104 & 74 & 70 & 72 & 52 & 43 & 58 & 582 & $10,5 \%$ \\
\hline MARINGA & 122 & 107 & 84 & 26 & 51 & 38 & 55 & 11 & 494 & $8,9 \%$ \\
\hline APUCARANA & 42 & 23 & 32 & 25 & 36 & 24 & 20 & 35 & 237 & $4,3 \%$ \\
\hline PAIPORA & 54 & 45 & 29 & 20 & 31 & 13 & 13 & 13 & 219 & $3,9 \%$ \\
\hline JACAREZ $\mid \mathrm{NHO}$ & 22 & 23 & 26 & 20 & 16 & 26 & 25 & 9 & 167 & $3,0 \%$ \\
\hline Regiăo Norte & 427 & 379 & 335 & 264 & 297 & 236 & 243 & 201 & 2.382 & $42,9 \%$ \\
\hline CURITIBA & 90 & 50 & 30 & 30 & 28 & 24 & 29 & 44 & 325 & $5,9 \%$ \\
\hline IRATI & 59 & 36 & 15 & 15 & 18 & 19 & 28 & 36 & 226 & $4,1 \%$ \\
\hline UNIAO DA VITORIA & 8 & 8 & 30 & 45 & 59 & 41 & 14 & 13 & 226 & $4,1 \%$ \\
\hline PONTA GROSSA & 23 & 25 & 9 & 20 & 9 & 4 & 12 & 26 & 128 & $2,3 \%$ \\
\hline GUARAFUAVA & 8 & 11 & 9 & 9 & 6 & 28 & 22 & 19 & 112 & $2, \square \%$ \\
\hline LARANJEIRAS DO SUL & 13 & 14 & 2 & 1 & 2 & 17 & 14 & 17 & 80 & $1,4 \%$ \\
\hline PARANAGUA & 2 & 1 & 2 & 5 & 1 & 9 & 10 & 7 & 37 & $0,7 \%$ \\
\hline Região Sul & 203 & 145 & 105 & 125 & 123 & 142 & 129 & 162 & 1.134 & $20,4 \%$ \\
\hline CAMPO MOURAO & 156 & 150 & 106 & 66 & 62 & 40 & 49 & 45 & 674 & $12,2 \%$ \\
\hline Região Centro-Oeste & 156 & 150 & 106 & 66 & 62 & 40 & 49 & 45 & 674 & $12,1 \%$ \\
\hline CASCAVEL & 58 & 75 & 50 & 52 & 34 & 25 & 30 & 33 & 357 & $6,4 \%$ \\
\hline TOLEDO & 37 & 26 & 25 & 16 & 44 & 19 & 16 & 31 & 214 & $3,9 \%$ \\
\hline Regiăo Oeste & 95 & 101 & 75 & 68 & 78 & 44 & 46 & 64 & 571 & $10,3 \%$ \\
\hline PARANAVAI & 67 & 76 & 37 & 20 & 26 & 15 & 19 & 37 & 297 & $5,4 \%$ \\
\hline UMUARAMA & 6i] & 35 & 52 & 33 & 26 & 31 & 12 & 10 & 259 & $4,7 \%$ \\
\hline Região Noroeste & 127 & 111 & 89 & 53 & 52 & 46 & 31 & 47 & 556 & $10,0 \%$ \\
\hline PATO BRANCO & 18 & 15 & 18 & 14 & 24 & 33 & 18 & 22 & 162 & $2,9 \%$ \\
\hline FRANCISCO EELTRAO & 14 & 16 & 12 & 5 & 2 & 8 & 7 & 5 & 69 & $1,2 \%$ \\
\hline Região Sudoeste & 32 & 31 & 30 & 19 & 26 & 41 & 25 & 27 & 231 & $4,2 \%$ \\
\hline TOTAL & 1.040 & 917 & 740 & 595 & 638 & 549 & 523 & 546 & 5.548 & $100 \%$ \\
\hline
\end{tabular}


Anexo C. Números e percentuais de intoxicação, por causas de intoxicação entre os núcleos regionais da SEAB

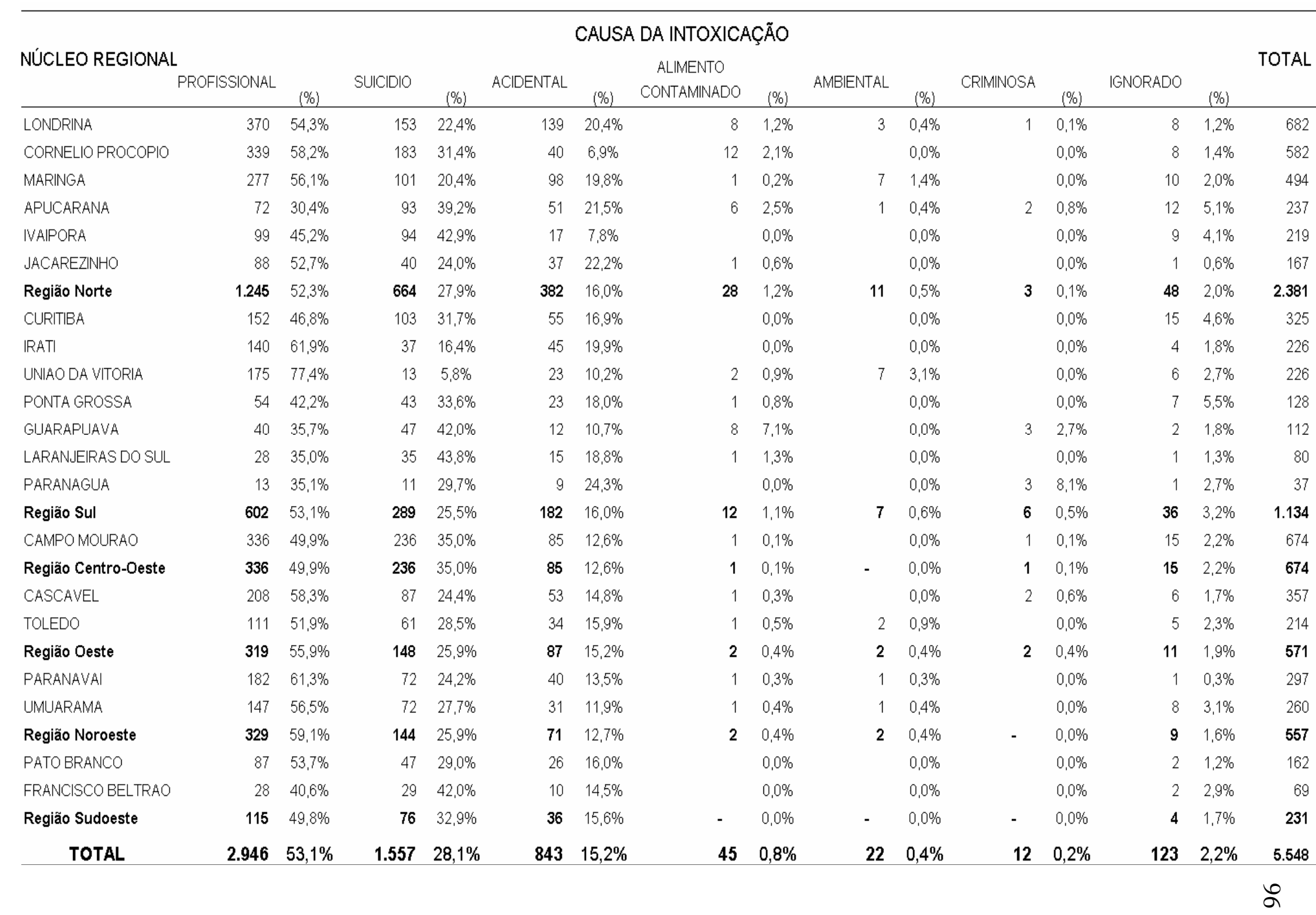


Anexo D. Número total de intoxicações, áreas dos grupos de cultivos e índices, nos diferentes núcleos regionais

\begin{tabular}{|c|c|c|c|c|c|c|c|c|c|c|c|c|}
\hline \multirow[b]{2}{*}{ NÚCLEO REGIONAL } & \multicolumn{3}{|c|}{ Intoxicações } & \multicolumn{6}{|c|}{ Áreas Grupos Culturas (ha) } & \multicolumn{2}{|c|}{ Área Total } & \multirow{2}{*}{$\begin{array}{c}\text { Área Tota } \\
\text { Região } \\
(\%)\end{array}$} \\
\hline & $\left(n^{\circ}\right)$ & $(\%)$ & Índice ${ }^{\pi}$ & Frutas & $\begin{array}{l}\text { Olericalas } \\
\text { Grandes }\end{array}$ & Olerícolas & $\begin{array}{c}\text { Culturas } \\
\text { Verẫo }\end{array}$ & $\begin{array}{l}\text { Culturas } \\
\text { Inverno }\end{array}$ & Outros & (ha) & $(\%)$ & \\
\hline LONDRINA & 684 & $12,3 \%$ & 2,23 & 14.964 & 2.289 & 10.707 & 2.474 .615 & 399.521 & 163.501 & 3.065 .598 & $19 \%$ & \\
\hline CORNELIO PROCOPIO & 582 & $10,5 \%$ & 1,63 & 19.189 & 2.650 & 2.632 & 2.637 .997 & 661.777 & 251.139 & 3.575 .384 & $22 \%$ & \\
\hline MARINGA & 494 & $8,9 \%$ & 1,66 & 23.430 & 694 & 3.066 & 2.444 .860 & 278.978 & 221.099 & 2.972 .126 & $19 \%$ & \\
\hline APUCARANA & 237 & $4,3 \%$ & 1,86 & 6.849 & 1.949 & 8.181 & 1.033 .894 & 171.590 & 54.108 & 1.276 .571 & $8 \%$ & \\
\hline VAIPORA & 218 & $3,9 \%$ & 0,70 & 2.0 .037 & 1.073 & 1.255 & 2.910 .498 & 140.280 & 43.475 & 3.098 .617 & $19 \%$ & \\
\hline JACAREZINHO & 167 & $3,0 \%$ & 0,86 & 12.682 & 3.640 & 4.629 & 1.610 .992 & 70.939 & 245.005 & 1.947 .897 & $12 \%$ & \\
\hline Região Norte & 2.382 & $43 \%$ & 1,49 & 79.151 & 12.294 & 30.470 & 13.112 .856 & 1.723 .085 & 978.326 & 15.936 .183 & $100 \%$ & $29 \%$ \\
\hline CURITIEA & 325 & $5,9 \%$ & 1,63 & 33.597 & 172.731 & 70.235 & 1.681 .523 & 15.040 & 23.779 & 1.996 .905 & $15 \%$ & \\
\hline IRAMTI & 226 & $4,1 \%$ & 1,45 & 2.179 & 23.042 & 1.558 & 1.392 .903 & 80.159 & 58.387 & 1.558 .228 & $11 \%$ & \\
\hline UNU|AOO DA VITORIA & 226 & $4,1 \%$ & 2,31 & 3.528 & 24.210 & 5.545 & 902.609 & 11.858 & 29.076 & 976.825 & $7 \%$ & \\
\hline PONTA GROSSA & 128 & $2,3 \%$ & 0,27 & 3.189 & 24.682 & 10.059 & 4.113 .715 & 484.435 & 39.378 & 4.675 .458 & $34 \%$ & \\
\hline GUARAPUAVA & 112 & $2,0 \%$ & 0,36 & 4.253 & 36.945 & 5.247 & 2.657 .592 & 344.130 & 20.545 & 3.068 .712 & $22 \%$ & \\
\hline LARANJEIRAS DO SUL & 80 & $1,4 \%$ & 0,61 & 703 & 409 & 1.359 & 1.263 .919 & 38.646 & 14.054 & 1.319 .089 & $10 \%$ & \\
\hline PARANAGUA & 37 & $0,7 \%$ & 8,37 & 19.379 & 276 & 3.360 & 14.947 & - & 6.214 & 44.184 & $0 \%$ & \\
\hline Região Sul & 1.134 & $20 \%$ & 0,83 & 66.828 & 282.294 & 97.370 & 12.027 .208 & 974.268 & 191.432 & 13.639 .401 & $100 \%$ & $25 \%$ \\
\hline CAMPO MOURAO & 674 & $12,2 \%$ & 1,09 & 2.249 & 1.008 & 1.140 & 5.007 .157 & 943.245 & 214.014 & 6.168 .813 & $100 \%$ & \\
\hline Região Centro-Oestı & 674 & $12 \%$ & 1,09 & 2.249 & 1.008 & 1.140 & 5.007 .157 & 943.245 & 214.014 & 6.168 .813 & $100 \%$ & $11 \%$ \\
\hline CASCAVEL & 357 & $6,4 \%$ & 0,70 & 6.294 & 631 & 3.727 & 4.524 .517 & 484.550 & 67761 & 5.087 .480 & $47 \%$ & \\
\hline TOLEDO & 214 & $3,9 \%$ & 0,37 & 3.620 & 594 & 1.960 & 5.166 .638 & 562.562 & 90.790 & 5.826 .164 & $53 \%$ & \\
\hline Região Oeste & 571 & $10 \%$ & 0,52 & 9.914 & 1.225 & 5.687 & 9.691 .155 & 1.047 .112 & 158.551 & 10.913 .644 & $100 \%$ & $20 \%$ \\
\hline PARANAYAI & 297 & $5,4 \%$ & 399 & 23.227 & 44 & 220 & 405.213 & 5.330 & 241.892 & 755.933 & $32 \%$ & \\
\hline $\begin{array}{l}\text { UMUARAMA } \\
\text { Regiäo Noroeste }\end{array}$ & $\begin{array}{r}259 \\
556\end{array}$ & $\begin{array}{l}4,7 \% \\
10 \%\end{array}$ & $\begin{array}{l}1,65 \\
2,39\end{array}$ & $\begin{array}{r}7.825 \\
31.052\end{array}$ & $\begin{array}{r}167 \\
211\end{array}$ & $\begin{array}{r}1.518 \\
1.745\end{array}$ & $\begin{array}{r}1.253 .284 \\
1.738 .497\end{array}$ & $\begin{array}{r}20.695 \\
26.025\end{array}$ & $\begin{array}{r}290.591 \\
\mathbf{5 3 2 . 4 8 3}\end{array}$ & $\begin{array}{r}1.574 .080 \\
2.330 .013\end{array}$ & $\begin{array}{c}68 \% \\
100 \%\end{array}$ & $4 \%$ \\
\hline PATO BRANCO & 162 & $2,9 \%$ & 0,61 & 7.975 & 2.530 & 821 & 2.446 .114 & 163.305 & 20.808 & 2.641 .561 & $40 \%$ & \\
\hline FRANCISCO EELTRAO & 69 & $1,2 \%$ & 0,18 & 7.328 & 1.782 & 2.805 & 3.787 .029 & 99.183 & 38.933 & 3937.060 & $60 \%$ & \\
\hline Região Sudoeste & 231 & $4 \%$ & 0,35 & 15.302 & 4.320 & 3.626 & 6.233 .143 & 262.488 & 59.741 & 6.578 .620 & $100 \%$ & $12 \%$ \\
\hline TOTAL & 5.548 & $100 \%$ & 1,00 & 204.496 & 301.352 & 140.039 & 47.810 .016 & 4.976 .222 & 2.134 .549 & 55.566 .674 & $100 \%$ & $100 \%$ \\
\hline
\end{tabular}

(*) Expresso pelo número total de intoxicações dividido pela respectiva área total, multiplicado por 10.000 . 
Anexo E. Número de intoxicações por classe e grupo químico dos agrotóxicos, durante os anos de 1993 a 2000

\begin{tabular}{|c|c|c|c|c|c|c|c|c|c|c|}
\hline \multirow{2}{*}{ CLASSE DE PRODUTO } & \multicolumn{8}{|c|}{ ANO } & \multicolumn{2}{|c|}{ TOTAL } \\
\hline & 1993 & 1994 & 1995 & 1996 & 1997 & 1998 & 1999 & 2000 & $n^{\circ}$ & $\%$ \\
\hline IASETICIDA & 274 & 474 & 326 & 246 & 230 & 195 & 210 & 158 & 2.113 & \\
\hline ORGANOFOSFORADO & 144 & 297 & 194 & 154 & 144 & 115 & 131 & 96 & 1.275 & $60,3 \%$ \\
\hline CAREMMATO & 31 & 62 & 37 & 23 & 29 & 35 & 27 & 22 & 266 & $12,6 \%$ \\
\hline PIRETRODE & 36 & 34 & 29 & 22 & 18 & 16 & 15 & 18 & 188 & $8,9 \%$ \\
\hline ESTER DO ASDC & 44 & 36 & 30 & 12 & 7 & 8 & 9 & 9 & 155 & $7,3 \%$ \\
\hline ORGANOCLORADO & 8 & 16 & 9 & 12 & 11 & 4 & 12 & 8 & 80 & $3,8 \%$ \\
\hline HERBICIDA & 116 & 102 & 129 & 112 & 141 & 139 & 124 & 134 & 997 & - \\
\hline DERIYADO DA GLICINÄ & 27 & 29 & 44 & 39 & 77 & 84 & 65 & 73 & 438 & $439 \%$ \\
\hline EIPR/IIILIOS & 37 & 30 & 35 & 33 & 30 & 17 & 15 & 26 & 223 & $22,4 \%$ \\
\hline DNNWTROANMLINAS & 22 & 14 & 11 & 5 & 8 & 7 & 5 & 2 & 74 & $7,4 \%$ \\
\hline FENOK|ACETICO + DER. AC. FICOLINICO & 9 & 12 & 6 & 11 & 8 & 5 & 10 & 9 & 70 & $7,0 \%$ \\
\hline FENOX|ACETICO & G & 2 & 6 & 3 & 1 & 1 & 8 & 13 & $4 \square$ & $4,0 \%$ \\
\hline FUNGICIDA & 9 & 25 & 17 & 26 & 28 & 25 & 8 & 13 & 151 & $1-\infty$ \\
\hline DITOCAREAMATO & 2 & 14 & 4 & 10 & 4 & 4 & 3 & 3 & 44 & $29,1 \%$ \\
\hline TFil. & 1 & 2 & 5 & 3 & 5 & 7 & 2 & 4 & 29 & $19,2 \%$ \\
\hline EENZIMWILAZZOL & - & 2 & 2 & 2 & 4 & 2 & - & 3 & 15 & $9,9 \%$ \\
\hline OUPFico & 3 & - & 1 & 2 & 3 & 2 & 2 & 1 & 14 & $9,3 \%$ \\
\hline TFIAZOIS + ORGAMOFOSFORADO & - & - & 1 & 1 & 7 & 4 & - & - & 13 & $8,6 \%$ \\
\hline REGULADORES & 9 & 6 & 6 & 8 & 6 & 7 & 5 & 4 & 51 & \\
\hline CIMAMDA & 5 & - & 4 & 4 & 5 & 5 & 2 & 2 & 27 & $52,9 \%$ \\
\hline 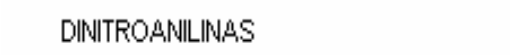 & 4 & 6 & 2 & 4 & 1 & 2 & 3 & 2 & 24 & $47,1 \%$ \\
\hline MIISTURAS & 41 & 22 & 114 & 86 & 119 & 100 & 81 & 68 & 631 & \\
\hline OUTROS & 593 & 289 & 150 & 120 & 121 & 88 & 98 & 170 & 1.629 & \\
\hline TOTAL & 1.042 & 918 & 742 & 598 & 645 & 554 & 526 & 547 & 5.572 & - \\
\hline
\end{tabular}


Anexo F. Número de intoxicações por classe e grupo químico dos agrotóxicos e causas de intoxicação

\begin{tabular}{|c|c|c|c|c|c|c|c|c|c|}
\hline \multirow{2}{*}{ CLASSE DE PRODUTO } & \multicolumn{7}{|c|}{ CAUSA DE CONTAMINACÄO } & \multicolumn{2}{|c|}{ TOTAL } \\
\hline & ACIDENTAL & $\begin{array}{c}\text { ALIMENVO } \\
\text { CONTAMMINADO }\end{array}$ & AMEIENTAL & CRMMUOSA & IGNORADO & PROFISSIONAL & sucílo & $n 1^{\circ}$ & $\%$ \\
\hline IASETICIDA & 304 & 29 & 10 & 6 & 16 & 1.040 & 708 & 2.113 & $\cdot$ \\
\hline ORGANOFOSFORADO & 168 & 26 & 2 & 2 & 10 & 543 & 524 & 1.275 & $60,3 \%$ \\
\hline CAREMATO & 41 & 1 & - & 4 & 2 & 192 & 26 & 266 & $12,6 \%$ \\
\hline PIRETRODE & 29 & 1 & 3 & - & 1 & 96 & 58 & 180 & $89 \%$ \\
\hline ESTER DO ASDC & 13 & - & - & - & - & 95 & 47 & 155 & $7,3 \%$ \\
\hline ORGMNOLORMLO & 21 & - & 5 & - & 2 & 13 & 39 & 80 & $3,8 \%$ \\
\hline HEREICIDA & 155 & 3 & - & 1 & 23 & 503 & 312 & 997 & - \\
\hline CERNVADO DA GLCONHA & 90 & 2 & - & 1 & 6 & 204 & 135 & 430 & $43,9 \%$ \\
\hline EIFIFIDILIOS & 27 & - & - & - & 7 & 96 & 93 & 223 & $22,4 \%$ \\
\hline [DNNTROMNNLINSS & 9 & - & - & - & 1 & 49 & 15 & 74 & $7,4 \%$ \\
\hline FENOXVLCETCO + DER. AC FICOLNNICO & 7 & - & - & - & - & 47 & 16 & 70 & $7,0 \%$ \\
\hline FENOKASEETCO & 7 & 1 & - & - & 2 & 16 & 14 & 40 & $4,0 \%$ \\
\hline FUNGICIDA & 32 & 2 & 1 & - & 1 & 94 & 21 & 151 & \\
\hline DITOCARBAMATO & 11 & - & 1 & - & 1 & 26 & 5 & 44 & $29,1 \%$ \\
\hline TFIMZOIS & 5 & 1 & - & - & - & 13 & 10 & 29 & $19,2 \%$ \\
\hline EENTIMIDIZZOL & - & - & - & - & - & 12 & 3 & 15 & $99 \%$ \\
\hline CIPFiCO & 5 & - & - & - & - & 8 & 1 & 14 & $9,3 \%$ \\
\hline TF|MZOS + ORGANOFOSFORMDO & 2 & - & - & - & - & 11 & - & 13 & $8,6 \%$ \\
\hline REGULADORES & 4 & - & - & - & - & 36 & 11 & 51 & - \\
\hline CIMNAMLA & 3 & - & - & - & - & 21 & 3 & 27 & $52,9 \%$ \\
\hline 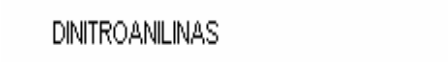 & 1 & - & - & - & - & 15 & 8 & 24 & $47,1 \%$ \\
\hline MISTURAS & 66 & 2 & 4 & - & 4 & 517 & 38 & 631 & - \\
\hline OUTROS & 289 & 9 & 7 & 5 & 79 & 772 & 468 & 1.629 & - \\
\hline TOTAL & 850 & 45 & 22 & 12 & 123 & 2.962 & 1.558 & 5.572 & - \\
\hline
\end{tabular}


Anexo G. Número de intoxicações por classe e grupo químico dos agrotóxicos e vias de intoxicação

\begin{tabular}{|c|c|c|c|c|c|c|c|c|c|}
\hline \multirow[b]{2}{*}{ CLASSE DE PRODUUTO } & \multicolumn{7}{|c|}{ CAUSA DE CONTAMINACGÄO } & \multicolumn{2}{|c|}{ TOTAL } \\
\hline & RESPIRATÓRIAA & CIGESTVA & CUTANNEA & $\begin{array}{c}\text { CUTÂNEA } \\
\text { RESPIRATORIAA }\end{array}$ & IGNORADA & $\begin{array}{l}\text { DIGESTVA } \\
\text { RESPIRATORIAA }\end{array}$ & $\begin{array}{l}\text { OUTANNEA } \\
\text { DIGESTVA }\end{array}$ & $11^{\circ}$ & $\%$ \\
\hline IASETICIDA & 756 & 857 & 113 & 316 & 54 & 14 & 3 & 2.113 & \\
\hline ORGAMOFOSFORADO & 413 & 611 & 52 & 159 & 26 & 11 & 3 & 1.275 & $60,3 \%$ \\
\hline CAREAMATO & 117 & 56 & 17 & 58 & 16 & 2 & - & 266 & $12,6 \%$ \\
\hline FIRETRODE & 77 & 63 & 20 & 24 & 3 & 1 & - & 180 & $8,9 \%$ \\
\hline ESTER DO ASOC & 69 & 54 & 7 & 22 & 3 & - & - & 155 & $7,3 \%$ \\
\hline ORGANOCLORADO & 23 & 45 & 4 & 5 & 3 & - & - & 80 & $3,8 \%$ \\
\hline HERBICIDA & 341 & 384 & 80 & 154 & 29 & 5 & 4 & 997 & - \\
\hline DEFIVADO DA GLCINAG & 144 & 172 & 34 & 70 & 13 & 4 & 1 & 430 & $43,9 \%$ \\
\hline EIFRIILLOS & 61 & 109 & 17 & 28 & 8 & - & - & 223 & $22,4 \%$ \\
\hline DNNTROMNULNMS & 40 & 19 & 6 & 8 & & - & 1 & 74 & $7,4 \%$ \\
\hline FENOXIMCETICO + DER. AC. FCOLINICO & 29 & 18 & 3 & 17 & 2 & - & 1 & 70 & $7,0 \%$ \\
\hline FENOXIACETICO & 8 & 18 & 4 & 10 & & - & - & 40 & $4,0 \%$ \\
\hline FUHGICIDA & 55 & 43 & 21 & 31 & 1 & - & - & 151 & - \\
\hline CITOCHREMMTO & 15 & 12 & 8 & 8 & 1 & - & - & 44 & $29,1 \%$ \\
\hline TFläZOS & 8 & 13 & 2 & 6 & - & - & - & 29 & $19,2 \%$ \\
\hline EENIZMIDAZZOL & 5 & 3 & 1 & 6 & - & - & - & 15 & $99 \%$ \\
\hline CUPFICO & 6 & 7 & - & 1 & - & - & - & 14 & $9,3 \%$ \\
\hline TF|MZZOS + ORGMNOFOSFORADO & 2 & 1 & 7 & 3 & - & - & - & 13 & $8,6 \%$ \\
\hline REGULADORES & 18 & 11 & 14 & 7 & 1 & - & - & 51 & \\
\hline CANMLAM & 9 & 3 & 11 & 3 & 1 & - & - & 27 & $52,9 \%$ \\
\hline DINTTROMNLINAS & 9 & 8 & 3 & 4 & - & - & - & 24 & $47,1 \%$ \\
\hline MISTURAS & 228 & 63 & 127 & 183 & 28 & 2 & - & 631 & - \\
\hline OUTROS & 675 & 580 & 114 & 115 & 129 & 6 & 2 & 1.629 & - \\
\hline TOTAL & 2.073 & 1.946 & 469 & 806 & 242 & 27 & 9 & 5.572 & - \\
\hline
\end{tabular}


Anexo H. Número de intoxicações nas regiões e respectivos núcleos regionais, segundo as classes e principais grupos químicos dos agrotóxicos

\begin{tabular}{|c|c|c|c|c|c|c|c|c|c|c|c|c|c|c|c|c|c|c|c|c|c|c|c|c|c|c|c|}
\hline \multirow[b]{2}{*}{ CLASSE DE PRODUTO } & \multirow[b]{2}{*}{ 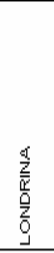 } & \multirow[b]{2}{*}{ 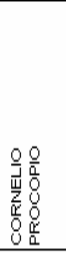 } & \multicolumn{4}{|c|}{ REGI/L̈O NORTE } & \multirow[b]{2}{*}{$\begin{array}{l}\frac{1}{6} \\
\stackrel{6}{6} \\
\end{array}$} & \multirow[b]{2}{*}{ 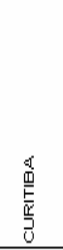 } & \multirow[b]{2}{*}{$\begin{array}{l}E \\
\underline{\underline{\underline{w}}}\end{array}$} & \multirow[b]{2}{*}{ 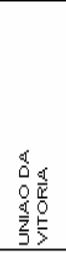 } & \multicolumn{3}{|c|}{ REGLÄO SULL } & \multirow[b]{2}{*}{ 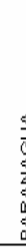 } & \multirow[b]{2}{*}{ 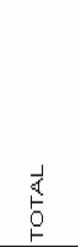 } & \multicolumn{2}{|c|}{ 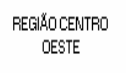 } & \multicolumn{3}{|c|}{ REGIÄ̈O OESTE } & \multicolumn{3}{|c|}{ REG|ÄO NOROESTE } & \multicolumn{3}{|c|}{ REgi|ẤO SUDOESTE } & \multirow[b]{2}{*}{ TOTAL } \\
\hline & & & $\begin{array}{l}\frac{5}{10} \\
\frac{10}{\frac{2}{2}} \\
\frac{1}{5} \\
\frac{1}{2}\end{array}$ & 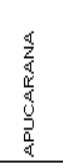 & 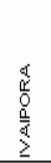 & & & & & & 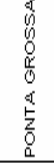 & $\begin{array}{l}\frac{1}{1} \\
\frac{1}{3} \\
\frac{3}{3} \\
\frac{1}{3} \\
\frac{a}{3}\end{array}$ & 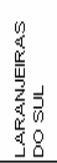 & & & 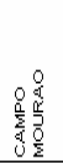 & $\begin{array}{l}\frac{1}{6} \\
\stackrel{5}{6} \\
\end{array}$ & 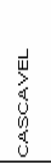 & $\begin{array}{l}0 \\
\stackrel{u}{u} \\
0 \\
\end{array}$ & $\begin{array}{l}\frac{1}{4} \\
5 \\
\stackrel{5}{F}\end{array}$ & 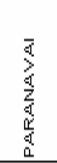 & $\begin{array}{l}\frac{1}{2} \\
\frac{1}{1} \\
\frac{1}{1} \\
\bar{z} \\
\end{array}$ & $\begin{array}{l}\vec{\alpha} \\
\stackrel{6}{6} \\
\end{array}$ & $\begin{array}{l}8 \\
\frac{0}{2} \\
1 \\
\frac{1}{1} \\
0 \\
0 \\
0 \\
0 \\
\end{array}$ & 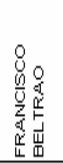 & 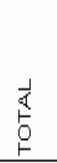 & \\
\hline INSETICIDA & 293 & 280 & 204 & 98 & 79 & 65 & 1.019 & 83 & 86 & 22 & 40 & 22 & 9 & 9 & 271 & 296 & 296 & 111 & 82 & 193 & 151 & 126 & 277 & 30 & 27 & 57 & 2.113 \\
\hline ORGANOFOSFORADO & 139 & 184 & 118 & 64 & 59 & 39 & 603 & 66 & 46 & 16 & 29 & 15 & 3 & 4 & 179 & 173 & 173 & 85 & 56 & 141 & 77 & 59 & 136 & 22 & 21 & 4.3 & 1.275 \\
\hline CAREAMATO & 42 & 37 & 31 & 16 & 2 & 7 & 135 & 6 & 25 & 2 & 5 & 4 & 1 & 5 & 48 & 33 & 33 & 7 & 11 & 18 & 18 & 11 & 29 & 2 & 1 & 3 & 266 \\
\hline PIRETRODE & 30 & 22 & 17 & 1 & 4 & 7 & 89 & 5 & 6 & 1 & 3 & 0 & 1 & 0 & 16 & 26 & 26 & 8 & 7 & 15 & 20 & 19 & 39 & 2 & 1 & 3 & 188 \\
\hline ESTER DO ASDC & 11 & 21 & 16 & 3 & 10 & 5 & 66 & 0 & 0 & 0 & 0 & 0 & 0 & 0 & 0 & 42 & 42 & 5 & 3 & 8 & 17 & 21 & 38 & 0 & 1 & 1 & 155 \\
\hline ORGANOCLRADO & 20 & 8 & 11 & 7 & 2 & 0 & 48 & 3 & 0 & 1 & 2 & 1 & 1 & 0 & 8 & 1 & 1 & 1 & 3 & 4 & 8 & 9 & 17 & 2 & 0 & 2 & 80 \\
\hline HERBICIDA & 145 & 55 & 72 & 39 & 55 & 42 & 408 & 65 & 44 & 27 & 28 & 40 & 39 & 7 & 250 & 67 & 67 & 96 & 28 & 124 & 31 & 17 & 48 & 85 & 15 & 100 & 997 \\
\hline DERIVADO DA GLLINA & 86 & 26 & 43 & 29 & 14 & 23 & 223 & 21 & 15 & 7 & 9 & 7 & 15 & 4 & 78 & 24 & 24 & 39 & 12 & 51 & 15 & 7 & 22 & 33 & 7 & 40 & 438 \\
\hline ERPRDLLOS & 20 & 0 & 4 & 3 & 28 & 5 & 60 & 26 & 13 & 9 & 14 & 21 & 11 & 1 & 95 & 10 & 10 & 12 & 5 & 17 & 1 & 1 & 2 & 37 & 2 & 39 & 223 \\
\hline DINITROAMLINAS & 5 & 7 & 11 & 3 & 1 & 0 & 27 & 4 & 6 & 5 & 1 & 0 & 0 & 0 & 16 & 15 & 15 & 6 & 2 & 8 & 3 & 2 & 5 & 1 & 2 & 3 & 74 \\
\hline FENON|HCETICO + DER. AC. FCOLNINCO & 11 & 5 & 3 & 0 & 0 & 3 & 22 & 1 & 0 & 0 & 1 & 0 & 3 & 0 & 5 & 2 & 2 & 25 & 2 & 27 & 5 & 4 & 9 & 4 & 1 & 5 & 70 \\
\hline FENOKNLCETICO & 8 & 5 & 3 & 0 & 1 & 0 & 17 & 4 & 1 & 0 & 0 & 0 & 2 & 1 & 8 & 4 & 4 & 6 & 2 & 8 & 0 & 0 & 0 & 2 & 1 & 3 & 40 \\
\hline FUNGICIDA & 31 & 23 & 11 & 9 & 4 & 10 & 88 & 13 & 3 & 11 & 0 & 4 & 1 & 4 & 36 & 11 & 11 & 2 & 3 & 5 & 3 & 4 & 7 & 4 & 0 & 4 & 151 \\
\hline IITOCAREAMATÓ & 4 & 5 & 4 & 1 & 1 & 1 & 16 & 8 & 2 & 11 & 0 & 0 & 1 & 4 & 26 & 1 & 1 & 0 & 0 & 0 & 0 & 0 & 0 & 1 & 0 & 1 & 44 \\
\hline TRRIROZIS & 5 & 5 & 2 & 3 & 0 & 2 & 17 & 0 & 0 & 0 & 0 & 1 & 0 & 0 & 1 & 5 & 5 & 0 & 2 & 2 & 1 & 2 & 3 & 1 & 0 & 1 & 29 \\
\hline EENIMDOAZOL & 3 & 3 & 0 & 2 & 2 & 0 & 10 & 0 & 0 & 0 & 0 & 0 & 0 & 0 & 0 & 1 & 1 & 2 & 0 & 2 & 0 & 0 & 0 & 2 & 0 & 2 & 15 \\
\hline CIPFICO & 3 & 1 & 1 & 1 & 1 & 2 & 9 & 1 & 1 & 0 & 0 & 0 & 0 & 0 & 2 & 1 & 1 & 0 & 0 & 0 & 1 & 1 & 2 & 0 & 0 & 0 & 14 \\
\hline TFlLZZOS + OFGAMOFOOSFORADO & 7 & 1 & 0 & 0 & 0 & 3 & 11 & 0 & 0 & 0 & 0 & 0 & 0 & 0 & 0 & 1 & 1 & 0 & 0 & 0 & 0 & 1 & 1 & 0 & 0 & 0 & 13 \\
\hline REGULADORES & 7 & 10 & 10 & 0 & 0 & 0 & 27 & 11 & 8 & 1 & 0 & 0 & 1 & 0 & 21 & 0 & 0 & 0 & 0 & 0 & 0 & 0 & 0 & 1 & 2 & 3 & 51 \\
\hline CIAMAMDA. & 7 & 10 & 10 & 0 & 0 & 0 & 27 & 0 & 0 & 0 & 0 & 0 & 0 & 0 & 0 & 0 & 0 & 0 & 0 & 0 & 0 & 0 & 0 & 0 & 0 & 0 & 27 \\
\hline DIMUROAMULNAS & 0 & 0 & 0 & 0 & 0 & 0 & 0 & 11 & 8 & 1 & 0 & 0 & 1 & 0 & 21 & 0 & 0 & 0 & 0 & 0 & 0 & 0 & 0 & 1 & 2 & 3 & 24 \\
\hline MISTURAS & 64 & 53 & 49 & 8 & 20 & 11 & 205 & 25 & 21 & 134 & 9 & 7 & 6 & 3 & 205 & 63 & 63 & 36 & 45 & 81 & 22 & 39 & 61 & 15 & 1 & 16 & 631 \\
\hline OUTROS & 154 & 162 & 148 & 85 & 61 & 43 & 653 & 129 & 64 & 31 & 51 & 39 & 24 & 14 & 352 & 239 & 239 & 112 & 57 & 169 & 90 & 75 & 165 & 27 & 24 & 51 & 1.629 \\
\hline TOTAL & 694 & 583 & 494 & 239 & 219 & 171 & 2.400 & 326 & 226 & 226 & 128 & 112 & 80 & 37 & 1.135 & 676 & 676 & 357 & 215 & 572 & 297 & 261 & 558 & 162 & 69 & 231 & 5.572 \\
\hline
\end{tabular}


Anexo I. Número de óbitos nas regiões e respectivos núcleos regionais, segundo as classes e principais grupos químicos dos agrotóxicos

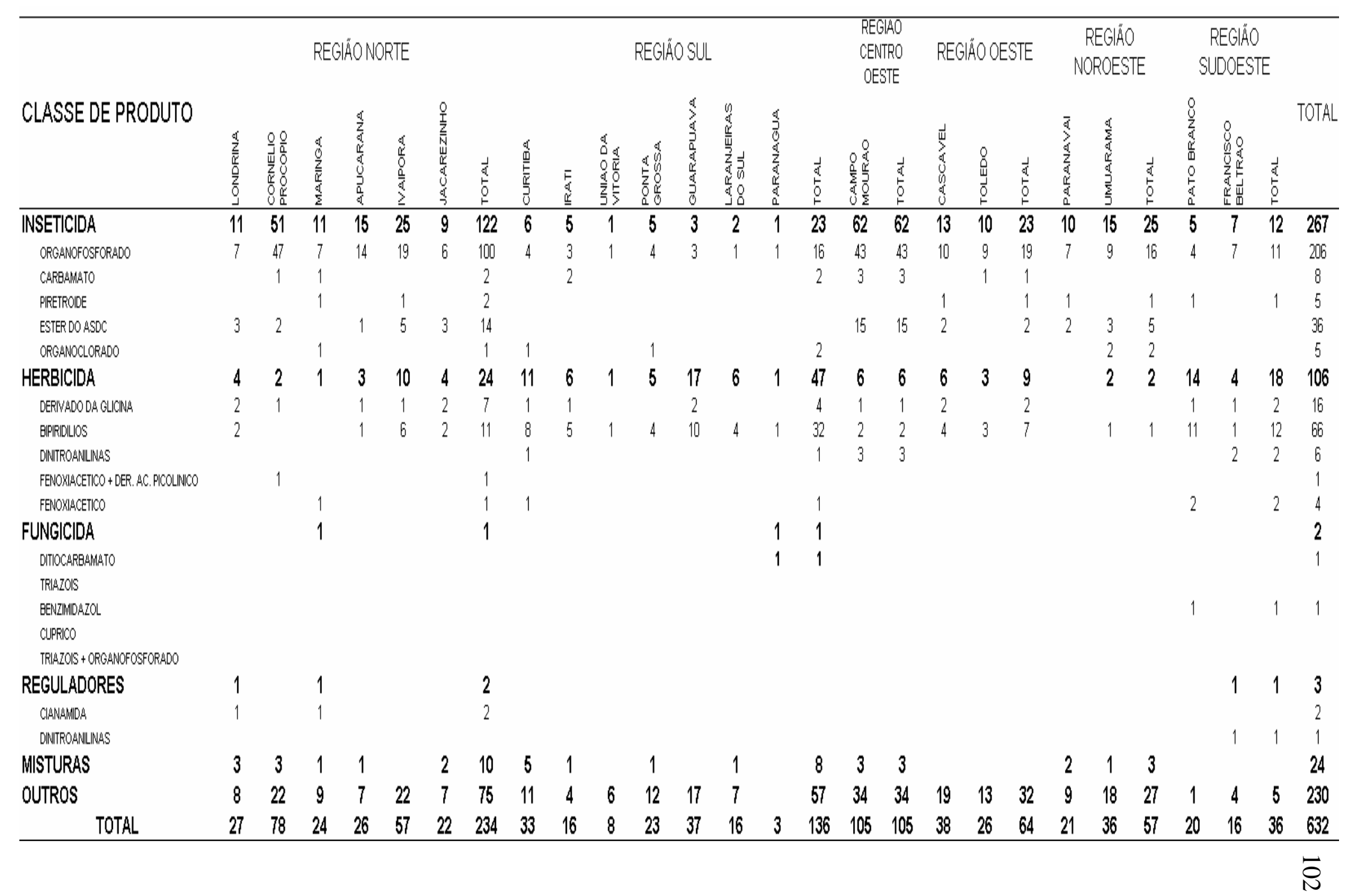


Anexo J. Número de óbitos nas classes de idade, por sexo, segundo as classes e principais grupos químicos dos agrotóxicos

\begin{tabular}{|c|c|c|c|c|c|c|c|c|c|c|c|c|c|c|c|c|c|c|c|c|c|c|c|c|c|c|}
\hline \multirow{3}{*}{ CLASSE DE PRODUTO } & \multicolumn{24}{|c|}{ CLASSE DE IDADE } & \multirow{2}{*}{\multicolumn{2}{|c|}{ TOTAL }} \\
\hline & \multicolumn{2}{|c|}{025} & \multicolumn{2}{|c|}{$6 a 11$} & \multicolumn{2}{|c|}{12 a 17} & \multicolumn{2}{|c|}{18 a 23} & \multicolumn{2}{|c|}{24 a 29} & \multicolumn{2}{|c|}{30 a 35} & \multicolumn{2}{|c|}{36 a 41} & \multicolumn{2}{|c|}{$42 a 47$} & \multicolumn{2}{|c|}{$48 \mathrm{a} 53$} & \multicolumn{2}{|c|}{54 a 59} & \multicolumn{2}{|c|}{$>=60$} & \multicolumn{2}{|c|}{ IGNORADO } & & \\
\hline & $F$ & M & $F$ & M & $F$ & M & $\mathrm{F}$ & M & $\mathrm{F}$ & M & $F$ & M & $F$ & M & $F$ & M & $F$ & M & $F$ & M & $F$ & M & $F$ & M & $\mathbf{F}$ & M \\
\hline INSETICIDA & 3 & 2 & 1 & & 6 & 8 & 16 & 30 & $g$ & 31 & 7 & 27 & 9 & 28 & 7 & 22 & 5 & 11 & 1 & 19 & 4 & 20 & 1 & & 69 & 198 \\
\hline ORGANOFOSFORADO & 3 & 1 & & & 4 & 3 & 12 & 20 & 8 & 23 & 5 & 23 & 8 & 22 & 6 & 17 & 4 & 7 & 1 & 16 & 3 & 19 & 1 & & 55 & 151 \\
\hline CARPAMHTO & & & & & & 1 & & & & & & 1 & & 1 & & 1 & & 3 & & & & 1 & & & & 8 \\
\hline PIREROIDE & & & & & & & 1 & & & 2 & & & & & & 1 & 1 & & & & & & & & 2 & 3 \\
\hline ETTER DOASDC & & & 1 & & 2 & 2 & 3 & 7 & 1 & 4 & 2 & 2 & 1 & 4 & 1 & 2 & & 1 & & 3 & & & & & 11 & 25 \\
\hline ORGAMOCLORADO & & & & & & 1 & & 1 & & & & 1 & & & & 1 & & & & & 1 & & & & 1 & 4 \\
\hline HERBICIDA & & 2 & & & 2 & 1 & 3 & 12 & 4 & 14 & 5 & 14 & & 13 & 3 & 5 & 3 & 6 & 3 & 6 & 2 & 6 & & 2 & 25 & 81 \\
\hline DERMYADODAG GLCOMA & & & & & 1 & & & & 1 & 3 & 2 & 2 & & 1 & 1 & 1 & & 2 & & 1 & & 1 & & & 5 & 11 \\
\hline EPRIILLIOS & & & & & 1 & 1 & & 10 & 2 & 8 & 3 & 11 & & 10 & 1 & 4 & 3 & 4 & 1 & 1 & 2 & 4 & & & 13 & 53 \\
\hline DINTROANLINAS & & 1 & & & & & 3 & & & & & & & & & & & & & 1 & & & & 1 & 3 & 3 \\
\hline FENOXACEETCO+ DER. AC. PCOLLNCOC & & & & & & & & & & 1 & & & & & & & & & & & & & & & & 1 \\
\hline FENOXACETCO & & 1 & & & & & & & & & & & & 1 & 1 & & & & & 1 & & & & & 1 & 3 \\
\hline FUNGICIDA & & & & & & & & & & & & 1 & & & & 1 & & & & & & & & & & 2 \\
\hline DITOCAREMMHTO & & & & & & & & & & & & 1 & & & & & & & & & & & & & & 1 \\
\hline TFl|HZ0|S & & & & & & & & & & & & & & & & & & & & & & & & & & \\
\hline EENIIMDAROLL & & & & & & & & & & & & & & & & 1 & & & & & & & & & & 1 \\
\hline CuPRICO & & & & & & & & & & & & & & & & & & & & & & & & & & \\
\hline TRHROZIS + ORGANOFOSFORADO & & & & & & & & & & & & & & & & & & & & & & & & & & \\
\hline REGULADORES & & & & & & & & & & & & & & 1 & & & & & & 1 & & 1 & & & & 3 \\
\hline CIANMMDA & & & & & & & & & & & & & & 1 & & & & & & & & 1 & & & & 2 \\
\hline DINTPOANULNAS & & & & & & & & & & & & & & & & & & & & 1 & & & & & & 1 \\
\hline MISTURAS & & 1 & & & 1 & & 3 & 2 & 1 & 5 & 1 & 2 & & 2 & & 4 & & & & 1 & & 1 & & & 6 & 18 \\
\hline OUTROS & & 3 & 2 & & 16 & 8 & 9 & 25 & 8 & 24 & 5 & 27 & 6 & 16 & 3 & 14 & 4 & 19 & 3 & 18 & 1 & 17 & 1 & 2 & 58 & 173 \\
\hline TOTAL & 3 & 7 & 3 & & 25 & 17 & 31 & 69 & 22 & 74 & 18 & 71 & 15 & 60 & 13 & 46 & 12 & 36 & 7 & 45 & 7 & 45 & 2 & 4 & 158 & 474 \\
\hline
\end{tabular}




\section{REFERÊNCIAS BIBLIOGRÁFICAS}

AGOSTINETTO, D.; PUCHALSKI, L.E.A.; AZEVEDO, R. de et al. Utilização de equipamentos de proteção individual e intoxicações por agrotóxicos entre fumicultores do Município de Pelotas-RS. Pesticidas, v.8, p.45-56, jan./dez. 1988.

ALBUQUERQUE, M.A.; PENNA, F.L.R.; NEVES, N.S. Riscos ambientais causados pela agricultura, na microbacia hidrográfica do Córrego dos Bertoldo, Caratinga-MG. http://www.cibergeo.org/agbnacional/VICBG2004/Eixo2/E2_220.htm. (07 nov.2004).

ALMEIDA, N.F.; PIEDADE, J.R.; SOUZA, D.A. Química dos pesticidas. São Paulo: Instituto Biológico, 1962. 325p.

ALMEIDA, W.F.; MELLO, D. de; PUGA, F.R. et al. Intoxicações profissionais por praguicidas. In: MENDES, R. Medicina do trabalho: doenças profissionais. São Paulo: Sarvier, 1980. p.511-569.

ALVES FILHO, J.P. Uso de agrotóxicos no Brasil: controle social e interesses corporativos. São Paulo: Annablume, 2002. 188p. 
ARAÚJO, A.C.P.; NOGUEIRA, D.P.; AUGUSTO, L.G.S. Impacto dos praguicidas na saúde: estudo da cultura do tomate. Revista de Saúde Pública, v.34, n.3, p.309-313, jun. 2000.

ASSOCIAÇÃO NACIONAL DE DEFESA VEGETAL. Banco de dados: distribuição e vendas por Estado. http://www.andef.com.br. (09 abr. 2002).

ASSUNÇÃO, L.F.; RIBEIRO, A. Consumo de agrotóxicos cresce a cada ano. http://www.an.uol.com.br/anverde/especiais/mat_esp01.htm. (03 nov. 2004).

\section{BALDERRAMA, E.S.R. Intoxicação profissional rural por agrotóxicos no} Estado do Paraná na última década. Curitiba: UFPR, Setor de Ciências da Saúde, 2000. 45p.

BRASIL. Ministério da Agricultura e do Abastecimento. AGROFIT 98: uso adequado de agrotóxicos (compact disc). São Paulo, 1998.

BRASIL. Lei no 8069 de 13 de julho de 1990. http://www.planalto.gov.br/ccivil_03/Leis/L8069Compilado.htm. (12 abr. 2005).

BUENO, W.C. Veneno no prato, açucar na pauta: a comunicação a serviço do lobby dos agrotóxicos.

http://www.comunicasaude.com.br/artigowilbuenoagrotoxicos.htm. (07 nov. 2004).

BULL, D.; HATHAWAY, D. Pragas e venenos: agrotóxicos no Brasil e no terceiro mundo. Petrópolis: Ed. Vozes, 1986. 236p.

CARSON, R. Silent spring. Greenwich: Fawcett Publ., 1970. 304p. 
CARVALHO, I.S. Agrotóxicos: usos e implicações. Mundo \& Vida. v.2, n.1, p.29-31, 2000.

CICIOLLI, R. Confirmado: campesinos de San Pedro Del Paraná fueron intoxicados por agrotóxicos. http://www.reluita.org/agricultura/agrotóxicos/paraguay-3htm. (12 nov.2004).

CRIVISQUI, E.; VILLAMONTE, G. Apresentação dos métodos da análise fatorial de correspondência simples e múltipla. Londrina: Programme Presta, 1999. 176p.

DELGADO, I.F.; PAUMGARTTEN, F.J.R. Intoxicações e uso de pesticidas por agricultores do Município de Paty do Alferes, Rio de Janeiro, Brasil.

Cadernos de Saúde Pública, v.20, n.1, p.180-186, jan./fev. 2004.

DURAN-NAH, J.J.; COLLI-QUINTAL, J. Intoxicación aguda por plaguicidas. Salud Pública de México, v.42, n.1, p.53-55, ene./feb. 2000.

EMPRESA BRASILEIRA DE PESQUISA AGROPECUÁRIA. Algodão (Bt). http://www.cnpma.embrapa.br/projetos/index.php3?sec=bioss::23. (01abr. 2005).

FARIA, N.M.X.; FACCHINI, L.A.; FASSA, A.G. et al. Trabalho rural e intoxicações por agrotóxicos. Cadernos de Saúde Pública, v.20, n.5, vol.20, p.1298-1308, set./out. 2004.

FORATTINI, O.P. Epidemiologia geral. São Paulo: Edgard Blucher, 1976. 210p. 
FUNDAÇÃO INSTITUTO OSWALDO CRUZ. Centro de Informação Científica e Tecnológica. Estatística anual de casos de intoxicação e envenenamento: Brasil: 1997. Rio de Janeiro, 1998. 80p.

FUNDAÇÃO INSTITUTO OSWALDO CRUZ. Centro de Informação Científica e Tecnológica. Estatística anual de casos de intoxicação e envenenamento: Brasil: 1999. Rio de Janeiro, 2000. 100p.

GANDOLFO, M.; ANTUNIASSI, U. Fora do padrão. http://www.revistagloborural.globo.com/GloboRural/0,6993,EEC6119521932,00.html. (05 nov. 2004).

GARCIA, E.G. Avaliação das conseqüências da "Lei dos Agrotóxicos" nas intoxicações e nas classificações toxicológica e de potencial de periculosidade ambiental no período de 1999 a 2000. São Paulo, 2001a. 132 p. Tese (Doutorado) - Faculdade de Saúde Pública, Universidade de São Paulo.

GARCIA, E.G. Segurança e saúde no trabalho rural: a questão dos agrotóxicos. São Paulo: Fundacentro, 2001b. 182p.

GARCIA, J.E. Acute poisoning from pesticides: human and economic costs. Revista Panamericana de Salud Publica, v.4, n.6, p.383-387, dec.1998.

GUIVANT, J.S. Percepção dos olericultores da grande Florianópolis (SC) sobre os riscos decorrentes do uso de agrotóxicos. Revista Brasileira de Saúde Ocupacional, v.22, n.82, p.47-57, 1994.

INSTITUTO BRASILEIRO DE GEOGRAFIA E ESTATÍSTICA. Censo agropecuário 1995-1996. Rio de Janeiro, 1997. n.20, 62p. 
LEVIGARD, Y.E. A interpretação dos profissionais de saúde acerca das queixas do nervoso no meio rural: uma aproximação ao problema das intoxicações por agrotóxicos.

http://portalteses.cict.fiocruz.br/transf.php?script=thes_cover\&id=000009\&lng =pt\&nrm=isso. (12 nov.2004).

LOBATO, S.M.R. O silêncio como metáfora. In: ENCONTRO DA ASSOCIAÇÃO NACIONAL DE PÓS-GRADUAÇÃO E PESQUISA EM AMBIENTE E SOCIEDADE, 2., Indaiatuba, 2004. Resumos. Indaiatuba: ANPPAS, 2004. http://www.anppas.org.br. (15 nov. 2004).

MEULENBELT, J.; DE VRIES, I. Acute work-related poisoning by pesticides in the Netherlands: a one year follow-up study. Przeglad Lekarski, v.54, n.10, p.665-670, 1997.

NASCIMENTO, C.R. Cadastramento de agrotóxicos: requisitos e banco de dados.dpolastr@esalq.usp.br. (17 nov. 2004).

NATIONAL RESEARCH COUNCIL. Alternative agriculture. Washington: National Academy Press, 1989. 448p.

NEWMAN, J.F. Pesticides. In: WRIGHT, S.J.L.; HILL, I.R. Pesticide microbiology. New York: Academic Press, 1978. p.1-16.

NIEWEGLOWSKI, A.M.A.; MEDEIROS, M.L.M.B. de; ZANIN, M. et al. Agrotóxico: coletânea sobre situação no Paraná. Curitiba: Secretaria do Meio Ambiente, 1992. 94p. 
NUNES, E.F.P.A. Sistema de Informação em Intoxicação por agrotóxicos no município de Londrina-PR. Londrina, 1995. 100 p. Dissertação (Mestrado) Universidade Estadual de Londrina.

OLIVEIRA-SILVA, J.J.; ALVES, S.R.; MEYER, A. et al. Influência de fatores socioeconômicos na contaminação por agrotóxicos, Brasil. Revista de Saúde Pública, v.35, n.2, p.130-135, dez. 2001.

ORGANIZAÇÃO PAN-AMERICANA DA SAÚDE. Manual de vigilância da saúde de populações expostas a agrotóxicos. Brasília, 1996. 69p.

ORGANIZAÇÃO PAN-AMERICANA DA SAÚDE. Situación epidemiológica de las Intoxicaciones agudas por plaguicidas en centroamérica, 1992-2000. Boletín Epidemiológico/OPS, v.23, n.3, p.5-9, sep. 2002.

PARANÁ. Leis, decretos, etc. Coletânea da legislação Estadual e Federal de agrotóxicos. Curitiba: SEAB, DEFIS, 1997. 215p.

PARANÁ. Secretaria de Estado da Agricultura e do Abastecimento do Paraná. Acompanhamento da situação agropecuária no Paraná. Curitiba, 2001. $64 p$.

PARANÁ. Secretaria de Estado da Saúde. Reunião sobre a política estadual a ser adotada para a destinação adequada de embalagens de agrotóxicos. marilene@inbrapenet.com.br. (10 abr.2002a).

PARANÁ. Secretaria de Estado da Agricultura e do Abastecimento do Paraná. Legislação on line. http://www.pr.gov.br/seab/agrotóxicos/dec4074.html. (12 nov.2002b). 
PARANÁ. Secretaria de Estado da Agricultura e do Abastecimento do Paraná. Valor bruto da produção.dpolastr@pr.gov.br. (18 out.2004).

PIRES, D.X.; CALDAS, E.D.; RECENA, M.C.P. Uso de agrotóxicos e suicídios no Estado do Mato Grosso do Sul, Brasil. Cadernos de Saúde Pública, v.21, n.2, p.598-605, mar./abr. 2005.

QUEVEDO, G.B.; CORRIOLS, M. Características epidemiológicas y ocupacionales de los controles de foco de intoxicaciones agudas por plaguicidas em Nicarágua, 1995-1998. Managua: Organización Panamericana de la Salud, 1999. 20p.

RAMOS, H.H. MAZIERO, J.V.G.; YANAI, K. et al. Exposição dérmica do aplicador de agrotóxicos na cultura da uva, com diferentes pulverizadores. Revista Brasileira de Engenharia Agrícola e Ambiental, v.6, n. 1, p.175179, 2002.

RUEGG, E.F.; PUGA, F.R.; SOUZA, M.C.M. de. et al. Impacto dos Agrotóxicos. 2.ed. São Paulo: Icone, 1991. 94p.

SHEU, J.J.; WANG, J.D.; WU, Y.K. Determinants of lethality from suicidal pesticide poisoning in metropolitan HsinChu. Veterinary and Human Toxicology, v.40, n.6, p.332-336, Dec. 1998.

TORDOIR, W.F.; MARONI, M. Basic concepts in the occupacional health management of pesticide workers. Toxicology, v.9, n.1, p.5-14, 1994.

\section{TRAPÉ, A.Z. Efeitos toxicológicos e registro de intoxicações por} agrotóxicos. http://www.agr.unicamp.br/tomates/pdfs/eftoxic.pdf. (07 nov. 2004). 
VAN der HOEK, W.; KONRADSEN, F.; ATHUKORALA, K. et al. Pesticide poisoning: a major health problem in Sri Lanka. Social Science and Medicine, v.46, n.4/5, p.495-504, Feb./Mar.1998.

WORLD HEALTH ORGANIZATION. Public health impact of pesticides used in agriculture. Geneve, 1990. 128p. 
APÊNDICES 
APÊNDICE 1. Ficha epidemiológica de ocorrência toxicológica

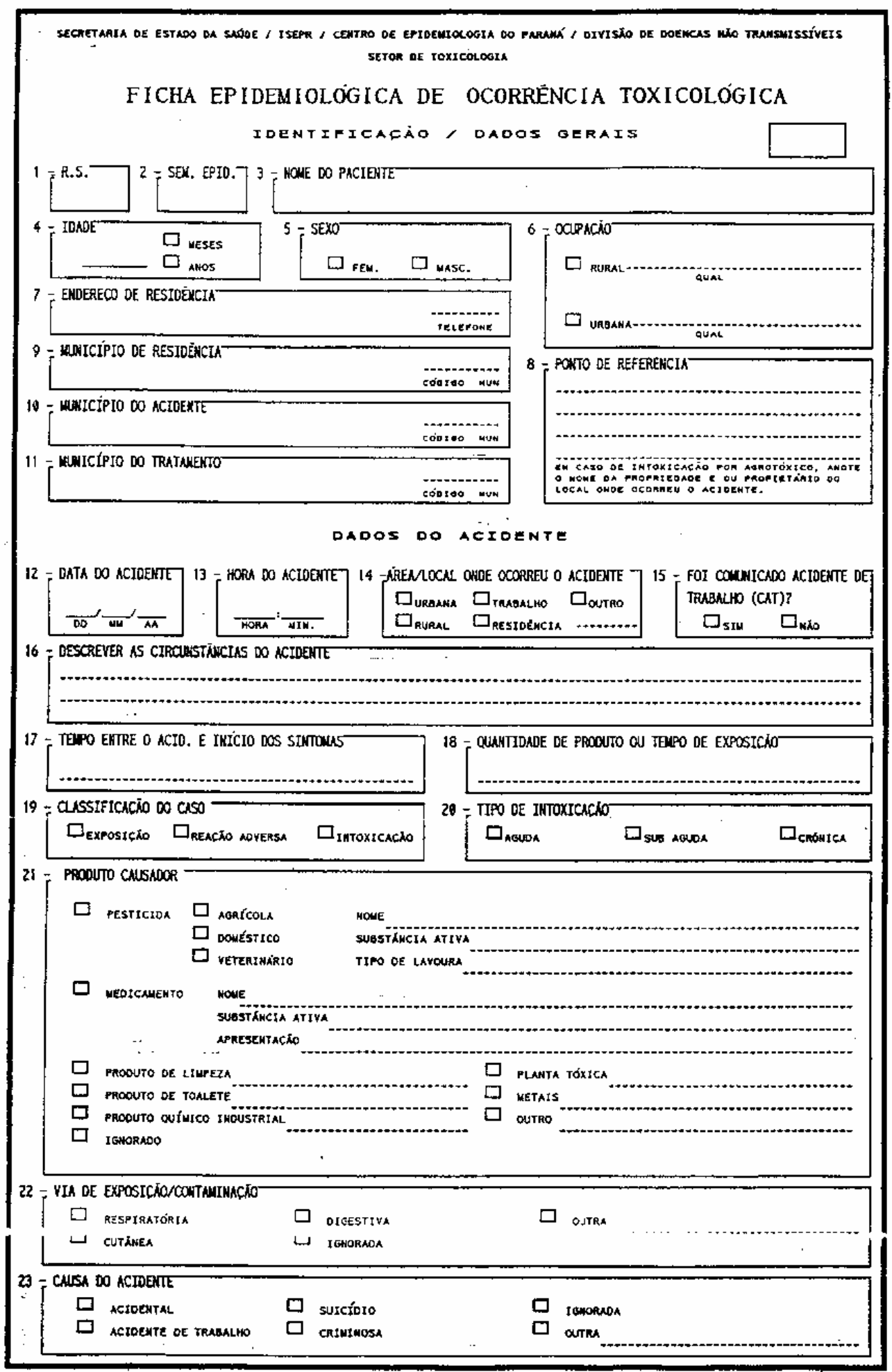


APÊNDICE 1. Ficha epidemiológica de ocorrência toxicológica

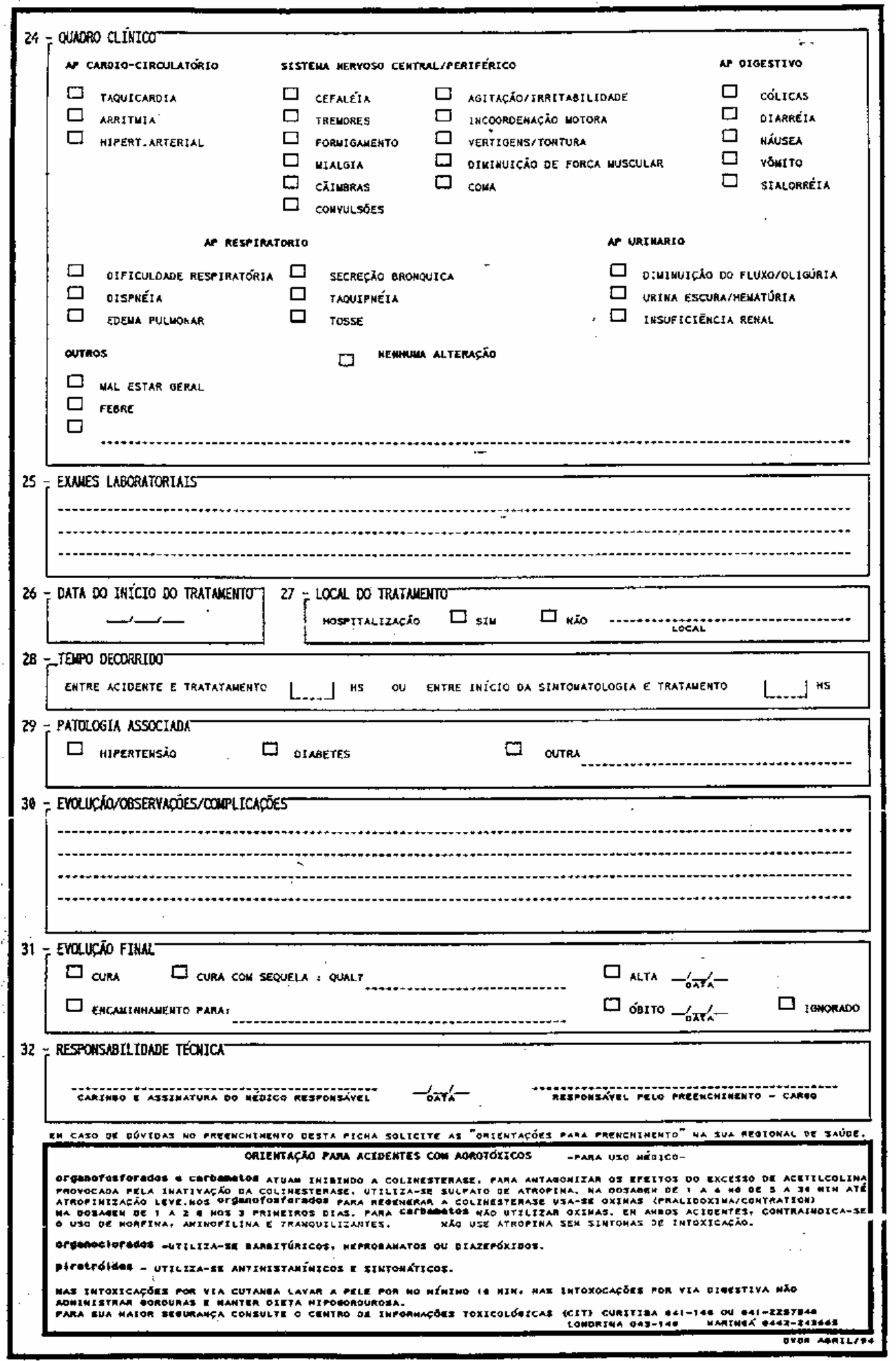




\section{APÊNDICE 2. Ficha individual de investigação - Intoxicaçăo por agrotóxicos}

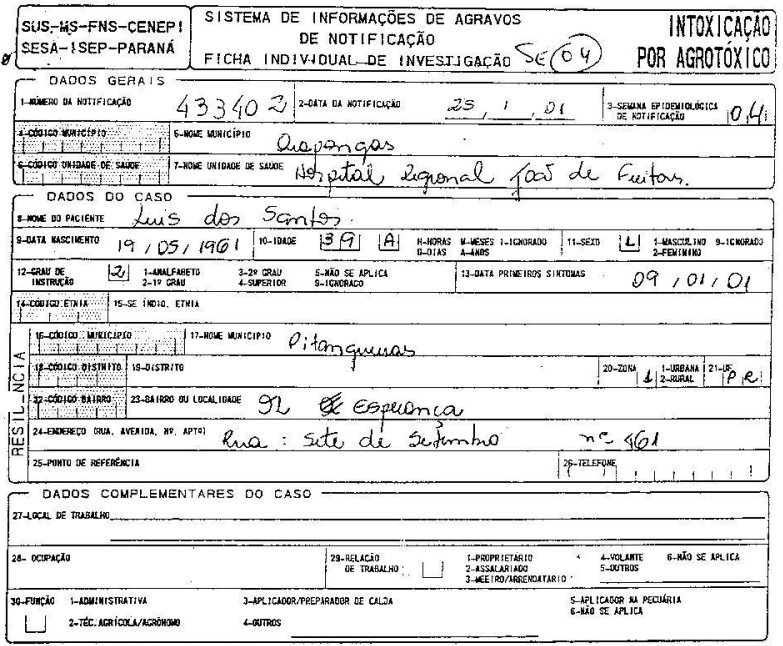

\section{- Local de dCORAENC A DA Exposicá}

\begin{tabular}{|c|c|c|c|}
\hline \multicolumn{2}{|c|}{ 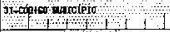 } & 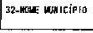 & Pitangunions \\
\hline 5TEN DISIRIMI & 34-0 ISTRITO & & \\
\hline modosengalnod & HE-BA IPRA O & W LRCAL loubs & Es \\
\hline
\end{tabular}

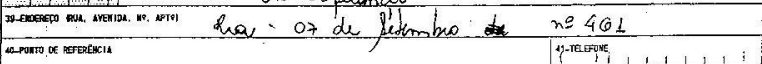

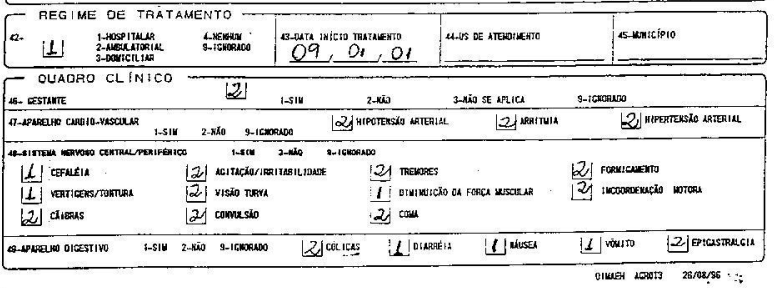


APÊNDICE 2. Ficha individual de investigação - Intoxicação por agrotóxicos

य FICHA INDIVIDUAL DE INVESTIGACĀO

INTOXICACAO POR AGROTOXICO

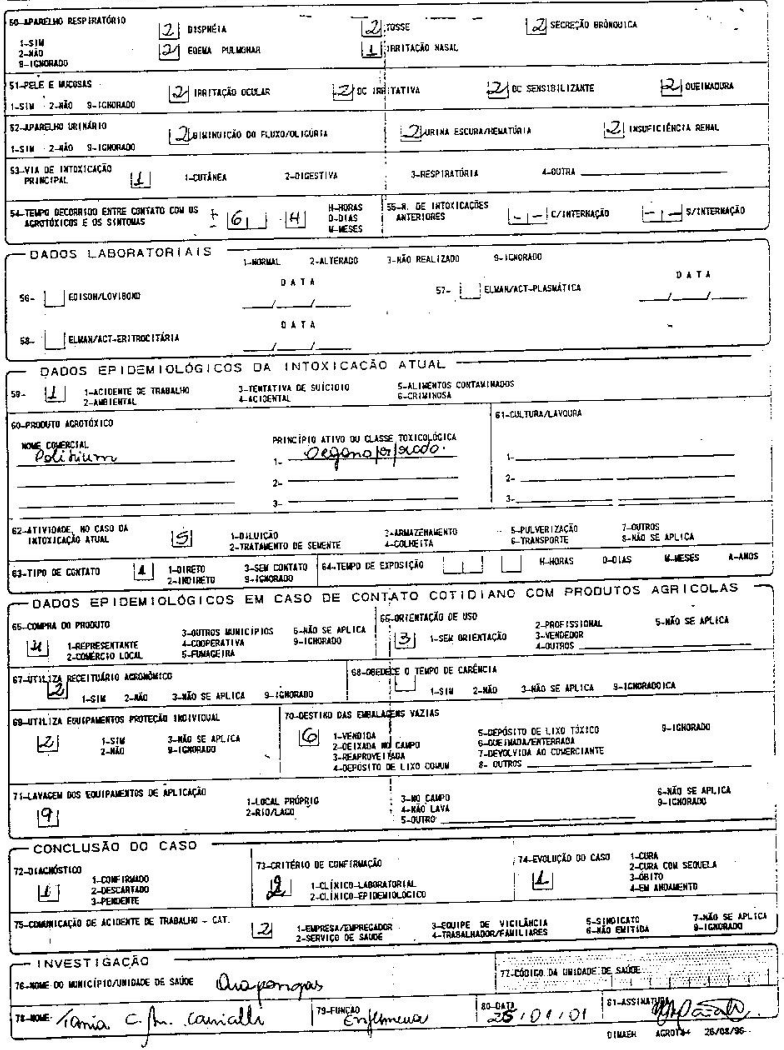

